管

\title{
palgraverpivot
}

\section{Intercultural Dialogue}

in the European

Education Policies

A Conceptual Approach

\section{Tuuli Lähdesmäki \\ Aino-Kaisa Koistinen \\ Susanne C. Ylönen}




\section{Intercultural Dialogue in the European Education Policies}

"Intercultural Dialogue is a key concept in EU Education Policy. This book opens up a novel and highly valuable angle in the field: by studying the meanings and usages of the concept in the EU's and the Council of Europe's policy documents, we learn both how decision-makers understand and operationalise it, and how to interpret it ourselves."

—Claudia Wiesner, Jean Monnet Chair, Professor of Political Science, Fulda University of Applied Sciences, Germany

"By linking cultural studies with education and policy making in contemporary Europe, this volume presents a meticulously structured study of intercultural dialogue. In times of trouble for the European Union as we know it, this seminal book provides for a solid analysis of how interculturality could be fostered and applied within the EU. Rooted in a critical approach, this production does not disappoint and addresses the identified issues in an elegant and thorough manner."

-Albin Wagener, Professor in Discourse Analysis and Digital Humanities, Campus Tech/Université Rennes 2, France 


\title{
Tuuli Lähdesmäki
}

Aino-Kaisa Koistinen • Susanne C. Ylönen

Intercultural Dialogue in the European Education Policies

\author{
A Conceptual Approach
}

palgrave macmillan 
Tuuli Lähdesmäki

Department of Music, Art and

Culture Studies

University of Jyväskylä

Jyväskylä, Finland

Susanne C. Ylönen

Department of Music, Art and

Culture Studies

University of Jyväskylä

Jyväskylä, Finland
Aino-Kaisa Koistinen

Department of Music, Art and

Culture Studies

University of Jyväskylä

Jyväskylä, Finland

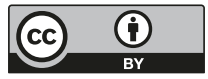

ISBN 978-3-030-41516-7

ISBN 978-3-030-41517-4 (eBook)

https://doi.org/10.1007/978-3-030-41517-4

(C) The Editor(s) (if applicable) and The Author(s) 2020 This book is an open access publication. Open Access This book is licensed under the terms of the Creative Commons Attribution 4.0 International License (http://creativecommons.org/licenses/by/4.0/), which permits use, sharing, adaptation, distribution and reproduction in any medium or format, as long as you give appropriate credit to the original author(s) and the source, provide a link to the Creative Commons licence and indicate if changes were made.

The images or other third party material in this book are included in the book's Creative Commons licence, unless indicated otherwise in a credit line to the material. If material is not included in the book's Creative Commons licence and your intended use is not permitted by statutory regulation or exceeds the permitted use, you will need to obtain permission directly from the copyright holder.

The use of general descriptive names, registered names, trademarks, service marks, etc. in this publication does not imply, even in the absence of a specific statement, that such names are exempt from the relevant protective laws and regulations and therefore free for general use. The publisher, the authors and the editors are safe to assume that the advice and information in this book are believed to be true and accurate at the date of publication. Neither the publisher nor the authors or the editors give a warranty, expressed or implied, with respect to the material contained herein or for any errors or omissions that may have been made. The publisher remains neutral with regard to jurisdictional claims in published maps and institutional affiliations.

This Palgrave Macmillan imprint is published by the registered company Springer Nature Switzerland AG.

The registered company address is: Gewerbestrasse 11, 6330 Cham, Switzerland 


\section{Preface}

This book stems from the intensive collaboration of three scholars whose divergent academic backgrounds create a multi- and interdisciplinary space in which to analyse European education policy documents. The book seeks to combine our expertise in critical cultural studies, art education, children's culture, research of identities and cultural diversities, transmedia research, policy analysis, and European and European Union studies. We build our approach from our manifold but overlapping interests, which are penetrated and brought together by a common framework. We share interests in discursivity, performativity, and affectivity of language.

The Dialogue and Argumentation for Cultural Literacy Learning in Schools (DIALLS) project seeks to advance intercultural dialogue through the creation, implementation, and research of a Cultural Literacy Learning Programme. During sessions within this programme, classroom discussions are catalysed by a selection of 45 wordless picture books and films produced in and around Europe. These are chosen from a broader bibliography of 145 wordless picture books and films created in the project that correspond to an increasingly multicultural, multi-ethnic, and multilingual social landscape of places, people, and ways of living in Europe, and promote DIALLS' core dispositions of tolerance, inclusion, and empathy for cultural encounter. DIALLS also implements this programme by facilitating a pupil-authored manifesto for cultural literacy and a virtual gallery of pupils' cultural artefacts created as part of the programme. As a research-based outcome, DIALLS provides comprehensive guidance for developing cultural literacy in schools by creating a scale of progression for cultural literacy learning. 
The DIALLS project started with an examination of national and European education policy documents. This task was led by Tuuli Lähdesmäki, and it included scholars from three universities: the University of Jyväskylä, Finland; the University of Vilnius, Lithuania; and the University of Cambridge, UK. We focused on a broad range of concepts identified by the principal investigators at these universities as important for the concept of cultural literacy. The aim of this analysis was to form a common Cultural Analysis Framework for further activities in the project, such as selecting the wordless picture books and films and creating the Cultural Literacy Learning Programme. The European education policy documents were analysed by the authors of this book-Tuuli Lähdesmäki, Aino-Kaisa Koistinen, and Susanne C. Ylönen from the University of Jyväskylä. Our analysis of the education policy documents produced by the Council of Europe and the European Union yielded draft texts, findings, and remarks that went beyond the original scope of the task and thus were not delivered to the European Commission. This book is based on the extension of our analysis, refocusing it on the core policy concept in our data-intercultural dialogue. We hope that the book provides useful information and research-based evidence on European education policies for decision-makers, policy-writers, scholars, educators, and teachers dealing with intercultural dialogue in Europe and beyond.

We want to thank our colleagues from the University of Vilnius, Irena Zaleskiene, Lilija Duobliené, and Sandra Kaire, and from the University of Cambridge, Fiona Maine, and Victoria Cook, for their inspiration and smooth collaboration in the creation of the Cultural Analysis Framework. The writing of the book has benefited from Lähdesmäki's work as a visiting fellow at the University of Cambridge in spring 2019, supported by the Academy of Finland. Due to our interest in contemporary Europe and its transformation influenced by recent political, social, and humanitarian challenges, our research is part of the University of Jyväskylä's current research profiling area Crises Redefined: Historical Continuity and Societal Change (CRISES), also funded by the Academy of Finland and co-led by Lähdesmäki. Part of the open access costs of the book has been covered by CRISES. This book has been proofread by Kate Sotejeff-Wilson, who deserves thanks for her detailed work in language editing. We also want to thank Senior Editor Eleanor Christie and Senior Editorial Assistant Rebecca Wyde from Palgrave Macmillan for seamless cooperation in the publishing process, as well as Palgrave's anonymous reviewers for their fruitful comments, which helped us sharpen our arguments. Finally, we 
want to thank the core financer of the DIALLS project, the European Commission, and its Horizon 2020 Programme, for the project funding under grant agreement no. 770045 , which made this book possible.

Jyväskylä, Finland

September 2019
Tuuli Lähdesmäki Aino-Kaisa Koistinen

Susanne C. Ylönen 


\section{ACKNOWLEDGEMENTS}

This book has been supported by the European Commission and its Horizon 2020 Research and Innovation Programme under grant agreement no. 770045. Dialogue and Argumentation for Cultural Literacy Learning in Schools (DIALLS) is a broad research consortium funded from the Horizon call 'Understanding Europe - Promoting the European Public and Cultural Space' under the topic 'Cultural Literacy of Young Generations in Europe'. The project runs from 2018 to 2021. It includes ten partner universities from Cyprus, Finland, France, Germany, Israel, Lithuania, Portugal, Spain, and the UK, and is led by Dr Fiona Maine from the University of Cambridge. See DIALLS' website for more information: https://dialls2020.eu/. Part of the book's open access costs has been supported by the Academy of Finland under Grant SA31 1877 (the University of Jyväskylä's profiling area Crises Redefined: Historical Continuity and Societal Change, CRISES). The content of this publication does not reflect the official opinion of the European Union. Responsibility for the information and views expressed therein lies entirely with the authors.

This project has received funding from the European Union's Horizon 2020 research and innovation Programme under grant agreement No 770045

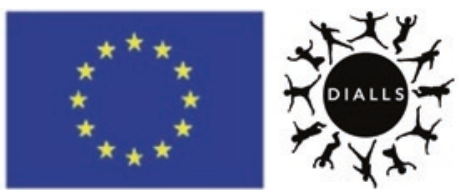




\section{Contents}

1 Introduction: What Is Intercultural Dialogue and Why It Is Needed in Europe Today?

2 Data and Methods: A Conceptual Approach to Intercultural Dialogue

3 Definitions and Contexts of Intercultural Dialogue in European Policy Documents

4 Analysing Intercultural Dialogue Through Conceptual Densities

5 Affective Rhetoric and 'Sticky Concepts' in European Education Policy Documents

6 Conclusions and Suggestions for Improving European Education Policies

Index 


\section{About the Authors}

Tuuli Lähdesmäki (PhD in Art History; DSocSc in Sociology) is an adjunct professor and senior researcher at the Department of Music, Art and Culture Studies, University of Jyväskylä (JYU), Finland. Her research interests and publications focus on governance of diversity, cultural identities and identity politics, belonging, cultural heritage, strategies of interpreting the past, populism, and the European Union and the Council of Europe and their policies. Lähdesmäki is leading the research project entitled Legitimation of European Cultural Heritage and the Dynamics of Identity Politics in the EU (EUROHERIT), funded by the European Research Council. She is also leading JYU's consortium partnership in the DIALLS project, funded from the European Union's Horizon 2020 Programme. In addition, she is one of the three leaders in JYU's research profiling area entitled Crises Redefined: Historical Continuity and Societal Change (CRISES). She has previously worked in various research projects exploring the roles of art and culture in contemporary societal and political contexts.

Aino-Kaisa Koistinen ( $\mathrm{PhD}$ in Contemporary Culture Studies) is a postdoctoral researcher at the Department of Music, Art and Culture Studies, University of Jyväskylä, Finland. Koistinen's expertise lies in cultural and media studies, such as performing close contextual analyses of cultural images and texts. Currently, Koistinen is working in the projects Legitimation of European Cultural Heritage and the Dynamics of Identity Politics in the EU (EUROHERIT), funded by the European Research Council, and Dialogue and Argumentation for Cultural 
Literacy Learning in Schools (DIALLS), funded from the European Union's Horizon 2020 Programme. She has previously worked in projects such as TRANSMEDIA LITERACY: Exploiting Transmedia Skills and Informal Learning Strategies to Improve Formal Education (funded from the Horizon 2020 Programme); global audience research in the World Hobbit Project (the Finnish sub-project funded by the Finnish Cultural Foundation); and Abusive Sexuality and Sexual Violence in Contemporary Culture (funded by Kone Foundation).

Susanne C. Ylönen ( $\mathrm{PhD}$ in Art Education) is a postdoctoral researcher at the Department of Music, Arts and Culture Studies, University of Jyväskylä, Finland. Her research focuses on cultural differences, especially in the context of the high/low culture divide and the valorization of children's culture. The study of children's culture has familiarized her with Finnish national education policy, and she has first-hand experience of cultural differences, being born into a German-Finnish family and having lived abroad for study and work on multiple occasions. Ylönen has worked in the project Dialogue and Argumentation for Cultural Literacy Learning in Schools (DIALLS), funded from the European Union's Horizon 2020 Programme. She investigates children's literature in her project Disturbingly Funny and Freakishly Cute: Aesthetic Sublation as a Mode of Pop Cultural Meaning Making, funded by the Finnish Cultural Foundation. 


\title{
Introduction: What Is Intercultural Dialogue and Why It Is Needed in Europe Today?
}

\begin{abstract}
The authors introduce the concept of intercultural dialogue and how it has been utilized as a policy by the Council of Europe and the European Union since the early 2000s. First, we explore intercultural dialogue's relation to and differences from other concepts commonly used to describe different stances in the governance of diversity, ranging from assimilation to integration and from multiculturalism to interculturalism. These different conceptual stances are contextualized by exploring the recent transformations in Europe and their impact on the political aims, goals, and discourses of the Council of Europe and the European Union. Second, we review the previous research on the concept of intercultural dialogue and discuss the criticism of the concept and its meaning and uses in policy discourses.
\end{abstract}

Keywords Intercultural dialogue $\bullet$ Interculturalism $\bullet$ Multiculturalism - Assimilation • Integration

There is an increasing need for a respectful cultural encounter, mutual understanding, and constructive dialogue in today's pluricultural, but polarized, Europe. This book is motivated by the current condition of European societies that have transformed quickly during the past decades due to global cultural flows, the influence of social media on culture and communication, and the forced and voluntary movement of people to and 
within Europe. While Europe has become an increasingly diverse continent where many people simultaneously identify with multiple different cultural and social groups, monoculturalist views and cultural purism have also struck back in many cultural contexts, (social) media, and political debates. European societies have faced a rise in populist, nationalist, and extremist movements that have incited xenophobic, anti-immigration, racist, anti-Semitic, and Islamophobic political attitudes and actions, as well as a selective defence of 'us' as a monocultural group. Attacks motivated by extremist ideologies have influenced people's views and notions of Europe and how to build its future.

European societies have commonly recognized cultural pluralization as a richness that, however, entails diverse challenges if cultural encounter is not based on mutual respect and an interest in understanding differences. The recent transformations in Europe are transnational, and prejudiced attitudes to and intolerance of differences present challenges to the whole continent; therefore, they have to be addressed also at the European level. The continent's core international organizations - the Council of Europe and the European Union-have sought to respond to the challenges that diversification and a lack of interest in understanding differences may entail by promoting policies that engender inclusion, tolerance, and respect for diversity. The ultimate goal of these policies is to strengthen social cohesion in inclusive societies. During the past decade, intercultural dialogue has been a core policy instrument in these attempts-commonly repeated in the policy discourses of the Council of Europe and the European Union.

Education is a key sector through which inclusion, tolerance, and respect for diversity can be advanced. It is, however, a profoundly national sector with distinct national education acts, policies, and curricula. The Council of Europe and the European Union have actively sought to impact on this sector through their conventions, declarations, policy recommendations, programmes, and projects aimed at children and young people, including educating them to encounter cultural differences. This book focuses on the education policies of these two European organizations and how they address, give meanings to, and utilize the concept and idea of intercultural dialogue in their education policy discourses.

Intercultural dialogue has been approached in previous research as a practice connected to various social and societal domains in contemporary societies. Scholars have explored diverse practices of intercultural dialogue, 
for example in intercultural education (e.g. Portera 2008; O'Grady 2010; Kowalczyk 2011; Ganesh and Holmes 2011; Zay 2011; Besley and Peters 2012; Štrajn 2018); intercultural communication (e.g. Houghton 2009; Hoskins and Sallah 2011; Ganesh and Holmes 2011); governing of diversities (e.g. Wiesand et al. 2008; Wilk-Wós 2010; Lähdesmäki and Wagener 2015); and art and urban design in today's culturally diverse environments (e.g. Wood and Landry 2008; Sandercock and Attili 2009; Leikkilä et al. 2013; Gonçalves and Majhanovich 2016). Intercultural dialogue has also been broadly discussed in academia in relation to the debate between multiculturalism and interculturalism-briefly explored later in this chapter. The previous research still lacks an in-depth examination of the complex meanings intertwined with the conceptualization of intercultural dialogue in education policies at the European level. This kind of conceptual analysis is needed since intercultural dialogue has become an ideal commonly repeated in various contexts in Council of Europe and European Union policy discourses. Moreover, the meanings of several other concepts commonly used in connection with intercultural dialogue in these discourses, such as identity, culture, heritage, and diversity, may remain vague, so these concepts may serve as rhetorical tools to promote diverse political goals beyond intercultural dialogue as such (see Wagener 2012; Lähdesmäki and Wagener 2015).

In addition to broadening the scope of previous research on intercultural dialogue by scrutinizing the policy discourses of the Council of Europe and the European Union, our aim is to offer a new methodological approach to the topic. Our research is firmly grounded in the practical application of in-depth concept analysis. In this book, we scrutinize how, and with what effect, intercultural dialogue-and the diverse concepts through which it is defined, explained, and discussed - is dealt with in the education policy documents of the Council of Europe and the European Union (hereinafter the European education policy documents). We approach concepts in these policy documents as 'actants' that generate meanings for the idea of intercultural dialogue and simultaneously either explicitly or implicitly frame a set of values related to it, construct the actors whom it concerns, and guide and govern the action included in it. Through an in-depth concept analysis, our research reveals the kinds of ideologies and political goals related to and beyond intercultural dialogue that are included in the policy discourses within the Council of Europe and the European Union. 
Our book is structured into six chapters, of which this introduction explores intercultural dialogue's relationship with other concepts commonly used to describe different stances in the governance of diversity. These different conceptual stances are contextualized by exploring the recent transformations in Europe and their impact on the political aims, goals, and discourses of the Council of Europe and the European Union. The introduction is followed by a detailed description of our method, our data, and the character of the Council of Europe and the European Union as promoters of intercultural dialogue and creators of policy documents regarding it. Our analysis is divided into three chapters. In the first one, we focus on the explicit meanings of intercultural dialogue in European education policy documents and how these meanings are both explicitly and implicitly produced in relation to other concepts and terms. This includes an in-depth analysis of the occurrences, co-occurrences, and thematic overlapping of these concepts. In the second analysis chapter, we focus on analysing 'densities' of interrelated concepts in policy documents. We scrutinize instances in the documents where many of the core concepts of intercultural dialogue appear in clusters. Our third analysis chapter brings a novel theoretical twist to the concept analysis of education policy rhetoric. In it, we discuss the 'politics of affect', as our conceptual approach includes an examination of affective rhetoric in general, and in particular of the affective nature of concepts used in the European education policy documents.

At the time of writing, a decade after the leading European politicians declared that multiculturalism had failed, a decade after the Council of Europe and the European Union started to actively promote intercultural dialogue as a response to this 'failure', and a decade after the differences and similarities between multiculturalism and interculturalism have been debated in academia, it is time to critically review the European policy documentation on intercultural dialogue and the meanings of the concept constructed in it. Our aim is to rethink the concept of intercultural dialogue and explore how policies regarding it could be developed. The final chapter of the book provides suggestions for improving future policies to better encompass the concerns connected to the lack of dialogue in a pluricultural and increasingly diversified, but also polarized, Europe. Lastly, we introduce a new conceptual tool-cultural literacy-to enhance intercultural dialogue in education in practice. 


\section{Contexts for Intercultural Dialogue In Today's Europe}

In the 2000s, Europe - as a part of a globalized world—has faced various challenges ranging from climate change to humanitarian tragedies, and from political turbulences and extremist attacks to social adversities within, at, and beyond its borders. Moreover, the European Union has been struggling with diverse crises-as political and media discourses in Europe have called them - that have impacted on European societies and their current politics. These interrelated crises range from the economic crisis of the eurozone and European financial markets to diverse political crises stemming from the so-called legitimation and democratic deficits of the European Union and the increase of Eurosceptic political parties seeking to exit the eurozone and/or the Union. The recent 'refugee crisis' has impacted on the political crises in the European Union, as the political actors in the Union and its member states have contradictory views on how to respond. Instead of as a 'refugee crisis', scholars have approached these intertwined challenges as Europe's border crisis (Vaughan-Williams 2015) or racial crisis (De Genova 2018). Moreover, and as closely related to all other challenges and crises, scholars have long perceived that the European Union is struggling with an identity crisis (e.g. Hoffmann 1994; Weiss 2002; Jenkins 2008). This identity crisis focuses on a difficulty to define what Europe is, what and who belongs to it, who Europeans are, and which elements a European identity or identities could or should be based on a Europe full of diverse political, material, and symbolic divisions and distinctions (Jenkins 2008; Lähdesmäki et al. 2020). The Council of Europe and the European Union have sought to respond to these intertwined challenges and crises in Europe by advancing the idea of unity and a new European narrative-along with respect and tolerance for diversity - and by enhancing both symbolic and concrete integration in and of European societies (Lähdesmäki 2016; Lähdesmäki et al. 2020).

Besides the Council of Europe and the European Union, various populist and radical right movements and parties around Europe have been interested in contributing to the European narrative and unity in Europe from their exclusive ideological bases. Besides 'the national', these movements and parties commonly identify with European roots and inheritance, particularly when they feel threatened by non-European others - immigrants from the Middle East, Africa, and Asia (see Lähdesmäki 2015, 2019; Brubaker 2017; Kaya and De Cesari 2019). 
Interpretations of the European past and narratives of its present and future are tools utilized by all parties across the political spectrum. All of them seek to advance what they see as best for the people. In populist and radical right movements and parties, the 'discourse of the people' (see Hellström 2006; Mudde 2007) plays a particular role: either explicitly or implicitly, it constructs the idea of the nation. Mudde $(2017,4)$ has emphasized that one of the ideological cornerstones of populism is nativism, which he defines as

an ideology that holds that states should be inhabited exclusively by members of the native group (the nation), and non-native (or alien) elements, whether persons or ideas, are fundamentally threatening to the homogeneous nation-state.

Nativism as an ideology combines nationalism and xenophobia. It links and lays the groundwork for diverse discriminative attitudes and practices among European populist and radical right parties, such as white supremacism, welfare chauvinism, misogyny, and homophobia. The emphasis on generational ties, ancestral roots, and 'bloodlines' presents the nation as a container, as a family to which one has access and belongs by birth (Norocel 2013; Wodak 2015, 76-77). In this ideology, the nation means a limited and sovereign community that exists and persists through time and is tied to a specific territory (space), inherently and essentially constructed through in/out opposition (Wodak 2015, 76-77). The populist and radical right parties' objection to the European Union and its integration stems from this nativist ideology. For these parties, the promotion of a pluralistic model of society and supranational institutions and political actors in Europe represents an attempt to destroy nations and the 'natural' order of nationalism, and thereby a sense of belonging and identity (Betz and Johnson 2004).

The fervour for national identities among the radical right and in populist parties, and their xenophobic, anti-immigration, racist, anti-Semitic, and Islamophobic political attitudes and actions have been explained from various social, socio-economic, and psychological points of view that do not require further discussion here. What is more relevant for this book is to understand the recent challenges and crises in Europe not as reactive to a 'chaotic European reality' but as proactive. Challenges and crises must be tackled and new policies created to respond to the transformed conditions. As Jenkins (2008) claims regarding the European Union, challenges, 
crises, and a lack of consensus enable and justify attempts to increase stability and consensus in and by the Union. For him, the lack of consensus on the idea of Europe is not a state of emergency in the European Union, either, but rather normality that may even be a source of its strength. Similarly, Eder (2014) notes how diverse crises, stemming from the problems with political, economic, and structural systems of the European Union, create opportunities to invent a European community in a new way.

The emphasis on intercultural dialogue in the Council of Europe and the European Union can be interpreted as an attempt to increase stability in Europe and to create a new narrative about European community and communality (see also Wilk-Wo's 2010). This attempt has motivated the European Union's recent idea to work jointly towards a European Education Area. In the European Commission's communication titled Strengthening European Identity through Education and Culture this work is justified as follows:

When our European values and democracies are tested by awakening populist forces at home and abroad or by the spreading of 'fake news' and the manipulation of our information networks, it is the moment when European Leaders and the EU institutions must react. (EC 2017,2)

Quoting the president of the Commission Jean-Claude Juncker, the communication declares:

Education and culture are the key to the future- both for the individual as well as for our Union as a whole. It is how we turn circumstance into opportunity, how we turn mirrors into windows and how we give roots to what it means to be 'European', in all its diversity. (EC 2017, 1)

Even though diverse tensions, confrontations, and controversies between population groups commonly receive much media attention, peaceful and respectful everyday living in pluricultural Europe has become the norm. During the past few decades, most European societies have changed rapidly through cultural diversification, and recognition of and increasing openness towards various differences. Contemporary European societies have been perceived as 'super-diversified' (Vertovec 2007), in which diversity itself is broad, multidimensional, and fluid (Vertovec 2007; Blommaert and Rampton 2011), and characterized as 'complex' (Krauss 2011) when different positions - whether cultural, ethnic, national, social, 
religious, or linguistic - intersect. Fluid social ties, statuses, positions, and competences blur and complicate any simple categories or structures of diversity.

The increasing super-diversity of European societies normalizes intercultural dialogue as practice but also creates challenges for policy discourse. Policymakers need greater sensitivity to the complexities and fluidity included in today's diversity. This understanding should be reflected in the conceptual language used in their policy documentation.

\section{Locating Intercultural Dialogue Within Diversity Policies}

To support social and cultural well-being in diversified societies and to tackle the real or imagined problems, conflicts, and tensions that diversification may entail, societies have developed policies to govern diversity and initiatives, programmes, and projects to implement them in practice-with mixed results. The ERICart report surveyed diversity policies in 34 European countries in 2008. From their main policy approaches concerning majority-minority relations, the report identified a scale ranging from 'homogenization' to 'open intercultural dialogue' with intermediate steps of 'assimilation', 'cohesion-led integration', 'multiculturalism', 'diversityled integration', 'affirmative/positive action towards diversity', and 'intercultural encounters' (Wiesand et al. 2008, 89). According to the report, none of the surveyed countries could be clearly located in the category of 'open intercultural dialogue'.

The differences in diversity policies have been described with varying terms and concepts. There is no standard or single accepted definition for them, but their meanings vary between and within countries-and over time (see Mulcahy 2006; Barrett 2013, 17-19). One of the conceptual dimensions that are often used within these policies is the distinction between 'assimilation' and 'integration'. According to Barrett $(2013,24)$, “the term 'integration' denotes the incorporation of minority cultural groups into mainstream society through a two-way interaction process in which both cultural minorities and the cultural majority make accommodation to each other", while in assimilation "the accommodation is made only by cultural minorities". However, Meer and Modood (2013, 25) have noted how, in political discourse, the term 'assimilation' has often 
been replaced by 'integration', but this term has been given an assimilative interpretation.

Perhaps the most used terms within diversity policies - and the most debated conceptual pair-are multiculturalism and interculturalism. Multiculturalism is commonly described as "a shared commitment in multicultural society to recognise, maintain, and to accord respect and value to the different cultures that coexist within a territorially defined space" (Wiesand et al. 2008, 13). Although it includes many variances, it involves rejection of the idea that minorities should abandon their distinctive cultural beliefs and practices and assimilate into the dominant majority culture. Instead, multiculturalism sees that, by adjusting and adapting laws, rules, and regulations, societies should enable minorities to adhere to their own cultural practices (Kymlicka 1995, 2003; Barrett 2013, 16; Levrau and Loobuyck 2018).

At the end of the 2000s, European societies faced a 'backlash against multiculturalism' as many of the leading European politicians accused it of creating social problems and controversies between people rather than solving them (Bauböck 2008; Vertovec and Wessendorf 2010; Modood and Meer 2012; Barrett 2013). Also in scholarly debates, multiculturalism was criticized for encouraging members of different cultures to live separately in parallel communities without deeper interaction with and trust in one another, for emphasizing instead of blurring boundaries, and for focusing mainly on ethnic and national issues instead of the intersectional diversity in societies (e.g. Rodríguez-García 2010; Taylor 2012; Barrett 2013). The critics of multiculturalism have discussed contemporary intersectional diversities with the concept of interculturalism, emphasizing the importance of creating new opportunities across cultures and of supporting interaction between different cultural communities (Cantle 2013).

Several scholars have pointed out that the concepts and policy goals of multiculturalism and interculturalism are discursively fluid and that it is difficult to draw any clear or stable demarcation between the two (Levey 2012; Modood and Meer 2012; Wieviorka 2012; Taylor 2012; Barrett 2013; Meer and Modood 2013). As Modood and Meer (2012) and Modood (2017) have noted, the qualities that are often used to promote interculturalism (such as encouraging communication, recognition of dynamic identities, promotion of unity, and critique of illiberal cultural practice) are equally important (and on occasion foundational) features of multiculturalism. Some forms of the latter approach, which Parekh (2006) 
has called 'dialogical multiculturalism', particularly emphasize open and equal dialogue between cultural communities in multicultural societies.

Advocates of multiculturalism have also emphasized the politicization of the concept in public debates. On the one hand, the European attack on multiculturalism has been interpreted as stemming from the political failure to implement it in practice: multiculturalism has been blamed for certain phenomena of ghettoization and alienation of immigrants, instead of recognizing the political failures to promote integration and combat discrimination (Taylor 2012, 414). On the other hand, some scholars have noted how hostility to multiculturalism is mainly an exercise in avoiding the term rather than a retreat from implementing it: multiculturalist policies are still being implemented in most Western countries, although alongside new civic integration policies (Levrau and Loobuyck 2018). Moreover, scholars have pointed out how the whole discussion about the failure of multiculturalism and the need for new diversity policies has circled around the debates on Muslim communities in Western societies (Parekh 2008; Cantle 2013; Meer and Modood 2013). In fact, the policies promoting interculturalism have also been perceived to implicitly address the 'Muslim other' (Lähdesmäki and Wagener 2015). In both multiculturalism and interculturalism, the term 'culture' may hide explicit references to 'race', 'ethnicity', or 'religion' (see Bunjes 2013, 49) and, thus, include hierarchical power dynamics implicitly discussed with cultural terms.

Although the roots of the concept of interculturalism as a diversity policy reach back to the 1980s and 1990s (Portera 2008; Besley and Peters 2012; Cantle 2013), its growing use in policy discourse dates to the debate on the failure of multiculturalism. Interculturalism is often seen as built on the ideas of equality and non-discrimination. Critics note the 'failure' of multiculturalism to create cohesion among the different cultures living side by side (or in their own enclaves) in multicultural societies and have presented interculturalism as a solution to this. Interculturalism is located in a stronger emphasis on 'community cohesion'-in Cantle's (2001) terms -interaction, exchange, and dialogue (Cantle 2013; Barrett 2013, 26). It is, thus, seen as helping people to develop an understanding of different cultural beliefs and practices; fostering mutual understanding; increasing interpersonal trust, tolerance, and mutual respect; reducing prejudice and stereotypes; facilitating relationships between different communities; and fostering integration (Barrett 2013,26). As interculturalism stems from the critical view of multiculturalism and/or attempts to 
improve its shortcomings in practice, some scholars, such as Levrau and Loobuyck $(2018,7)$, have approached it "as a particular multicultural theory that has stressed some specific elements that other streams within the multicultural paradigm have somewhat neglected". The critics have, however, seen interculturalism as so fundamentally different from multiculturalism that they cannot be seen only as different emphases within the same diversity policy (Zapata-Barrero 2016, 2017).

A key to interculturalism is shared values-whether jointly developed in the interaction of communities or relying on commonly accepted 'universal values'. For example, the Council of Europe builds its interculturalism on "the universal values" of "respect for the equal dignity of all human beings, human rights, the rule of law and democratic principles", and "freedom of expression and other fundamental freedoms" (CofE 2008, 19). The idea of the universality of values as common ground for interculturalism is, however, problematic as values are never neutral or without a context. Even 'universal values', such as human rights and democracy, and the international organizations' interpretations of their meanings, can be seen as Western ideological constructions stemming from certain philosophical and political discussions in that part of the world (Panikkar 1982; Sharma 2006; Mouffe 2009). Bouchard $(2013,99)$ notes that "no state is culturally neutral" as no state refrains (or is able to refrain) from cultural interventions in favour of a certain group or a set of certain moral values seen as a 'good life' standard. Cherished societal norms and values are commonly defined by a culturally dominant group.

One of the core conceptual innovations closely related to interculturalism is intercultural dialogue. For Cantle $(2013,80)$, it is a practice or a process that is instrumental to implementing the aims of interculturalism, such as fostering understanding and empathy with others. It has also been seen as a "political strategy or instrument to promote cultural diversity or to foster social cohesion" (Wiesand et al. 2008, 4). Intercultural dialogue has been characterized as seeking to "develop a deeper understanding of diverse perspectives and practices; to increase participation and the freedom and ability to make choices; to foster equality; and to enhance creative processes" (Wiesand et al. 2008, xiii). The research dealing with intercultural dialogue has commonly emphasized its importance for democracy. Intercultural dialogue is perceived as a core skill to negotiate diverse backgrounds and viewpoints in a democratic society that is founded on the premise of inclusion of diverse viewpoints (see Papacharissi 2010, 38). It is also seen as founded on the 
critique of the essentialist notions of identity: intercultural dialogue is described as stipulating and fostering identities as transforming, plural, and fluid, as well as grounded on the idea of heterogeneity of all cultural and social groups (see Wilson 2013, 60). Moreover, the general view is that intercultural dialogue requires particular societal acts and settings, as well as creative abilities to encounter other people and to convert insights and challenges into innovation processes and new forms of expression (Wiesand et al. 2008, xiii).

One of the societal prerequisites commonly emphasized as key for intercultural dialogue is a 'shared space'-whether a physical space or a virtual environment (Wiesand et al. 2008, 10; Barrett 2013, 28; Wilson 2013,61 ). Relying on UNESCO's report, Our Creative Diversity (1996), shared space functions as an arena where new ideas and values can be publicly recognized in a dialogue. The ERICart report (Wiesand et al. 2008, 10) explains the idea of shared space as follows:

The main prerequisite to establish a dialogic climate is the attitude that no part/side/partner in the dialogue stays in the center of the world or in an absolute position. On the contrary, the 'center' must be emptied for the sake of dialogue in order for the majority-minority discourse to be overcome.

Moreover, intercultural dialogue has been seen as requiring particular skills and intercultural competencies, such as "open-mindedness, empathy, multiperspectivity, cognitive flexibility, communicative awareness, the ability to adapt one's behaviour to new cultural contexts, and linguistic, sociolinguistic and discourse skills including skills in managing breakdowns in communication" (Barrett 2013,26). These skills and competencies are considered important to learn at all levels of society. The formal education system, including schools, colleges, and universities, has a major role in these attempts (Barrett 2013, 27; Bunjes 2013, 49-50; Bouchard $2013,107)$. Some scholars have particularly emphasized empathy as a key skill for and practice of intercultural dialogue. For Houghton (2012), "intellectual empathy" means a bottom-up process and cognitive skill that necessitates the suspension of prior knowledge and values in favour of basing one's understanding only on the information provided by the interlocutor. As such, the practice of intellectual empathy results in a decentring (of one's own cultural positioning) that "seems to help reduce the resistance to the ideas of others" (Houghton 2012, 97). Houghton (2012, 98 ) mentions stereotypes as an example of the empathy-inhibiting force of 
pre-existing ideas and knowledge or frames. People often find it easier to empathize with others that are similar to them (Houghton 2012, 100).

Intercultural dialogue has been implemented in various ways in different sectors of society. Yet it is a challenge to produce a comprehensive comparative view of how it is implemented, as approaches to and understandings of the concept vary greatly in Europe (Eurobarometer 2007, 23). The ERICart report presents a survey of the implementation of intercultural dialogue in European countries, but emphasizes that its notions and practices are difficult to categorize due to the varying historical contexts, societal and political conditions, diversity structures, legal or political recognition of defined minority cultures and identities, and needs for social cohesion (Wiesand et al. 2008, 18-38). Due to this variety of contexts, the report claims that "one single model encompassing all national approaches to intercultural dialogue cannot realistically be expected, at present" (Wiesand et al. 2008, v).

The ERICart report also explored national education policy approaches to intercultural dialogue and perceived them as ranging from civic education (throughout Europe) to intercultural education, identified as a part of the general school curriculum in Austria, Belgium, Estonia, Ireland, Italy, Malta, the Netherlands, and the UK (Wiesand et al. 2008, vii, 41). According to the report, one of the main policy objectives for promoting dialogue across Europe was to provide resources for language learning (Wiesand et al. 2008, vii). Different takes on intercultural dialogue in the education sector are difficult to compare because of the divergent conceptual preferences for dealing with diversity. According to Hadjisoteriou et al. (2015), for instance, educators in Germany, Greece, and Ireland have preferred the terms interculturalism and intercultural education, while Britain and the Netherlands have historically worked with the concept of multiculturalism. The work of Koopmans and colleagues (2005, 2012 ) is equally indicative of the range of national policy-practice links, arguing that cross-national differences are shaped by historical legacies and have not become smaller over the past three decades.

Researchers in the DIALLS project who worked on European national education policy documentation from Cyprus, Finland, France, Germany, Israel, Lithuania, Portugal, Spain, and the UK found differences in conceptual approaches to cultural encounter, interaction, and dialogue (DIALLS 2018). In the surveyed education acts and curricula from these countries, intercultural dialogue was explicitly only briefly referred to in the data from Finland and Cyprus. The concept was used in the Finnish 
documents with reference to teaching and learning Sami culture, and in the Cypriot documents, in the context of communication, peaceful coexistence, cooperation, and solidarity between people in a multicultural society (DIALLS 2018, 81, 96).

\section{Critical Views of Intercultural Dialogue}

Besides agreeing with the importance of intercultural dialogue in superdiversified societies, scholars have expressed criticism of its implicit meaning and uses in policy discourses, as well as its implementation in practice. One common criticism is that intercultural dialogue alone is insufficient to tackle social, societal, and structural inequalities in super-diversified societies (Barrett 2013, 30). Critics have highlighted the need for concrete structural measures and economic resources to deliver them (Lähdesmäki and Wagener 2015, 27). Some critics have perceived intercultural dialogue as reducing cultural groups to separate and clearly identifiable units, although in super-diversified societies differences are intersectional and do not follow any clear demarcations (Barrett 2013, 30).

Most of the critical views of intercultural dialogue focus on structural power imbalances included in its policy rhetoric and implementation. For example, Lee (2016) has noted how the concept emphasizes talk over other means of expression and, thus, privileges those who have the capacity and 'voice' to speak. She showed how intercultural dialogue is itself an elitist construction available to those who can access it through education. Moreover, she pointed out how research on intercultural dialogue is dominated by Western scholarship as, irrespective of countries of origin, most scholars in the field have learned and internalized Western approaches to scholarship (Lee 2016, 240). Silvestri (2007, n.p.) has asked whether intercultural dialogue includes a "reference to the Western 'civilising mission' of the past" as the concept has been utilized in the European Union's attempts to promote European citizenship, belonging to Europe and to the Union, and a 'new European narrative' as its shared basis.

Previous research on diversity policies of the Council of Europe and European Union have identified various explicit and implicit power structures in the policy rhetoric on intercultural dialogue. Lähdesmäki and Wagener (2015) have criticized the Council of Europe's policy discourses on the concept for poorly recognizing the societal or historical differences between societies and for approaching diversity from a limited Western European perspective, narrowly emphasizing a Eurocentric understanding 
of cultures and cultural differences. The previous research on these European policy discourses on intercultural dialogue has also indicated that the concept includes power hierarchies between those who are expected to facilitate the dialogue and those expected to participate in it (Barrett 2013, 31; Lähdesmäki and Wagener 2015; Lähdesmäki et al. 2015), and how it implicitly consolidates differences between Europeans and their other-'we' and 'them' in the dialogue - rather than bringing subjects together (Aman 2012). Even though these policy discourses commonly seek to reach beyond the issues of migration and ethnic diversity to embrace other aspects of difference, the common subjects of the discourse have been perceived to be non-European, non-white, nonChristian, and non-educated migrants and ethnic groups (Lähdesmäki et al. 2015). The policy discourses could even unintentionally present the coexistence of distinct cultures as a problem and source of conflict, which is contradictory to the fundamental principle of intercultural dialogue as a policy and practice (Lähdesmäki and Wagener 2015; Lähdesmäki et al. 2015).

In general, the Council of Europe and European Union have been criticized for defining the concept of intercultural dialogue vaguely in their policy documents, or explaining it indistinctly and ambiguously (Näss 2010; Lähdesmäki et al. 2015). It is this conceptual vagueness that our book aims to clarify through in-depth concept analysis.

\section{REFERENCES}

Aman, R. 2012. The EU and the Recycling of Colonialism: Formation of Europeans Through Intercultural Dialogue. Educational Philosophy and Theory 44 (9): 1010-1023.

Barrett, M. 2013. Introduction: Interculturalism and Multiculturalism: Concepts and Controversies. In Interculturalism and Multiculturalism: Similarities and Differences, ed. M. Barrett, 15-42. Strasbourg: Council of Europe.

Bauböck, R. 2008. Beyond Culturalism and Statism: Liberal Responses to Diversity. EUROSPHERE Working Paper Series 6. https://EconPapers.repec.org/ RePEc:erp:ewpxxx:p0030.

Besley, T., and M.A. Peters. 2012. Interculturalism, Education and Dialogue. Bern: Peter Lang.

Betz, H.-G., and C. Johnson. 2004. Against the Current-Stemming the Tide: The Nostalgic Ideology of the Contemporary Radical Populist Right. Journal of Political Ideologies 9 (3): 311-327. 
Blommaert, J., and B. Rampton. 2011. Language and Superdiversity. Diversities $13(2): 1-21$.

Bouchard, G. 2013. Interculturalism: What Makes it Distinctive? In Interculturalism and Multiculturalism: Similarities and Differences, ed. M. Barrett, 93-110. Strasbourg: Council of Europe.

Brubaker, R. 2017. Between Nationalism and Civilizationism: The European Populist Moment in Comparative Perspective. Ethnic and Racial Studies 40 (8): 1191-1226.

Bunjes, U. 2013. The Intercultural Milestone: The History of the Council of Europe's White Paper on Intercultural Dialogue. In Interculturalism and Multiculturalism: Similarities and Differences, ed. M. Barrett, 43-52. Strasbourg: Council of Europe.

Cantle, T. 2001. Community Cohesion: A Report of the Independent Review Team. London: Home Office.

- 2013. Interculturalism as a New Narrative for the Era of Globalisation and Super-Diversity. In Interculturalism and Multiculturalism: Similarities and Differences, ed. M. Barrett, 69-92. Strasbourg: Council of Europe.

CofE (Council of Europe). 2008. White Paper on Intercultural Dialogue: "Living Together As Equals in Dignity”. Strasbourg: Council of Europe.

De Genova, N. 2018. The 'Migrant Crisis' as Racial Crisis: Do Black Lives Matter in Europe? Ethnic and Racial Studies 41 (10): 1765-1782.

DIALLS. 2018. Cultural Analysis Framework. https://dialls2020.eu/wp-content/uploads/2019/09/resubmitted-cultural-analysis-framework-with-coversheet-pdf.

EC (European Commission). 2017. Communication from the Commission to the European Parliament, the Council, the European Economic and Social Committee and the Committee of the Regions Strengthening European Identity Through Education and Culture. The European Commission's Contribution to the Leaders' Meeting in Gothenburg, November 17. COM (2017) 673 Final.

Eder, K. 2014. The EU in Search of Its People: The Birth of a Society Out of the Crisis of Europe. European Journal of Social Theory 17 (3): 219-237.

Eurobarometer. 2007. Special Eurobarometer 278: European Cultural Values. Brussels: European Commission.

Ganesh, S., and P. Holmes. 2011. Positioning Intercultural Dialogue: Theories, Pragmatics, and an Agenda. Journal of International and Intercultural Communication 4 (2): 81-86.

Gonçalves, S., and S. Majhanovich, eds. 2016. Art and Intercultural Dialogue. Rotterdam: Sense Publishers.

Hadjisoteriou, C., D. Faas, and P. Angelides. 2015. The Europeanisation of Intercultural Education? Responses from EU Policy-Makers. Educational Review 67 (2): 218-235.

Hellström, A. 2006. Bringing Europe Down to Earth. Lund: Lund University Press. 
Hoffmann, S. 1994. Europe's Identity Crisis Revisited. Daedalus 123 (2): 1-23. Hoskins, B., and M. Sallah. 2011. Developing Intercultural Competence in Europe: The Challenges. Language and Intercultural Communication 11 (2): 113-125.

Houghton, S.A. 2009. The Role of Intercultural Communicative Competence in the Development of World Englishes and Lingua Francas. Journal of Language, Linguistics and Literature 15: 69-95.

- 2012. Intercultural Dialogue in Practice: Managing Value Judgement Through Foreign Language Education. Bristol: Channel View Publications.

Jenkins, R. 2008. The Ambiguity of Europe. European Societies 10 (2): 153-176.

Kaya, A., and C. De Cesari. 2019. Introduction. In European Memory in Populism: Representations of Self and Other, ed. C. de Cesari and A. Kaya, 1-25. London: Routledge.

Koopmans, R., P. Statham, M. Giugni, and F. Passy. 2005. Contested Citizenship: Immigration and Cultural Diversity in Europe. Minneapolis: University of Minnesota Press.

Koopmans, R., I. Michalowski, and S. Waibel. 2012. Citizenship Rights for Immigrants: National Political Processes and Cross-National Convergence in Western Europe, 1980-2008. American Journal of Sociology 117 (4): 1202-1245.

Kowalczyk, J. 2011. The Immigration Problem' and European Education Reforms: From the Education of Migrants' Children to Intercultural Education. European Education 42 (4): 5-24.

Krauss, P. 2011. The Politics of Complex Diversity: A European Perspective. Ethnicities 12 (3): 3-25.

Kymlicka, W. 1995. Multicultural Citizenship: A Liberal Theory of Minority Rights. Oxford: Oxford University Press.

- 2003. Multicultural States and Intercultural Citizens. Theory and Research in Education 1 (2): 147-169.

Lähdesmäki, T. 2015. The Ambiguity of Europe and European Identity in Finnish Populist Political Discourse. Identities: Global Studies in Culture and Power 22 (1): 71-87.

- 2016. Politics of Tangibility, Intangibility, and Place in the Making of European Cultural Heritage in EU Heritage Policy. International Journal of Heritage Studies 22 (10): 766-780.

- 2019. European Culture, History, and Heritage as Political Tools in the Rhetoric of the Finns Party. In European Memory in Populism: Representations of Self and Other, ed. C. De Cesari and A. Kaya, 191-209. London: Routledge. Lähdesmäki, T., and A. Wagener. 2015. Discourses on Governing Diversity in Europe: Critical Analysis of the White Paper on Intercultural Dialogue. International Journal of Intercultural Relations 44: 13-28. 
Lähdesmäki, T., P.C.C.A. Heynderickx, A. Wagener, and S.M.F. Dieltjens. 2015. Negations and Negativity as Linguistic Devices in Policy Discourse of Intercultural Cities. Journal of Multicultural Discourses 10 (3): 332-348.

Lähdesmäki, T., V. Čeginskas, S. Kaasik-Krogerus, K. Mäkinen, and J. Turunen. 2020. Creating and Governing Cultural Heritage in the European Union: The European Heritage Label. London: Routledge. https://www.routledge.com/ Creating-and-Governing-Cultural-Heritage-in-the-European-Union-OpenAccess/Lahdesmaki-Ceginskas-Kaasik-Krogerus-Makinen-Turunen/p/ book/9780367148355.

Lee, E.L. 2016. Intercultural Dialogue in Theory and Practice: A Review. Journal of Multicultural Discourses 11 (2): 236-242.

Leikkilä, J., M. Faehnle, and M. Galanakis. 2013. Promoting Interculturalism by Planning of Urban Nature. Urban Forestry \& Urban Greening 12 (2): 183-190.

Levey, G.B. 2012. Interculturalism vs. Multiculturalism: A Distinction Without a Difference? Journal of Intercultural Studies 33 (2): 217-224.

Levrau, F., and P. Loobuyck. 2018. Introduction: Mapping the MulticulturalismInterculturalism Debate. Comparative Migration Studies 6 (13): 1-13.

Meer, N., and T. Modood. 2013. Interacting Interculturalism with Multiculturalism: Observations on Theory and Practice. In Interculturalism and Multiculturalism: Similarities and Differences, ed. M. Barrett, 111-132. Strasbourg: Council of Europe.

Modood, T. 2017. Must Interculturalists Misrepresent Multiculturalism? Comparative Migration Studies 5 (15): 1-17. https://doi.org/10.1186/ s40878-017-0058-y.

Modood, T., and N. Meer. 2012. How Does Interculturalism Contrast with Multiculturalism? Journal of Intercultural Studies 33 (2): 175-196.

Mouffe, C. 2009. Democracy in a Multipolar World. Millennium: Journal of International Studies 37 (3): 549-561.

Mudde, C. 2007. Populist Radical Right Parties in Europe. Cambridge: Cambridge University Press.

- 2017. Introduction to the Populist Radical Right. In The Populist Radical Right: A Reader, ed. C. Mudde, 1-10. London: Routledge.

Mulcahy, S. 2006. At the Borders of Europe: Ireland and Immigrant Integration from a Comparative European Perspective. In 6th Biennial Conference of ECSA-Canada: What Kind of Europe? Multiculturalism, Migration, Political Community and Lessons from Canada. Victoria, B.C. Canada, May 19-20.

Näss, H.E. 2010. The Ambiguities of Intercultural Dialogue: Critical Perspectives on the European Union's New Agenda for Culture. Journal of Intercultural Communication 23. https://www.immi.se/intercultural/nr23/nass.htm.

Norocel, O.C. 2013. Our People-A Tight-Knit Family Under the Same Protective Roof: A Critical Study of Gendered Conceptual Metaphors at Work in Radical Right Populism. Helsinki: University of Helsinki. 
O'Grady, K. 2010. Researching Religious Education Pedagogy Through an Action Research Community of Practice. British Journal of Religious Education 32 (2): 119-131.

Panikkar, R. 1982. Is the Notion of Human Rights a Western Concept? Diogenes 30 (120): 75-102.

Papacharissi, Z.A. 2010. A Private Sphere. Democracy in a Digital Age. Cambridge: Polity.

Parekh, B. 2006. Rethinking Multiculturalism: Cultural Diversity and Political Theory. Basingstoke: Palgrave Macmillan.

—. 2008. European Liberalism and 'The Muslim Question'. ISIM Paper 9. Leiden: Amsterdam University Press.

Portera, A. 2008. Intercultural Education in Europe: Epistemological and Semantic Aspects. Intercultural Education 19 (6): 481-491.

Rodríguez-García, D. 2010. Beyond Assimilation and Multiculturalism: A Critical Review of the Debate on Managing Diversity. Journal of International Migration and Integration 11 (3): 251-271.

Sandercock, L., and G. Attili. 2009. Where Strangers Become Neighbours: Integrating Immigrants in Vancouver, Canada. Berlin: Springer.

Sharma, A. 2006. Are Human Rights Western? A Contribution to the Dialogue of Civilizations. Oxford: Oxford University Press.

Silvestri, S. 2007. Policy Brief: Islam and the EU: The Merits and Risks of Intercultural Dialogue. Brussels: European Policy Centre.

Štrajn, D. 2018. The Intercultural Dialogue: Preparing Teachers for Diversity. International Review of Education 64 (3): 411-413.

Taylor, C. 2012. Interculturalism or Multiculturalism? Philosophy and Social Criticism 70 (4-5): 413-423.

UNESCO. 1996. Our Creative Diversity. Paris: UNESCO.

Vaughan-Williams, N. 2015. Europe's Border Crisis: Biopolitical Security and Beyond. Oxford: Oxford University Press.

Vertovec, S. 2007. New Complexities of Cohesion in Britain: Super-Diversity, Transnationalism and Civil-integration. Wetherby: Communities and Local Government Publications.

Vertovec, S., and S. Wessendorf. 2010. Introduction: Assessing the Backlash Against Multiculturalism. In The Multiculturalism Backlash: European Discourses, Policies and Practices, ed. S. Vertovec and S. Wessendorf, 1-31. New York: Routledge.

Wagener, A. 2012. Deconstructing Culture: Towards an Interactional Triad. Journal of Intercultural Communication 29. https://www.immi.se/intercultural/nr29/wagener.html.

Weiss, G. 2002. Searching for Europe: The Problem of Legitimisation and Representation in Recent Political Speeches on Europe. Journal of Language and Politics 1 (1): 59-83. 
Wiesand, A., I. Heiskanen, R. Mitchell, D. Cliché, M. Fisher, and L. Marsio. 2008. Sharing Diversity. National Approaches to Intercultural Dialogue in Europe. Bonn: European Institute for Comparative Cultural Research.

Wieviorka, M. 2012. Multiculturalism: A Concept to Be Redefined and Certainly Not Replaced by the Extremely Vague Term of Interculturalism. Journal of Intercultural Studies 33 (2): 225-231.

Wilk-Woś, Z. 2010. The Role of Intercultural Dialogue in the EU Policy. Journal of Intercultural Management 2 (1): 78-88.

Wilson, R. 2013. The Urgency of Intercultural Dialogue in a Europe of Insecurity. In Interculturalism and Multiculturalism: Similarities and Differences, ed. M. Barrett, 53-68. Strasbourg: Council of Europe.

Wodak, R. 2015. The Politics of Fear: What Right-Wing Populist Discourses Mean. London: Sage.

Wood, P., and C. Landry. 2008. The Intercultural City: Planning for Diversity Advantage. London: Earthscan.

Zapata-Barrero, R. 2016. Theorising Intercultural Citizenship. In Multiculturalism and Interculturalism: Debating the Dividing Lines, ed. N. Meer, T. Modood, and R. Zapata-Barrero, 53-76. Edinburgh: Edinburgh University Press.

- 2017. Interculturalism in the Post-Multicultural Debate: A Defence. Comparative Migration Studies 5 (1): 14. https://doi.org/10.1186/ s40878-017-0057-z.

Zay, D. 2011. A Cooperative School Model to Promote Intercultural Dialogue Between Citizens-to-Be. Policy Futures in Education 9 (1): 96-103.

Open Access This chapter is licensed under the terms of the Creative Commons Attribution 4.0 International License (http://creativecommons.org/licenses/ by $/ 4.0 /$ ), which permits use, sharing, adaptation, distribution and reproduction in any medium or format, as long as you give appropriate credit to the original author(s) and the source, provide a link to the Creative Commons licence and indicate if changes were made.

The images or other third party material in this chapter are included in the chapter's Creative Commons licence, unless indicated otherwise in a credit line to the material. If material is not included in the chapter's Creative Commons licence and your intended use is not permitted by statutory regulation or exceeds the permitted use, you will need to obtain permission directly from the copyright holder.

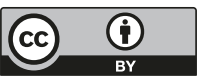




\title{
Data and Methods: A Conceptual Approach to Intercultural Dialogue
}

\begin{abstract}
In this chapter, we discuss the constructivist perspective on concepts and explain how we utilize this in our analysis of concepts used by the Council of Europe and the European Union in their education policy documents. In this perspective, political language and administrative documents not only describe the reality of administrated issues but also participate in their construction and meaning-making. The authors emphasize the performativity of language and discuss its significance for political rhetoric. Besides the theoretical and methodological frameworks, we describe the data and elaborate on the genre of education policy documents. We also provide an overview of the development, contents, and goals of European education policies in general and discuss their challenges as 'soft law' instruments based on non-enforceable recommendations and incentives.
\end{abstract}

Keywords Constructivist perspective $\bullet$ Concept analysis $\bullet$ The Council of Europe $\bullet$ The European Union $\bullet$ Genre $\bullet$ Education policy documents

Politics emerge from competing discourses on the uses of power. As outcomes of politics, policies concretize political will through written statements of intent. Therefore, the use of language is a crucial element of policies. Intercultural dialogue has been both a political innovation and a 
conceptual change in diversity policies. Due to the discursive nature of politics, political innovations are commonly simultaneously conceptual innovations and conceptual changes regarding social and societal issues that embody politics (Farr 1989, 31). Political language in policy documents does not only describe the reality of policies but also participate in their production. In such documents, language produces problems as well as subjects, objects, and their-often hierarchical—relations (Shore et al. 2011). Moreover, political language not only shapes the issues being discussed, but it also modifies the ideas of the community being governed through policies (Lähdesmäki et al. 2019). Following Austin's (1982) speech act theory, political language has thus been perceived as a performative speech act-even though its explicit claims might not be fulfilled (see e.g. Skinner 2002).

Our work is firmly rooted in the previous social-constructivist research on European politics. For two decades, scholars have examined the European Union and its politics and policies by emphasizing discourses, rhetoric, narration, and the use of language as a space for both conscious and unconscious production of meaning (e.g. Rosamond 2000; Christiansen et al. 2001; Risse 2004; Light and Young 2009). Diez (2001, 88) has even argued that the history of the European Union, with its agreements, declarations, directives, and decisions, can be seen as a broad collection of speech acts.

The methodological framework of this book stems from a constructivist perspective on concepts, emphasizing their contested, ambiguous, controversial, and transforming nature (see Skinner 1989; Koselleck 2002; Guzzini 2005), and a constructionist approach to language use and linguistic meaning-making processes. Concepts are not only abstract theoretical categories that are used to describe and make sense of the object of speech. As Wiesner $(2019,9)$ notes, the meaning of concepts "has a decisive function in ordering the world around us". In political discourses, they are also indicators of social, institutional, and political changes, debates, and conflicts, since conceptual controversies are often simultaneously political controversies (Wiesner and Schmidt-Gleim 2014; Wiesner et al. 2017, 2018; Wiesner 2019; Lähdesmäki et al. 2019). Moreover, semantic transformations of concepts not only reflect changes in the object of speech; concepts are tools for making these changes (Ball et al. 1989). Thus, the constructivist perspective on concepts emphasizes their performative nature: concepts bring about action (Austin 1982; Guzzini 2005).

Our approach emphasizes the performativity of language and its broader significance for policy documents and political rhetoric. For us, policies 
function as 'actants' that create social and semantic spaces, webs of meanings, and action. Semantic transformations and new concepts renew political ideas and views, and function as tools for introducing and establishing new policies (Lähdesmäki et al. 2019). The concept of intercultural dialogue in the policy documents discursively generates the idea and ideals of encountering and governing diversity in Europe. Through acts of naming and categorizing issues, policy discourses modify the ways in which diverse political and societal problems are approached and defined (Shore and Wright 1997).

Although the Council of Europe and the European Union frequently refer to intercultural dialogue in their education policy documents, the concept is rarely more broadly explored and explained in them. However, the uses of the concept in these documents entail various implicit meanings discursively constructed by embedding in the policy language various other concepts, terms, and textual contexts. These can be used to combine differing elements as an assemblage (Newman and Clarke 2009, 26). Our analysis of these assemblages stems from Skinner's 'contextualism' in the research of concepts (on this in relation to Koselleck's conceptual history, see e.g. Palonen 2014).

We adopt Skinner's emphasis on the relations between language and power in the research of concepts. Skinner $(1999,60-61)$ argues that such research should

focus on the various terms - the entire normative vocabulary-in which such concepts are habitually expressed. These terms, the paradigms of which are perhaps the names of the virtues and vices, are those which perform evaluative as well as descriptive functions in natural languages.

In his take, concepts are seen less as statements about the world than as tools and weapons of ideological debate. Thus the aim is to understand what can be done with concepts in argumentation and how they function as the engine of social change (Skinner 1999, 62-63, 2002, 4, 177). Skinner $(2002,5)$ notes:

[W]e employ our language not merely to communicate information but at the same time to claim authority for our utterances, to arouse the emotions of our interlocutors, to create boundaries of inclusion and exclusion and to engage in many other exercises of social control.

This kind of language use characterizes the discussions on intercultural dialogue in the European education policy documents. 


\section{The Council of Europe and the European Union as Policymakers}

The Council of Europe and the European Union share an explicit interest in promoting culture, identity, and values described and defined as European in their policy discourses. Both also act in the field of education in various ways. Due to their different institutional natures, however, the premises of their action differ. The Council of Europe mainly works through conventions developed by its member states. These member states maintain their sovereignty but commit themselves to conventions that function as common legal standards to be followed at the national level. The member states of the Union, in contrast, transfer part of their national legislative and executive power to Union administrative bodies. Although its directives deal with education in a rather generic manner, the European Union has a broad impact on educational issues in its member states through a diverse array of decisions and recommendations on specific educational matters, as well as through various funding instruments and programmes regarding children and young people.

In terms of membership and geographical scope, the Council of Europe and the European Union represent two different ideas of Europe. While after Brexit the Union would include 27 member states that are bound together through diverse administrative bonds and forms of integration, the Council has 47 member states whose societal, economic, political, cultural, and religious contexts differ greatly. Geographically, the Council represents a much broader idea of Europe, spreading further to the east than the European Union and including transcontinental states (Lähdesmäki 2019).

Neither of these organizations should be seen as a single actor or a policymaker working unanimously towards a common goal. Their policy documents are created in cooperation with diverse actors-including policymakers from different sectors, external experts, and stakeholders consulted at various events during multistage policymaking processes (Lähdesmäki 2019). Their policy documents, thus, are a reflection or result of negotiations drawn together by secretaries, officers, or other implementors at these organizations. Moreover, the policy discourses and conceptual choices made by the Council of Europe and the European Union reflect those of other international organizations, such as UNESCO. Their discourses are also closely connected through common policy areas, goals, actors, and joint initiatives. The Council of Europe has 
had a major influence on the development and conceptualization of the European Union's policy discourse. The Council's rhetorical formulations and interest areas have often been absorbed into the Union's policy discourse and goals with only a short delay, particularly in questions related to culture (Sassatelli 2009, 43; Patel 2013, 6).

Even though the Council of Europe and the European Union share a common interest in impacting on education policies in Europe, their ability to do so is limited. In the European Union, education is dealt with according to the principle of subsidiarity: the competencies for education are recognized to lie with member states at the national, regional, and local level (e.g. EC 2017, 2). The education policies of both bodies can be considered as 'soft law' instruments based mostly on non-enforceable recommendations and incentives (see Dewey 2010). Their education policies thus have a highly 'symbolic nature' characterized by a limited legal framework, yet including ambitious objectives of social cohesion, inclusion, and identity-building. The symbolic nature of these policies is also highlighted by the abstract and affective rhetoric used in the policy documents.

\section{Policy Development for Intercultural Dialogue}

As described in the introductory chapter, both the Council of Europe and the European Union have been active in promoting intercultural dialogue as an approach in their diversity policies. The political and scholarly debates over multiculturalism speeded up the shift away from it to intercultural dialogue as a core focus of their diversity policy vocabulary. Next, we will briefly explore how the concept was adapted to their policy discourses.

The dialogical approach to intercultural encounter was initiated in the 1980s by UNESCO (Wiesand et al. 2008). A similar approach started to characterize Council of Europe and European Union initiatives and programmes during the 1990s. Even though some Council policy documents explicitly referred to intercultural dialogue in the 1990s (e.g. the Framework Convention for the Protection of National Minorities, 1995), the emergence of the concept in Council and Union policy discourses can be timed to the beginning of the 2000s. At that time, the Council of Europe started a process that resulted in its White Paper on Intercultural Dialogue, finally published in 2008.

This process was initiated by Bennett $(2001,65-66)$ in his report advising the Council of Europe to facilitate the development of international codes of best practice in cultural diversity by involving various stakehold- 
ers in the development of cultural diversity policies and supporting the establishment and coordination of research networks on them. The recommendations of the report were applied by consulting the diverse bodies of the Council and various organizations and communities in its member states, through a questionnaire study of practices and needs for diversity policies. On the basis of the survey, the Council of Europe published a White Paper on Intercultural Dialogue (2008) seeking to provide practical suggestions for responding to the various challenges that diversified European societies were considered to face through dialogue between cultures (see Bunjes 2013 for the development process of the White Paper). The concept had been used previously in some Council declarations, such as the Declaration on Intercultural Dialogue and Conflict Prevention (2003) and the Faro Declaration on the Council of Europe's Strategy for Developing Intercultural Dialogue (2005).

The concept emerged in the European Union's policy discourse in the same period. Intercultural dialogue had a central place in the Union's cultural agenda titled A European Agenda for Culture in a Globalising World, published in 2007. The following year, the Union celebrated the European Year of Intercultural Dialogue; one of its goals was to raise awareness of the concept. The core motive behind the European Commission's decision to celebrate this year was the eastern enlargement of the Union and anticipated need for its old and new citizens to know each other's cultures better. Other thematic foci of the year included diversification through immigration and impacts of globalization (Wiesand et al. 2008). The evaluation report found that the core goals of the year were not fully implemented. Since intercultural dialogue was not precisely defined, the concept risked being understood too narrowly, excluding discussion of the most challenging social and political issues regarding diversity (ECOTEC $2009,24)$.

Since then, the European Union has embedded intercultural dialogue into its policy objectives and operational guidelines in the areas of culture, citizenship, multilingualism, education, training, and sport - either explicitly or indirectly by referring to the need of developing intercultural skills and competences and creating dialogue between people in multicultural environments (Wiesand et al. 2008, 100; DIALLS 2018). The ERICart report (Wiesand et al. 2008, 100) noted, however, that "the context within which [the concept] is embedded, varies significantly across the different policies and in some cases there are indications that clear definitions have not been established". In the 2010 s, intercultural dialogue has 
been a priority area in the European Union's broad cultural programmes, Culture Programme 2007-2013, followed by Creative Europe 2014-2020.

More recently, the European Union has also emphasized intercultural dialogue in its policies regarding refugees and migrants. In response to the 'refugee crisis' in 2015, the Union sought to connect its cultural politics and diversity policies more closely to include refugees and migrants in European societies. Experts and stakeholders from cultural sector were involved in these attempts, resulting in two reports: Promoting Intercultural Dialogue and Bringing Communities Together through Culture in Shared Public Spaces (2016) and How Culture and the Arts Can Promote Intercultural Dialogue in the Context of the Migratory and Refugee Crisis (2017). In them, intercultural dialogue is the core concept used to deal with differences in diversified societies. In 2017, the Council of the European Union adopted conclusions on Culture in the European Union's External Relations by welcoming the European Commission's joint communication, Towards an EU Strategy for International Cultural Relations (2016). This communication lays the foundation for the Union's current and forthcoming cultural diplomacy policy by identifying three key work streams, of which the second focuses on "promoting culture and intercultural dialogue for peaceful inter-community relations" (EC 2016, 7). Over a decade, the concept has been adapted to the European Union's policy discourses in both its internal and external affairs.

Similarly, the Council of Europe has utilized the concept of intercultural dialogue in its diverse policy areas, emphasizing language learning, education, media, conflict prevention and management, post-conflict reconciliation, support for young refugees, asylum seekers, and displaced persons, and the promotion of global solidarity and cooperation. The Council of Europe's work on intercultural dialogue has resulted in various practical guidelines to advance its core goals. For example, the Council published a Toolkit for Conducting Intercultural Dialogue in 2012 as an outcome of its INGO Conference. Moreover, intercultural dialogue has been key to various programmes of the Directorate General of Democracy that have focused on democracy education among young people. The Council of Europe's work on advancing democratic societies and democratic culture, and on perceiving intercultural dialogue as a prerequisite for their processes and institutions, has concretized in its project that was realized in four phases between 2014 and 2017. As its result, the Council has created a conceptual model of the competences seen as important for citizens "to participate effectively in a culture of democracy" (CofE 2016, 3). The 20 
competences fall into four categories: values, attitudes, skills, and knowledge and critical understanding. As continuation of its work on promoting a culture of democracy, in 2018 the Council of Europe published the Reference Framework of Competences for Democratic Culture. The Framework seeks to meet a need which the Council saw in its member states for a clear focus and common goals in citizenship education (CofE $2018,5)$.

How do the Council of Europe and the European Union themselves define the concept of intercultural dialogue? In the Council White Paper (2008, 10-11),

[i]ntercultural dialogue is understood as an open and respectful exchange of views between individuals, groups with different ethnic, cultural, religious and linguistic backgrounds and heritage on the basis of mutual understanding and respect [-]. It operates at all levels-within societies, between the societies of Europe and between Europe and the wider world.

Besides the societal-level measures, the White Paper emphasizes the responsibility of grassroots actors in implementing intercultural dialogue. Beyond the school system, trade unions, workplaces, religious communities, and the public sphere, the White Paper extends its guidance to profoundly private spheres of human life, such as leisure activities and family environments (Lähdesmäki and Wagener 2015). Moreover, the White Paper (CofE 2008, 17) defines intercultural dialogue as

a process that comprises an open and respectful exchange of views between individuals and groups with different ethnic, cultural, religious and linguistic backgrounds and heritage, on the basis of mutual understanding and respect. It requires the freedom and ability to express oneself, as well as the willingness and capacity to listen to the views of others. Intercultural dialogue contributes to political, social, cultural and economic integration and the cohesion of culturally diverse societies. It fosters equality, human dignity and a sense of common purpose. It aims to develop a deeper understanding of diverse world views and practices, to increase co-operation and participation (or the freedom to make choices), to allow personal growth and transformation, and to promote tolerance and respect for the other.

The White Paper introduces intercultural dialogue as a new approach to diversity policy by differentiating it from multiculturalism. The European Union's definition of intercultural dialogue uses the same dis- 
course that stems from the critique of multiculturalism. The European Commission website (2019) notes:

Intercultural dialogue is, essentially, the exchange of views and opinions between different cultures. Unlike multiculturalism, where the focus is on the preservation of separate cultures, intercultural dialogue seeks to establish linkages and common ground between different cultures, communities, and people, promoting understanding and interaction.

The European Union's Decision on the European Year of Intercultural Dialogue (EC 2006, 44) emphasizes the contribution of different cultures to heritage and ways of life in the Union and describes the goals of intercultural dialogue as "learning to live together in harmony":

At the heart of the European project, it is important to provide the means for intercultural dialogue and dialogue between citizens to strengthen respect for cultural diversity and deal with the complex reality in our societies and the coexistence of different cultural identities and beliefs. Furthermore, it is important to highlight the contribution of different cultures to the Member States' heritage and way of life and to recognise that culture and intercultural dialogue are essential for learning to live together in harmony.

The Council of Europe's most recent definition of intercultural dialogue is formulated in the Reference Framework of Competences for Democratic Culture (2018):

Intercultural dialogue is an open exchange of views, on the basis of mutual understanding and respect, between individuals or groups who perceive themselves as having different cultural affiliations from each other. It requires the freedom and ability to express oneself, as well as the willingness and capacity to listen to the views of others. (CofE 2018, 74-75)

This document also recognizes various potential challenges in intercultural dialogue. As its glossary states:

Intercultural dialogue can be a difficult process. This is particularly the case when the participants perceive each other as representatives of cultures that have an adversarial relationship with one another (e.g. as a consequence of past or present armed conflict) or when a participant believes that their own 
cultural group has experienced significant harm (e.g. blatant discrimination, material exploitation or genocide) at the hands of another group to which they perceive their interlocutor as belonging. Under such circumstances, intercultural dialogue can be extremely difficult, requiring a high level of intercultural competence and very considerable emotional and social sensitivity, commitment, perseverance and courage. (CofE 2018, 75)

Both organizations base their notion of intercultural dialogue on particular 'shared European values' that are seen as the common legal, moral, and ethical framework for its implementation. These values-or rather a group of societal ideals and political principles of liberal democratic societies-are founded in human rights, democracy, and the rule of law. Moreover, the European Union commonly continues this list of values with respect for human dignity, freedom, equality, and the rights of persons belonging to minorities by defining them as common values to "a society in which pluralism, non-discrimination, tolerance, justice, solidarity and equality between women and men prevail", as the Treaty of Lisbon declares (EC 2008, Article 2).

Despite their good aims, European-level measures for advancing intercultural dialogue have been criticized for not reaching the national, regional, or local level. The ERICart report stated as early as 2008 that the European Union's agendas had not been uniformly incorporated in the national legislation or policies of member states (Wiesand et al. 2008, iv). Hadjisoteriou et al.'s $(2015,222)$ research also showed that the Union's turn towards intercultural education has influenced education policies, curricula, school textbooks, and teacher training in member states, though the European discourses often ran counter to national policy discourses. Moreover, the terminology of the intercultural dimension has been interpreted in diverse ways within national education policies (Hadjisoteriou et al. 2015, 233).

The idea and practice of intercultural dialogue has been broadly adopted by various other international actors such as the United Nations, UNESCO, OECD, European Cultural Foundation, the European Forum for the Arts and Heritage, and other NGOs and civil society platforms (Wiesand et al. 2008; Besley and Peters 2012). UNESCO's interest in 'interculturality' has been a particular inspiration for policies on intercultural dialogue in the Council of Europe and the European Union. In 2005, the UNESCO General Assembly adopted the Convention on the Diversity of Cultural Expressions that came into force in 2007. Its objec- 
tives include "to encourage dialogue among cultures with a view to ensuring wider and balanced cultural exchanges in the world in favour of intercultural respect and a culture of peace; and to foster interculturality in order to develop cultural interaction in the spirit of building bridges among peoples" (UNESCO 2007, 5). The convention does not utilize the concept of intercultural dialogue as such but approaches it through other terms such as the interaction of cultures.

\section{Data Selection and Characteristics}

The Council of Europe and European Union policy documents include a broad range of texts of varying form, length, and focus. Many of them simultaneously address issues relevant to different policy sectors, such as culture, education, sport, economics, employment, regional politics, social politics, migration, refugees, and minorities. Our research focuses on education policies. In order to recognize these in such a wide range of documents, we chose to follow how these organizations themselves identify their core education policies.

The European Union documents were selected from the EUR-Lex database - the official database of all its legal texts. In it, the Summaries of EU Legislation section includes a policy collection titled 'Education, training, youth, sport'. From within that, the sub-collection on 'Education and training' was selected as the data source. Our data concerning the European Union consists of all 48 documents in this collection, excluding the 'archived documents', that is, (versions of the) documents that are no longer in force. The Council of Europe documents were selected from its official website. The core education policy documents produced by the Council can be accessed from the education section of this website via the links 'resources' and 'official texts'. These 19 documents include 4 conventions, 3 charters, and 12 recommendations. The data was collected in summer 2018 and totals 67 documents.

The European Union documents in the data seek to tackle a variety of educational issues, such as e-learning, digital competences, youth work, entrepreneurship in education, vocational education, lifelong learning, promoting school success, children with migrant backgrounds, multilingualism, media literacy, transnational partnerships in education, teacher education, and gender equality. The overarching context of all these documents is naturally education and training, but their other common contexts relate to employment, economic growth, the labour market, mobility, 
creativity, innovation, competitiveness, diversity, equity, equal access, and social cohesion. Some of the documents focus on the diversification of society due to immigration and globalization, whereas others emphasize sustainable development related to societal and economic issues, as well as the challenges of climate change. The context of violent upheavals, such as terrorism, is also mentioned in some documents - and connected with the simultaneous aims of safeguarding European values and promoting the acceptance of diversity. The time frame of the European Union's documents in the data ranges from 1975 to 2018.

The Council of Europe documents in the data likewise addressed various topics, such as history teaching, children and adolescents of migrant backgrounds, promotion of plurilingualism, democratic citizenship, higher education, and common values. Besides education and training, the contexts of these documents include respect for cultural diversity, integration of migrants, enhancing democracy and human rights, and advancing fair societies. The time frame of the recommendations in the data ranges from 2000 to 2014, while that of the conventions and charters range from 1954 to 2015 . In addition, the data includes a compilation document of thematic extracts from several conventions, recommendations, resolutions, and reports, published in 2018.

The Council of Europe documents were produced by its various committees, including representatives from the state parties, and its recommendations created by different committees of ministers. Most Union documents were created by the European Commission or the Council of the European Union with other Union institutions or administrative bodies, such as the European Parliament and representatives of the governments of member states. The explicit audience of the documents issued by the European Union is usually other Union institutions, and in the case of the Council of Europe, its member states. Based on the issues addressed, the intended end users of the documents are diverse, including policymakers, national, regional, and local education authorities, teachers and educators, schools, institutes of vocational and higher education, civil associations and (I)NGOs, health and social workers, employers and trade unions, cultural institutions, researchers, and learners.

The documents seldom explicitly refer to their creators as 'we'. However, the position of 'we' as Europeans or as representatives of the Council of Europe or the European Union is often implicitly created in their texts by using expressions such as "our common European principles" (CofEU \& RofGofMS 2006, 2) and statements such as "each of the many national, regional, minority and migrant languages spoken in Europe adds a facet to 
our common cultural background" (CofEC 2008, 5) or "cultural diversity in our societies should be welcomed" (CofEU 2009, 7). In the Union documents, Europe and Europeans become associated with this "our"Europeans have a society and can, thus, welcome or not welcome diversity (that is "others", such as immigrants). In the Council of Europe documents, the 'we' position is more implicit. Since the documents always speak from the perspective of the Council (with reference to "common heritage", "shared ideals and principles", and a wish to promote European identity and include "others", such as immigrants, in European economic and cultural spheres), it is clear that the speaker position is a European one.

A policy document is a genre that seeks to influence people by appealing to the policy's relevance, timeliness, and importance. The aim of such documents is to improve conditions and practices that policymakers perceive as inadequate, deficient, malfunctioning, or problematic (Lähdesmäki et al. 2015) and to create a better future by applying language that is forward-looking and relies upon a belief in progress and innovation (Kowalczyk 2011). This kind of language characterizes the documents in our data. Moreover, coherent narratives are commonly constructed in the policy documents by showing that the issues have been addressed earlier. Therefore, the genre of the European policy documents is characterized by numerous references to their earlier policy documents, using phrases and expressions from them. The documents seek to present their policy positions as 'natural' consequences of earlier discourses in a logical continuum (Lähdesmäki et al. 2019).

\section{Concept Analysis in Practice}

The concept analysis of the data was guided by theoretical views on the performativity of language, constructivist perspectives on concepts, and contextualism. The focus was on how the concept of intercultural dialogue was both explicitly and implicitly dealt with and given meanings in the policy documents. In practice, our scrutiny was based on a qualitative analysis of explicit and implicit meanings, relations, and co-occurrences of concepts, terms, and themes used to discuss intercultural dialogue and closely related issues arising in the data.

First, we explored how the concept of intercultural dialogue was generally understood and dealt with in the documents and how its meanings were produced in relation to other concepts and terms, such as culture, cultural heritage, identity, inclusion, empathy, tolerance, multiculturalism, citizenship, participation, and social responsibility. In the analysis, we paid 
special attention to the values and ideals conveyed by these concepts and by the education policy documents in general. Appearances of explicit and implicit value statements were traced from the documents to deduce how (the argumentation for) the need of intercultural dialogue was constructed and how it was related to the general aims, values, and ideals of the Council of Europe and the European Union. Second, we engaged in an in-depth analysis of the (CO-)occurrences and thematic overlapping of concepts that were closely related to intercultural dialogue. In this phase, we also explored the relationship between concepts (e.g. inclusion and integration, tolerance and mutual respect), and traced the links between the concepts of intercultural dialogue and intercultural skills and competences. This illuminated the conceptual network and semantics of the concept of intercultural dialogue.

We then extended our analysis to include broader 'densities' of interrelated concepts in selected policy documents. We scrutinized instances where many of the core concepts related to intercultural dialogue appeared at the same time. Our analysis of these densities revealed the closely intertwined nature of certain concepts and terms in the data and indicated how the understandings of intercultural dialogue depend not only on explicit definitions but equally on how interrelated concepts and terms are used in textual contexts of the documents. Moreover, we explored these densities in relation to the subject matter of the policy documents.

Concepts carry affective associations and cultural connotations. In the final stage of our conceptual analysis, we examined the affective nature of concepts and the affective rhetoric used in the data. Drawing on theories of affect (discussed more in detail in the fifth chapter), our research elaborated on the 'poetic dimension' of European education policy discourse (see Lähdesmäki 2017). Our analysis of conceptual densities showed that many of the conceptual conglomerations form affective peaks or rhetorical pinnacles that transmit the idea of intercultural dialogue-and the values attached to it-more forcefully than the mere definitions of the concept are able to do. Therefore, we concluded by focusing on the affective impact of these dense co-occurrences of the core concepts related to intercultural dialogue. We argue that when concepts with affective value (see e.g. Ahmed 2004; Lähdesmäki 2017) are brought together, their dense co-occurrences become heavy with affect. These dense co-occurrences are contrasted in the policy documents with the distancing impact of common policy jargon and sections with 'sparse' co-occurrences of concepts. Consequently, our analysis traced the affective transmission (Brennan 2004) or mediation of European ideals and values in the chosen docu- 
ments by relating the findings to existing research on affects within policy discourse. By examining what kind of affects and affective connotations "stick" (see Ahmed 2004) to the concept of intercultural dialogue, we suggest that the Council of Europe and the European Union use affective rhetoric in their education policy documents to promote their idea of intercultural dialogue and to legitimize their policies to advance it. Affective rhetoric can, thus, be perceived as a central tool in the governing of diversities in European education policies.

\section{REFERENCES}

Ahmed, S. 2004. The Cultural Politics of Emotion. Edinburgh: Edinburgh University Press.

Austin, J.L. 1982. How to Do Things with Words: The Williams James Lectures Delivered at Harvard University in 1955. New York: Oxford University Press.

Ball, T., J. Farr, and R.L. Hanson. 1989. Editors' Introduction. In Political Innovation and Conceptual Change, ed. T. Ball, J. Farr, and R.L. Hanson, 1-5. Cambridge: Cambridge University Press.

Bennett, T. 2001. Part I: Differing Diversities: Transversal Study on the Theme of Cultural Policy and Cultural Diversity. In Differing Diversities: Transversal Study on the Theme of Cultural Policy and Cultural Diversity, ed. T. Bennett, 7-69. Strasbourg: Council of Europe Publishing.

Besley, T., and M.A. Peters. 2012. Interculturalism, Education and Dialogue. Bern: Peter Lang.

Brennan, T. 2004. The Transmission of Affect. Ithaca: Cornell University Press.

Bunjes, U. 2013. The Intercultural Milestone: The History of the Council of Europe's White Paper on Intercultural Dialogue. In Interculturalism and Multiculturalism: Similarities and Differences, ed. M. Barrett, 43-52. Paris: Council of Europe.

Christiansen, T., K.E. Jørgensen, and A. Wiener, eds. 2001. The Social Construction of Europe. London: Sage Publications.

CofE (Council of Europe). 2008. White Paper on Intercultural Dialogue: "Living Together As Equals in Dignity”. Strasbourg: Council of Europe.

- 2016. Competences for Democratic Culture. Living Together as Equals in Culturally Diverse Democratic Societies. Strasbourg: Council of Europe.

- 2018. Reference Framework of Competences for Democratic Culture. Volume 1: Context, Concepts and Model. Strasbourg: Council of Europe.

CofEC (the Commission of the European Communities). 2008. Communication from the Commission to the European Parliament, the Council, the European Economic and Social Committee and the Committee of the Regions Multilingualism: an asset for Europe and a shared commitment. COM(2008) 566 final. Brussels: Commission of the European Communities. 
CofEU \& RofGofMS (Council of the European Union \& the Representatives of the Governments of the Member States). 2006. Resolution of the Council and of the Representatives of the Governments of the Member States, Meeting Within the Council, on the Recognition of the Value of Non-formal and Informal Learning within the European Youth Field. (2006/C 168/01). Official Journal of the European Union C168: 1-3.

CofEU (Council of the European Union). 2009. Council Conclusions of 26 November 2009 on the Education of Children with a Migrant Background. (2009/C 301/07). Official Journal of the European Union C301: 5-8.

Dewey, P. 2010. Power in European Union Cultural Policy. In International Cultural Policies and Power, ed. J.P. Singh, 113-126. New York: Palgrave Macmillan.

DIALLS. 2018. Cultural Analysis Framework. https://dialls2020.eu/wp-content/uploads/2019/09/resubmitted-cultural-analysis-framework-with-coversheet-pdf.

Diez, T. 2001. Speaking 'Europe': The Politics of Integration Discourse. In The Social Construction of Europe, ed. T. Christiansen, K.E. Jørgensen, and A. Wiener, 85-100. London: Sage.

EC (European Commission). 2006. Decision no 1983/2006/EC of the European Parliament and of the Council of 18 December 2006 concerning the European Year of Intercultural Dialogue (2008). Official Journal of the European Union L412: 44-50.

- 2008. Treaty of Lisbon. Brussels: European Commission.

. 2016. Joint Communication to the European Parliament and the Council: Towards an EU Strategy for International Cultural Relations. JOIN (2016) 29 Final, June 8. Brussels: European Commission.

- 2017. Communication from the Commission to the European Parliament, the Council, the European Economic and Social Committee and the Committee of the Regions Strengthening European Identity Through Education and Culture. The European Commission's Contribution to the Leaders' Meeting in Gothenburg, November 17. COM(2017) 673 Final. Brussels: European Commission.

- 2019. Culture: Intercultural Dialogue. Web Site. https://ec.europa.eu/ culture/policy/strategic-framework/intercultural-dialogue_en.

Ecotec. 2009. Evaluation of the European Year of Intercultural Dialogue 2008: Final Report. Birmingham, Ecotec.

Farr, J. 1989. Understanding Conceptual Change Politically. In Political Innovation and Conceptual Change, ed. T. Ball, J. Farr, and R.L. Hanson, 24-49. Cambridge: Cambridge University Press.

Guzzini, S. 2005. The Concept of Power: A Constructivist Analysis. Millennium: Journal of International Studies 33 (3): 495-521.

Hadjisoteriou, C., D. Faas, and P. Angelides. 2015. The Europeanisation of Intercultural Education? Responses from EU Policy-makers. Educational Review 67 (2): 218-235. 
Koselleck, R. 2002. The Practice of Conceptual History: Timing History, Spacing Concepts. Stanford: Stanford University Press.

Kowalczyk, J. 2011. The Immigration Problem' and European Education Reforms: From the Education of Migrants' Children to Intercultural Education. European Education 42 (4): 5-24.

Lähdesmäki, T. 2017. Politics of Affect in the EU Heritage Policy Discourse: An Analysis of Promotional Videos of Sites Awarded with the European Heritage Label. International Journal of Heritage Studies 23 (8): 709-722.

- 2019. Conflicts and Reconciliation in Postmillennial Heritage Policy Discourses of the Council of Europe and the European Union. In Dissonant Heritages and Memories in Contemporary Europe, ed. T. Lähdesmäki, L. Passerini, S. Kaasik-Krogerus, and I. van Huis, 25-50. New York: Palgrave Macmillan.

Lähdesmäki, T., and A. Wagener. 2015. Discourses on Governing Diversity in Europe: Critical Analysis of the White Paper on Intercultural Dialogue. International Journal of Intercultural Relations 44: 13-28.

Lähdesmäki, T., P.C.C.A. Heynderickx, A. Wagener, and S.M.F. Dieltjens. 2015. Negations and Negativity as Linguistic Devices in Policy Discourse of Intercultural Cities. Journal of Multicultural Discourses 10 (3): 332-348.

Lähdesmäki, T., S. Kaasik-Krogerus, and K. Mäkinen. 2019. Genealogy of the Concept of Heritage in the European Commission's Policy Discourse. Contributions to the History of Concepts 14 (1): 115-139.

Light, D., and C. Young. 2009. European Union Enlargement, Post-Accession Migration and Imaginative Geographies of the 'New Europe': Media Discourses in Romania and the United Kingdom. Journal of Cultural Geography 26 (3): 281-303.

Newman, J., and J. Clarke. 2009. Publics, Politics and Power: Remaking the Public in Public Services. London: Sage.

Palonen, K. 2014. Politics and Conceptual Histories. Rhetorical and Temporal Perspectives. Baden-Baden: Nomos/Bloomsbury.

Patel, K.K. 2013. Introduction. In The Cultural Politics of Europe. European Capitals of Culture and European Union Since the 1980s, ed. K.K. Patel, 1-15. London: Routledge.

Risse, T. 2004. European Institutions and Identity Change: What Have We Learned? In Transnational Identities. Becoming European in the EU, ed. R.K. Herrmann, T. Risse, and M.B. Brewer, 247-271. Oxford: Rowman and Battlefield.

Rosamond, B. 2000. Theories of European Integration. Basingstoke: Palgrave.

Sassatelli, M. 2009. Becoming Europeans. Cultural Identity and Cultural Policies. New York: Palgrave Macmillan.

Shore, C., and S. Wright. 1997. Policy: A New Field for Anthropology. In Anthropology of Policy: Critical Perspectives on Governance and Power, ed. C. Shore and S. Wright, 3-39. London: Routledge. 
Shore, C., S. Wright, and D. Però, eds. 2011. Policy Worlds. Anthropology and the Analysis of Contemporary Power. New York: Berghahn Books.

Skinner, Q. 1989. Language and Political Change. In Political Innovation and Conceptual Change, ed. T. Ball, J. Farr, and R.L. Hanson, 6-23. Cambridge: Cambridge University Press.

- 1999. Rhetoric and Conceptual Change. In Finnish Yearbook of Political Thought 3, ed. S. Haikala, J. Kotkavirta, and K. Palonen, 60-73. Jyväskylä: SoPhi.

- 2002. Visions of Politics-Volume 1: Regarding Method. Cambridge: Cambridge University Press.

UNESCO. 2007. Convention on the Diversity of Cultural Expressions. Paris: UNESCO.

Wiesand, A., I. Heiskanen, R. Mitchell, D. Cliché, M. Fisher, and L. Marsio. 2008. Sharing Diversity: National Approaches to Intercultural Dialogue in Europe. Bonn: European Institute for Comparative Cultural Research.

Wiesner, C. 2019. Inventing the EU as a Democratic Polity. New York: Palgrave Macmillan.

Wiesner, C., and M. Schmidt-Gleim. 2014. The Meanings of Europe: Introduction. In The Meanings of Europe. Changes and Exchanges of a Contested Concept, ed. C. Wiesner and M. Schmidt-Gleim, 1-15. London: Routledge.

Wiesner, C., T. Haapala, and K. Palonen. 2017. Debates, Rhetoric, and Political Action. Basingstoke: Palgrave Macmillan.

Wiesner, C., A. Björk, H.-M. Kivistö, and K. Mäkinen. 2018. Introduction: Shaping Citizenship as a Political Concept. In Shaping Citizenship. A Political Concept in Theory, Debate and Practice, ed. C. Wiesner, A. Björk, H.-M. Kivistö, and K. Mäkinen, 1-16. London: Routledge.

Open Access This chapter is licensed under the terms of the Creative Commons Attribution 4.0 International License (http://creativecommons.org/licenses/ by $/ 4.0 /$ ), which permits use, sharing, adaptation, distribution and reproduction in any medium or format, as long as you give appropriate credit to the original author(s) and the source, provide a link to the Creative Commons licence and indicate if changes were made.

The images or other third party material in this chapter are included in the chapter's Creative Commons licence, unless indicated otherwise in a credit line to the material. If material is not included in the chapter's Creative Commons licence and your intended use is not permitted by statutory regulation or exceeds the permitted use, you will need to obtain permission directly from the copyright holder.

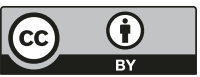




\title{
Definitions and Contexts of Intercultural Dialogue in European Policy Documents
}

\begin{abstract}
In this chapter, we analyse how the concept of intercultural dialogue is both explicitly and implicitly used in European education policy documents. First, we explore how the concept is explicitly dealt with in the documents and how its meanings are produced in relation to other concepts and terms, such as culture, cultural heritage, identity, inclusion, empathy, tolerance, multiculturalism, citizenship, participation, and social responsibility. We pay special attention to the values and ideals conveyed by the education policy documents in general and these concepts in particular. Second, we discuss the thematic overlap of these concepts and how different concepts, terms, and conceptual expressions can be used interchangeably in policy documents. These examples illuminate the conceptual network and semantics of the concept of intercultural dialogue.
\end{abstract}

Keywords Culture $\bullet$ Cultural heritage $\bullet$ Identity $\bullet$ Inclusion $\bullet$ Tolerance • Intercultural

The Council of Europe and European Union seek to impact on various social, societal, cultural, and economic issues in European societies through their education policy documents. Many of these documents in our data explicitly address intercultural dialogue, but its core aims and ideas are also often implicitly dealt with by referring to matters such as the

(C) The Author(s) 2020

T. Lähdesmäki et al., Intercultural Dialogue in the European

Education Policies, https://doi.org/10.1007/978-3-030-41517-4_3 
development of mutual understanding between people with different backgrounds or to the promotion of respect for difference. This kind of implicit ethos of intercultural dialogue can be found in documents written before the concept itself was established and explicitly included in the policy discourses of both these actors.

We start our analysis by exploring how the concept of intercultural dialogue, as well as the term 'intercultural' as a description of the relationship between different cultures, is explicitly used in our data, and what kinds of meanings they include. When looking at the explicit occurrences in the 67 documents we analysed, the concept of intercultural dialogue is not used very often. It appears explicitly in the European Union's documents 18 times and in the Council of Europe's documents 21 times, a total of 39 mentions. Implicitly and in different variations of the term 'intercultural' it, however, appears significantly more often.

Within the European Union's documents, intercultural dialogue is most often mentioned in the Commission's communication entitled Multilingualism: an Asset for Europe and a Shared Commitment (CofEC 2008). It explicitly occurs 13 times and is also referred to implicitly via similar terms, such as 'intercultural skills' (five times), 'intercultural competences' (once), 'dialogue between cultures' (once), and 'dialogue and mutual respect' (once). The communication was created in 2008 when the Union was celebrating the European Year of Intercultural Dialogue and it dates some months after the Council of Europe launched its White Paper on Intercultural Dialogue. In this document, intercultural dialogue is mostly understood as communication with people from varied cultural and linguistic backgrounds. The other European Union documents in which the concept of intercultural dialogue explicitly appears are as follows: twice in the Commission's Conclusions on a Strategic Framework for European Cooperation in Education and Training (CofEU 2009a); once in the European Parliament's and Council's Regulation on Establishing Erasmus+: the Union Programme for Education, Training, Youth and Sport (EP and CofEU 2013); once in the conclusions of the Commission and member states' governments on Promoting Creativity and Innovation through Education and Training (CofEU \& RofGofMS 2008); and once in the Council's and the Commission's Report on Implementing the Strategic Framework for European Cooperation in Education and Training (CofEU \& EC 2015). In these documents, intercultural dialogue is not defined or explained but gets its meanings through other concepts and terms related to the description of policy goals. As the 
titles of these documents indicate, they focus on transnational cooperation in education, increasing opportunities for European young people, and the employment potential of the Union as a whole.

Within the Council of Europe's data, intercultural dialogue has the highest occurrence in the recommendation on intercultural dialogue in history teaching (CofE 201 lb) (ten mentions of 'intercultural dialogue', one of 'dialogue between cultures', one of 'dialogue', and one of 'interfaith dialogue'). This frequency reflects the focus of the document, which is made explicit in its title. The Council's Charter on Education for Democratic Citizenship and Human Rights Education also refers to intercultural dialogue five times (CofE 2010), and the recommendation on integrating and educating young people from a migrant background (CofE 2018), which draws together extracts from various conventions, recommendations, resolutions, and reports, mentions it twice, as does its Recommendation on Ensuring Quality Education (CofE 2012a). Intercultural dialogue is not further defined in these documents, but policies of inclusion and encountering the 'other' form the semantical context for the concept. All these documents were created some years after the White Paper was published.

The term 'intercultural' appears 55 times in the European Union's documents and 69 times in the Council of Europe's documents in various configurations, ranging from intercultural dialogue to intercultural skills and intercultural communication. 'Dialogue', in turn, is used 57 times in the European Union's documents and 40 times in the Council of Europe's documents. The Council document with most occurrences of these two terms is the compilation document on the education and integration of migrant children (CofE 2018). This document mentions 'intercultural' 16 times but 'dialogue' only twice, which points to the fact that 'intercultural' is not only related to dialogue but also seen as a specific skill or competence. 'Dialogue' alone appears most often in the Council of Europe's Charter on Education for Democratic Citizenship and Human Rights Education (CofE 2010). As stated before, in the European Union documents the term 'intercultural' appears most often in the context of multilingualism. Besides dialogue, the Commission communication on multilingualism (CofEC 2008) refers to intercultural skills and competences.

The thematic contexts in which intercultural dialogue is most often discussed in our data thus include multilingualism, history teaching, and immigration. The documents dealing with these themes suggest that 
intercultural dialogue address cultural, linguistic, ethnic, religious, social, and national differences.

Instead of offering explicit definitions, most of the documents in our data simply use the concept of intercultural dialogue in connection to a frequently recurring set of values (such as tolerance, equality, and respect), skills (such as language skills), and groups of people (such as immigrants or people with migrant background). In the Council of Europe's documents, intercultural dialogue is often simply mentioned with reference to the White Paper on the subject or the European Year of Intercultural Dialogue, celebrated in 2008. The Council of Europe's Recommendation on Intercultural Dialogue and the Image of the Other in History Teaching, for example, encourages continuing "the activities of reflecting on and, where appropriate, reforming history teaching in order to create optimum conditions for development of intercultural dialogue founded on tolerance, heedfulness of others, dialogue and training as a responsible citizen capable of personal thought, critical analysis and research" (CofE 201 lb, 3 ). According to this recommendation, history teaching, "in association with other disciplines", should focus on "fostering the preconditions for productive intercultural dialogue, namely promotion of the common values and references such as the fundamental rights needed for dialogue to be established on a sound basis, as specified in the White Paper" (CofE $2011 \mathrm{~b}, 5)$. As these quotations indicate, common values and fundamental rights are depicted as the "preconditions" for cultural dialogue, which itself is described as being "founded on" tolerance and training in dialogical skills such as critical analysis. The explicit definition of intercultural dialogue is, however, missing.

The European Union documents also connect intercultural dialogue to common values such as tolerance, diversity, inclusion, integration, and belonging. The Council of the European Union's Conclusions on Reducing Early School Leaving and Promoting Success in Schools, for example, state that

[i]n our increasingly diverse societies, there is an urgent need for inclusive and coordinated responses from both educational and non-educational stakeholders which are aimed at promoting common values such as tolerance, mutual respect, equal opportunities and non-discrimination, as well as fostering social integration, intercultural understanding and a sense of belonging. (CofEU 2015c, 37) 
In the Commission's communication on multilingualism (CofEC 2008), half of the mentions of 'intercultural dialogue' are simply in subheadings, the table of contents, and references to activities such as the European Year of Intercultural Dialogue. The concept thus vaguely frames various activities, aims, and contents discussed in different sections of the document as intercultural dialogue. When mentioned in the actual body text (CofEC 2008, 2, 3, 5, 6), it usually appears with the concept of social cohesion and is connected to the concepts of (linguistic) diversity, identity, shared inheritance (implicitly invoking the idea of cultural heritage), and culture (as the plural form cultures). It appears in sentences like this: "A successful multilingualism policy can strengthen life chances of citizens: it may increase their employability, facilitate access to services and rights and contribute to solidarity through enhanced intercultural dialogue and social cohesion" (CofEC 2008, 3). Here, intercultural dialogue is discussed in the context of enhancing employment, solidarity, and citizens' rights.

As the previous quotation indicates, the European education policy documents explicitly connect intercultural dialogue to education and skill development. For example, in a Joint Report of the Council of the European Union and the Commission on the Implementation of the Strategic Framework for European Cooperation in Education and Training (CofEU \& EC 2015), intercultural dialogue is only mentioned once, while intercultural skills appear once and intercultural competences three times. These terms are used in the documents almost interchangeably. The Council of Europe's Recommendation on Ensuring Quality Education states that "education must enable pupils and students to develop proficiency in intercultural dialogue" (CofE 2012a, 2). The capacity for intercultural dialogue is, thus, cast as a competence or skill acquired through both formal and informal education-often in the context of lifelong learning.

In the data, informal education includes the work of national and international non-governmental organizations, as well as the contributions of information technology to everyday life. The Commission's communication on multilingualism, for instance, states that the media "have great potential to promote intercultural dialogue by conveying a more complex presentation of our society, allowing for many different voices"-hence the media can "be a great source of informal language learning through 'edutainment' and subtitled films" (CofEC 2008, 12). The same document states that " $[\mathrm{m}]$ ultilingual companies prove how linguistic diversity 
and investing in language and intercultural skills can be turned into a real asset for prosperity and a benefit for all" (CofEC 2008, 7). Here, the 'intercultural' in informal education is related to linguistic diversity, language learning, and learning from 'different voices' raised in the media.

\section{Core Concepts Used to Give Meaning to Intercultural Dialogue}

Since some concepts, such as culture, cultural heritage, and common values, as well as certain attitudes, such as empathy and tolerance, repeatedly come up in theoretical discussions and research on intercultural dialogue, we traced their uses and contexts in our data. We also broadened our analysis to concepts that are closely connected to the semantics of intercultural dialogue, such as identity, inclusion, multiculturalism, citizenship, participation, and social responsibility. All these concepts carry their own definitional ambiguities in both the theoretical literature and policy discourses. Hence, it is imperative that these ambiguities are considered and contextualized before exploring how they are used to construct the idea of intercultural dialogue in the education policies under scrutiny. In this section, we have clustered these concepts into three interrelated groups.

\section{Culture, Multiculturalism, and Cultural Values}

Culture can be defined as having material, social, and subjective components. Physical artefacts, institutions, shared knowledge, beliefs, attitudes, memories, values, and practices all contribute to its formation. Furthermore, social groups of many sizes may have their own distinctive cultures, which means that individuals belong to and participate in many different cultures simultaneously, be these related to nationality, ethnicity, neighbourhood, language, religion, generational ties, or particular organizational, occupational, or vocational groups, to name but a few. The cultural categories according to which interculturalism is defined may be based on perceptions of similarities and differences that shift attention from the interpersonal to the intercultural. These perceived similarities and differences also include styles or habitus related to gender, social class, and sexual orientation (Barrett 2013, 150-152). 
The European Union and the Council of Europe share an explicit aim to promote culture, identity, and values described and defined as European in their policy discourses. The cultural component has been included in both actors' interests from their inception. Although the European Union was initially built on economic and political cooperation, its very founding figures expected that cultural and social integration in Europe emerges as a spillover effect of successful cooperation in other policy fields (e.g. Rosamond 2000; Shore 2006; Sassatelli 2006; Näss 2009). In some views, culture has been considered as one of the underlying ideas that have even motivated the creation and building of the European Community and, later, the Union (Rosamond 2000; Sassatelli 2006; Näss 2009). Besides the culture-related interests during the early decades of European integration, cultural policy itself has become increasingly central to the European Union during the 2000s (e.g. Sassatelli 2009; Näss 2010; O'Callaghan 2011; Lähdesmäki 2012). Culture has been described as the third and the most recent 'wave' of European integration process (Karlsson 2010; Jarausch 2010; Lähdesmäki 2016a, 1; Troitino 2013, xi-xii) and perceived as the Union's “symbolic and poetic dimension” (Banús 2015; Lähdesmäki 2016a) as it offers an instrument and arena to narrate and represent (a wish for) unity, diverse but also shared cultural features, and common values and heritage in Europe.

The discursive prevalence of culture can be easily deciphered in the education policies of both organizations. They frequently refer to culture in our data (the European Union 108 times, of which 22 in the plural 'cultures', and the Council of Europe 44 times, of which 15 times in the plural). Both also refer to different cultural aspects (European Union 91 times/Council of Europe 185), especially in the intercultural sense (European Union 55/Council of Europe 69). The term intercultural is more prominent in the data than multicultural (124 mentions of 'intercultural' and only 14 mentions of 'multicultural'). This reflects the temporal emphasis of the data: all but six of the documents were published after the turn of the millennium, and half of them after 2008, the year of publication of the White Paper that positioned intercultural dialogue as a solution to the alleged failure of multiculturalism policies.

As the notions of multiculturalism and interculturalism demonstrate, the strengthened discourse on culture within Europe-building policiesthat the documents in our data also represent-is largely used as a tool for diversity policies and politics. In some academic studies, the prominence of culture in policy discourses has been explored (and criticized) as a move 
that has merely replaced the by now invalidated concept of 'race', and the politically charged concept of 'nationality', in the framing of difference (Cronin 2002, 313; Lentin and Titley 2012). In European cultural policies, the definition of culture has been interpreted as following an anthropological view that emphasizes shared values and cultural production and practices as underlying elements of all human behaviour, and sees culture as "a key arena in which contestations over identities and rights are played out" (Cronin 2002, 309). Although culture (and cultural consumption) is often framed in European cultural policies in terms of belonging, it nevertheless often excludes various groups of marginalized or dispossessed people (e.g. Cronin 2002, 317).

Following the interest in culturalization of European integration, the ideal of unity within diversity, repeated again and again in European policy documents, became understood as arising from embracing a set of 'common' (cultural/culturalized) values, such as democracy and human rights, or valuing certain freedoms, such as gender equality, freedom of speech, and individualism (de Leeuw and van Wichelen 2012, 198). In this discourse, differences in ways of life are considered assets as long as they do not conflict with these 'common' values and freedoms. De Leeuw and van Wichelen (2012) have noted how these values and freedoms mirror Western European ideals of secular liberalism and exclude, for example, conservative religiousness from the sphere of Europeanness. While embracing unity, the value discourse simultaneously creates cultural others, such as Muslim immigrants. This exclusive discourse may also be detected within the East-West divide of the European Union. As Jones and Subotic $(2011,543)$ note in their analysis of the political aspects of the Eurovision song contest, "the process of Europeanization is fundamentally a process of political imagination". In this context, "European states with uncertain or transitional identities on the European 'periphery' use performative symbols, such as carnivals, festivals or cultural events" (Jones and Subotic 2011, 542), to create an image or illusion of shared beliefs in Europe, at the same time expressing their own beliefs and identities, which may conflict with the European values of tolerance, for instance in relation to gender and sexual minorities. This performative process of conflicting values can, according to Jones and Subotic (2011), be interpreted as a struggle for power and equality in the European sphere. Thus culture as a marker of shared European values may be used as an indicator of difference, like race, ethnicity, and nationality. The line 
between similarity and difference is drawn according to sharing or dissociating from liberal secular values.

In the European education policies, the 'fundamental European values' are described as encompassing tolerance, mutual understanding, human rights, and democratic values (CofE 2001, 2, 4, 5, 8, 15). 'Common European values' are stated to include freedom, tolerance, and non-discrimination (e.g. CofEU 2015a, 2, 2n6, c, 36; 2016, 5nl; CofEU \& EC 2015, 25n2; CofEU \& RofGofMS 2016, ln4). The documents also discuss ethical values that prevent corruption (CofE 2000, 1, 2) and social values shared by the European social area represented by the Council of Europe's contracting parties (CofE 2015, 445). The Council of the European Union's conclusions on Developing Media Literacy and Critical Thinking through Education and Training (CofEU 2016) explicitly refer to common values listed in the current treaty of the European Union, the Treaty of Lisbon (2008). The conclusions emphasize how "the Union is founded on the values of respect for human dignity, freedom, democracy, equality, the rule of law and respect for human rights, including the rights of persons belonging to minorities" (CofEU 2016, 5). Here, the references to minorities and equality also evoke the idea of diversity.

\section{Tolerance, Empathy, and Identity}

The Council of Europe and the European Union define their common or fundamental values in their education policies in a way that reflects how the values involved in intercultural competencies are defined in scholarly literature on interculturalism. Barrett $(2013,153)$, for example, breaks down the values involved in intercultural competence into valuing cultural diversity and valuing pluralism of perspectives and practices. In this valuing, the idea and practice of tolerance becomes important. As seen above, tolerance is both explicitly and implicitly one of the core values presented in the data as a component of 'Europeanness' and European citizenship. In the European Union documents, the shared 'Europeanness' of values is depicted as including "cultural, religious and linguistic diversity, [-] openness towards other cultures, tolerance and acceptance of others" (CofEC 2005, 2-3). The same pages state that "respect for linguistic diversity is a core value of the European Union". Tolerance, diversity, and an open-minded or open attitude towards other cultures and people, thus, form an interrelated triad of values defining 'Europeanness' in the data. 
Openness implicitly invokes the idea of intercultural dialogue, since dialogue requires openness towards other people's points of view.

Scholars have noted how tolerance is a "controversial, multifaceted and complex concept" (Isac et al. 2018a, 128) that evokes both positive and negative meanings (DIALLS 2018). If it is understood as a willingness to put up with objectionable ideas and groups (Sniderman et al. 1989; Mutz 2002), it encompasses negative attitudes towards difference, including prejudice and intolerance (Isac et al. 2018b). In a positive sense, however, tolerance denotes the willingness to extend "freedoms to those whose ideas one rejects, whatever these might be" (Sullivan et al. 1979, 784).

The UNESCO definition of tolerance builds on the positive stance as it speaks of respect, acceptance, openness, harmony, and recognizing others' freedoms:

Tolerance is respect, acceptance and appreciation of the rich diversity of our world's cultures, our forms of expression and ways of being human. It is fostered by knowledge, openness, communication, and freedom of thought, conscience and belief. Tolerance is harmony in difference [-]. Tolerance is, above all, an active attitude prompted by recognition of the universal human rights and fundamental freedoms of others. (UNESCO 1995, 5)

Yet, as tolerance is explicitly related to diversity and difference in European cultural and education policies, diversity and difference are seen in them both as an asset and as a problem. The double-sidedness of tolerance is exemplified by the fact that the word 'tolerance' occurs seven times in the Council of Europe's documents, while 'intolerance' appears nine times. These documents use the term 'tolerant' three times and 'intolerant' once. Tolerance is, thus, often addressed via references to aspirations and projects combating intolerance.

If acceptance includes dealing with differences that one is opposed to, promoting acceptance encompasses an emotional element related not only to values but also to affective structures (related, for example, to beliefs and ideals) that may be difficult to define. In our analysis, we have sought to complement the exploration of tolerance by paying attention to references to empathy. As stated in the introductory chapter, empathy is commonly depicted as a skill that is foundational for intercultural dialogue (Houghton 2012, 97-100; Barrett 2013, 26; Cantle 2013, 80). In studies of interculturalism and intercultural dialogue, tolerance and empathy are often singled out as necessary features of intercultural competence. The 
European education policies, however, rarely address empathy. In the European Union documents, empathy occurs explicitly only once: it is mentioned as one of the key skills related to the social and civic competences of lifelong learning (EP \& CofEU 2006, 17). In the Council of Europe documents, 'empathy' is mentioned twice: it is brought forth in relation to disability and "others who are different" or have unequal opportunities. Both mentions are in the document Democracy and Human Rights Start with Us, in an excerpt that feels like a side comment, pointing to the human rights education manuals Compasito and Compass, which deal with empathy education (CofE 2012b, 31, 32). The word 'empathic' is used only once in the document on intercultural dialogue and the image of the other in history teaching. The appendix to this document on "how to live together" in post-conflict situations notes that, in such contexts, history teaching should "contribute to the necessary processes of empathic responsiveness to others" (CofE 2011b, 6).

While empathy is rarely referred to explicitly in our data, calls for respect, and reconciliation are present in both organizations' education policies. Implicitly, empathy may also be linked to ideas like solidarity, social cohesion, and emotional care as is done in the Commission's communication on multilingualism, which states that multiculturalism contributes "to solidarity through enhanced intercultural dialogue and social cohesion" (CofEC 2008, 3). Moreover, the idea of empathy can be implicitly read into the concept of mutual understanding, which is a more common term in the education policies of both the European Union and the Council of Europe.

Identities form key features of difference, and difference can be understood as the key point of cultural negotiation in dialogic processes (Ganesh and Holmes 2011,82). Yet, our analysis revealed that identity was, next to empathy and tolerance, one of the less used concepts in the European education policies. In the data, the Council of Europe mentioned it only 8 times (of which 3 in the plural form 'identities') and the European Union referred to it 32 times (of which 5 in the plural). The contexts in which identity was referred to also varied broadly from references to national and European identities to migrants' identities, learners' identities, and protecting the identities of whistle-blowers (CofE 2001, 4, 2011 b , 1, 2014a, 3 , b , 3, 2018, 21). The concept of identity was also brought up in relation to language issues, cultural heritage, diversity of cultures, and the identity-shaping aspects of sport (CofEC 2005, 8, 2008, 3; CofEU 2014). In the European Union documents, identity was rarely 
related to cultural identity but was instead used to refer, for example, to the identity of institutes or executive agencies, or to discuss the identification of people more generally-which explains the relatively high number of explicit occurrences.

What is relevant for our analysis here, however, is that identity was explicitly phrased as cultural identity in the context of immigration and integration (CofEU 2009b, 7; EP \& CofEU 2006, 17; CofE 2018, 21) and nationality (CofE 2001, 4; EP \& CofEU 2006, 17). It was also addressed in the context of lifelong learning (EP \& CofEU 2006, 17) and learners' identities in general (CofE 2014a, 3). In the data, identity was articulated thrice as European identity, implying a shared European cultural identity (EP \& CofEU 2006, 17, 2013, 53; CofE 2011b, 1). In the documents, national cultural identity and European identity could also be explicitly connected, such as in the definition of social and civic competences that include " $[\mathrm{u}]$ nderstanding the multi-cultural and socio-economic dimensions of European societies and how national cultural identity interacts with the European identity" (EP \& CofEU 2006, 17). Identity formations in the documents, thus, ranged from broad collective identities to personal understandings of the self.

\section{Inclusion and Heritage}

According to researchers such as de Leeuw and van Wichelen (2012), cultural alignment may become a ticket to inclusion. In the European Union's education policy documents, the concept of inclusion (a total of 55 mentions) is relegated to various contexts, such as socio-economic development (CofEU \& RofGofMS 2016, 2), social inclusion and employment (EC 2017, 2; EP \& CofEU 2013, 57; CofEU 2015b), and active citizenship (e.g. EC 2010, 8; EP \& CofEU 2013, 57, 59; CofEU \& EC 2015, 25-26; CofEU 2015b). It is also implicitly discussed through the prevention of (social) exclusion (e.g. EC 2010, 8) and discrimination (e.g. CofE 1997, 5; CofEU 2009b). In the Council of Europe's documents inclusion (a total of 18 mentions) is commonly discussed through the concept of integration (a total of 121 mentions, including forms such as 'integrate' and 'integrating') and contextually related above all to the integration of migrants and their children into European societies. The European Convention on the Legal Status of Migrant Workers, for example, speaks of providing migrant workers with the "right to admission" (CofE 1997, 2) and "access to higher education" (CofE 1997, 6), and the 
recommendation on validating migrants' skills (CofE 201 la, 1-2) speaks of national integration policies contributing to greater unity between the member states. In the context of immigration, integration is, furthermore, defined as "an interactive process based upon mutual willingness to adapt by both migrants and the receiving society" (CofE 2008, 1). Here, inclusion (a disposition often assigned to the 'tolerant' receiving populace) largely becomes reconceptualized as integration, a two-way process that places considerably more weight on the adaptive participation of the immigrant. Scholars such as de Leeuw and van Wichelen $(2012,198)$ have discussed this burden of adaptation by analysing the Dutch integration exam as a technique of governmentality, directed above all at Muslim immigrants.

In general, inclusion seems to be a 'softer' term than integration in our data, used more in educational contexts (although also e.g. in political contexts referring to social inclusion), while integration seems to be a 'harder' political concept, used with reference to European integration and creating unified societies. It is, thus, often applied when discussing immigrants and their integration into European societies. Both concepts are related to discussions about how to approach cultural backgrounds or heritages that differ from those of a majority that forms a norm in the society.

The concept of 'cultural heritage', in this particular form, appears in the documents a total of eight times: three times in those of the European Union and five times in those of the Council of Europe. However, it occurs implicitly in numerous other forms such as plain heritage; shared inheritance; (our) common cultural background; heritage language; heritage culture; EU heritage; Europe's rich heritage; public and private heritage; architectural heritage; common (historical) heritage; shared ideals and principles; university heritage; academic heritage; shared heritage; cultural and linguistic heritage; and a student's heritage. These implicit references to cultural heritage make the concept altogether more common than the explicit numbers imply. In the European Union documents, cultural heritage is discussed in contexts such as linguistic diversity (CofEC 2008) and migration (CofEU 2009b) and mostly framed as European either implicitly or explicitly (e.g. CofEC 2008, 4; EP \& CofEU 2013, $53)$. In the Council of Europe's education policies, the concept is used most often in the Recommendation on History Teaching in the Twentyfirst Century Europe (CofE 2001), where it is mentioned ten times in its different forms (five as "cultural heritage", as mentioned above). In the 
other documents, heritage is mostly expressed in the context of "common heritage" of the Council of Europe's members. This common heritage is defined as the shared "ideals and principles" of the member countries (e.g. CofE 1954, 1, 1977, 1, 2014b, 1). In the 2001 recommendation on history teaching, heritage is also explicitly linked to identity and citizenship through statements, such as asserting that history teaching should "enable European citizens to enhance their own individual and collective identity through knowledge of their common historical heritage in its local, regional, national, European and global dimensions" (CofE 2001, 5). This statement indicates that heritage can also be perceived in the policy language as multilayered, simultaneously including different scalar meanings.

The meanings of cultural heritage in the data are created with reference to the political and societal principles and ideals of secular liberalism promoted by both European organizations. In particular, 'common' or 'shared' values are turned into heritage in policy discourses that seek to appeal to the unity of these organizations and European societies more broadly (Lähdesmäki 2016b). In their immigration policies, the integration of immigrants into European societies can be dealt with as integration of immigrants to these values and principles - and, thus, to European cultural heritage. Some scholars have even seen potential here for a discriminative discourse: setting liberal secular values of (Western) European countries against (Muslim) immigrants perceived as coming from intolerant religious cultural backgrounds (Lentin and Titley 2012, 134).

\section{Conceptual Overlaps and Interchangeable Concepts}

The analysis of European education policy documents indicated that some of the concepts that are commonly discussed in scholarly literature on intercultural dialogue-which is why we chose to examine them more closely-occurred often in our data, while others were less frequently used. Moreover, some of the concepts turned out to have less significant content for illuminating the idea and practices of intercultural dialogue. For instance, citizenship and participation were commonly addressed in the data without a direct link or in contexts irrelevant to intercultural dialogue and did not feature prominently in the 'dense' extracts that explicitly and/or implicitly addressed intercultural dialogue (that are analysed in the next chapter). Other concepts, such as (cultural) identity, tolerance, 
and empathy, were rarely used in our data, although they play an important role in the idea and practices of intercultural dialogue.

The European education policy documents in our data often seemed to deal with the idea and practices of intercultural dialogue without explicitly referring to the concept as such. Similarly, the core concepts that we chose to examine more closely were often addressed through various other concepts, terms, and expressions. Inclusion, for example, was mostly dealt with in terms of 'integration' in the Council of Europe documents and as social inclusion in the European Union documents. In some instances, inclusion was also referred to in (value) statements that spoke of cohesion, unity, understanding, recognition, admission, access, approval, accession (in relation to working against discrimination), non-discrimination, and equality. Empathy was also rarely used explicitly, but addressed by calling for respect, solidarity, mutual understanding, and reconciliation. Tolerance, in turn, was often referred to via references to aspirations and projects combating intolerance. Multiculturalism was likewise hardly mentioned as such in the data, but multicultural circumstances were referred to via terms such as plurilingualism and cultural diversity. Social responsibility was not mentioned explicitly in the documents, but the concept appeared once as 'socially responsible' when referring to the "the need to understand and use language in a positive and socially responsible manner". Socially responsible use of language was included in a "positive attitude" that requires "a disposition to critical and constructive dialogue [-] and an interest in interaction with others" (EP \& CofEU 2006, 14), thus echoing the ideals of intercultural dialogue, even though the passage discusses communication in a shared mother tongue. Yet, most of the documents can be interpreted as calls for social responsibility because of their nature as recommendations, conventions, and charters addressing social and cultural issues of inclusion, human rights, and social justice.

In the following list, we summarize the core concepts included in the examination of intercultural dialogue in European education policy documents and the varying forms of other concepts, terms, and expressions used to discuss them in the data. The list indicates how these core concepts are interrelated and overlapping, and their variations are used flexibly and interchangeably. At the same time, the list reveals the conceptual vagueness and ambiguity in European education policies.

Intercultural dialogue: (plain) dialogue (as indicating dialogue between people with different cultural backgrounds); dialogue between cultures; 
interfaith dialogue; ability to hear and respect other viewpoints; intercultural communication; intercultural competences; intercultural skills; intercultural education; intercultural understanding; intercultural awareness; interculturalism; diversity management; cultural exchange; multilingualism; cooperation (between cultures or countries, or at the European level); cross-cultural understanding; cross-cultural learning skills; harmonious coexistence (of many languages)

Culture: cultural (defining cultural qualities of various issues)

Cultural heritage: heritage; shared inheritance; (our) common cultural background; heritage language; heritage culture; EU heritage; Europe's rich heritage; public and private heritage; architectural heritage; common (historical) heritage; shared ideals and principles; university heritage; academic heritage; shared heritage; cultural and linguistic heritage; a student's heritage

Identity: national identity; European identity; learner's individual and collective identities; cultural identity

Inclusion: integration; cohesion; understanding; recognition; admission; equality; (equal) access; approval; accession (in relation to working against discrimination); (as opposed to) exclusion; social cohesion; inclusive society; inclusive education; unity within diversity; respect (for others)

Empathy: respect (for others); mutual understanding; reconciliation; empathic; emotional care; solidarity (as a feeling towards others)

Tolerance: (as opposed to) intolerance; understanding diversity and difference; mutual respect; non-discrimination; mutual understanding; overcoming prejudice; openness

Multiculturalism: multicultural; multilingual; multilingualism; cultural diversity; cultures; pluricultural; diverse backgrounds; cross-cultural understanding; cross-border cooperation; European cooperation; interculturalism; plurilingualism; plurilingual

Citizenship: citizen; citizens; democratic citizenship

Participation: access; admission; democratic citizenship

Social responsibility: social inclusion; solidarity; mutual assistance; building cohesive societies; (active) participation; non-discrimination; equal opportunities; democratic citizenship; socially responsible; a sense of responsibility; responsibility as an individual citizen 


\section{REFERENCES}

Banús, E. 2015. Keynote Speech in 13th International Conference European Culture. Cluj-Napoca, Romania, October 29-31.

Barrett, M. 2013. Intercultural Competence: A Distinctive Hallmark of Interculturalism? In Interculturalism and Multiculturalism: Similarities and Differences, ed. M. Barrett, 147-168. Strasbourg: Council of Europe.

Cantle, T. 2013. Interculturalism as a New Narrative for the Era of Globalization and Super-diversity. In Interculturalism and Multiculturalism: Similarities and Differences, ed. M. Barrett, 69-92. Strasbourg: Council of Europe Publishing.

CofE (Council of Europe). 1954. European Cultural Convention. Paris, December 19. Strasbourg: Council of Europe.

- 1977. European Convention on the Legal Status of Migrant Workers. Strasbourg, November 24. Strasbourg: Council of Europe.

. 1997. The Lisbon Convention. Convention on the Recognition of Qualifications Concerning Higher Education in the European Region. Lisbon, April 11. Strasbourg: Council of Europe.

- 2000. Recommendation Rec(2000) 10 on the Codes of Conduct for Public Officials. Adopted by the Committee of Ministers at its 106th Session on 11 May 2000. Strasbourg: Council of Europe.

- 2001. Recommendation Rec(2001)15 on History Teaching in Twenty-Firstcentury Europe. Adopted by the Committee of Ministers on 31 October 2001 at the 771st Meeting of the Ministers' Deputies. Strasbourg: Council of Europe.

- 2008. Recommendation Rec(2008)4 on Strengthening the Integration of Children of Migrants and of Immigrant Background. Adopted by the Committee of Ministers on 20 February 2008 at the 7018th Meeting of the Ministers' Deputies. Strasbourg: Council of Europe.

- 2010. Council of Europe Charter on Education for Democratic Citizenship and Human Rights Education. Strasbourg: Council of Europe.

- 2011a. Recommendation Rec(2011)2 on Validating Migrants' Skills. Adopted by the Committee of Ministers on 19 January 2011 at the 1103rd Meeting of the Ministers' Deputies. Strasbourg: Council of Europe.

- 2011b. Recommendation Rec(2011)6 on Intercultural Dialogue and the Image of the Other in History Teaching. Adopted by the Committee of Ministers on 6 July 2011 at the 1118th meeting of the Ministers' Deputies. Strasbourg: Council of Europe.

- 2012a. Recommendation Rec(2012)13 on Ensuring Quality Education. Adopted by the Committee of Ministers on 12 December 2012 at the 1158th Meeting of the Ministers' Deputies. Strasbourg: Council of Europe.

- 2012b. Democracy and Human Rights Start with Us-Charter for All. Council of Europe Charter on Education for Democratic Citizenship and Human Rights Education: Guidelines for Educators. Ed. E. Diez Villagrasa. Strasbourg: Council of Europe. 
2014a. Recommendation Rec(2014) 5 on the Importance of Competences in the Language(s) of Schooling for Equity and Quality in Education and for Educational Success. Adopted by the Committee of Ministers on 2 April 2014 at the 7196th Meeting of the Ministers' Deputies. Strasbourg: Council of Europe.

- 2014b. Recommendation Rec(2014)7 on the Protection of Whistleblowers. Adopted by the Committee of Ministers on 30 April 2014 at the 7198th Meeting of the Ministers' Deputies. Strasbourg: Council of Europe.

- 2015. European Social Charter (Collected Texts, 7 th Edition): 1 January 2015. Strasbourg: Council of Europe.

- 2018. Children and Adolescents from a Migrant Background: Integration and Education. Extracts from Conventions, Recommendations, Resolutions and Reports. Revised and Enriched Version-April. Strasbourg: Council of Europe.

CofEC (Commission of the European Communities). 2005. Communication from the Commission to the Council, the European Parliament, the European Economic and Social Committee and the Committee of the Regions. COM(2005) 596 Final. A New Framework Strategy for Multilingualism. Brussels: Commission of the European Communities.

- 2008. Communication from the Commission to the European Parliament, the Council, the European Economic and Social Committee and the Committee of the Regions-Multilingualism: An Asset for Europe and a Shared Commitment. $\operatorname{COM}(2008) 566$ Final. Brussels: Commission of the European Communities.

CofEU \& EC (Council of the European Union \& the European Commission). 2015. Joint Report of the Council and the Commission on the Implementation of the Strategic Framework for European Cooperation in Education and Training (ET 2020): New Priorities for European Cooperation in Education and Training. Official Journal of the European Union C417: 25-35.

CofEU \& RofGofMS (Council of the European Union and the Representatives of the Governments of the Member States). 2008. Conclusions of the Council and of the Representatives of the Governments of the Member States, Meeting within the Council of 22 May 2008 on Promoting Creativity and Innovation Through Education and Training. Official Journal C141: 17-20.

- 2016. Resolution of the Council and of the Representatives of the Governments of the Member States, meeting within the Council, 24 February 2016 on Promoting Socioeconomic Development and Inclusiveness in the EU Through Education: The Contribution of Education and Training to the European Semester 2016. Official Journal of the European Union C105: 1-4.

CofEU (Council of the European Union). 2009a. Council Conclusions of 12 May 2009 on a Strategic Framework for European Cooperation in Education and Training ('ET 2020'). (2009/C 119/02). Official Journal of the European Union C1 19: 2-10. 
2009b. Council Conclusions of 26 November 2009 on the Education of Children with a Migrant Background. Official Journal of the European Union C301: 5-8.

2014. Council Conclusions of 21 May 2014 on Gender Equality in Sport. Official Journal of the European Union C183: 39-42.

- 2015a. Council Conclusions on Reinforcing Youth Work to Ensure Cohesive Societies. Official Journal of the European Union C170: 2-3.

- 2015b. Council Conclusions on the Role of Early Childhood Education and Primary Education in Fostering Creativity, Innovation and Digital Competence. Official Journal of the European Union C172: 17-21.

- 2015c. Council Conclusions on Reducing Early School Leaving and Promoting Success in School. Official Journal of the European Union C417: 36-40.

- 2016. Council Conclusions of 30 May 2016 on Developing Media Literacy and Critical Thinking Through Education and Training. Official Journal of the European Union C212: 5-8.

Cronin, A.M. 2002. Consumer Rights/Cultural Rights: A New Politics of European Belonging. European Journal of Cultural Studies 5 (3): 307-323.

De Leeuw, M., and S. van Wichelen. 2012. Civilizing Migrants: Integration, Culture and Citizenship. European Journal of Cultural Studies 15 (2): 195-210.

DIALLS. 2018. Cultural Analysis Framework. https://dialls2020.eu/wp-content/uploads/2019/09/resubmitted-cultural-analysis-framework-with-coversheet-.pdf.

EC (European Commission). 2010. Communication from the Commission to the European Parliament, the Council, the European Economic and Social Committee and the Committee of the Regions. A New Impetus for European Cooperation in Vocational Education and Training to Support the Europe 2020 Strategy. $\operatorname{COM}(2010) 296$ Final. Brussels: European Commission.

- 2017. Communication from the Commission to the European Parliament, the Council, the European Economic and Social Committee and the Committee of the Regions. School Development and Excellent Teaching for a Great Start in Life. $\operatorname{COM}(2017) 248$ final. Brussels: European Commission.

EP \& CofEU (European Parliament and the Council of the European Union). 2006. Recommendation of the European Parliament and of the Council of 18 December 2006 on Key Competences for Lifelong Learning, 2006/962/ EC. Official Journal of the European Union L394: 10-18.

. 2013. Regulation (EU) No 1288/2013 of the European Parliament and of the Council of 11 December 2013 Establishing 'Erasmust': the Union Programme for Education, Training, Youth and Sport and Repealing Decisions No 1719/2006/EC, No 1720/2006/EC and No 1298/2008/EC (Text with EEA Relevance). Official Journal of the European Union L347: 50-73. 
Ganesh, S., and P. Holmes. 2011. Positioning Intercultural Dialogue: Theories, Pragmatics, and an Agenda. Journal of International and Intercultural Communication 4 (2): 81-86.

Houghton, S.A. 2012. Intercultural Dialogue in Practice: Managing Value Judgement through Foreign Language Education. Bristol: Multilingual Matters.

Isac, M.M., A. Sandoval-Hernández, and D. Miranda. 2018a. Teaching Tolerance in a Globalized World: Final Remarks. In Teaching Tolerance in a Globalized World, ed. A. Sandoval-Hernández, M.M. Isac, and D. Miranda, 125-135. Berlin: Springer Open.

- 2018b. Teaching Tolerance in a Globalized World: An Introduction. In Teaching Tolerance in a Globalized World, ed. A. Sandoval-Hernández, M.M. Isac, and D. Miranda, 1-10. Berlin: Springer Open.

Jarausch, K.H. 2010. Nightmares or Daydreams? A Postscript on the Europeanisation of Memories. In A European Memory? Contested Histories and Politics of Remembrance, ed. M. Pakier and B. Stråth, 309-320. New York: Berghahn Books.

Jones, S., and J. Subotic. 2011. Fantasies of Power: Performing Europeanization on the European Periphery. European Journal of Cultural Studies 14 (5): 542-557.

Karlsson, K.-G. 2010. The Uses of History and the Third Wave of Europeanisation. In A European Memory? Contested Histories and Politics of Remembrance, ed. M. Pakier and B. Stråth, 38-55. New York: Berghahn Books.

Lähdesmäki, T. 2012. Rhetoric of Unity and Cultural Diversity in the Making of European Cultural Identity. International Journal of Cultural Policy 18 (1): 59-75.

- 2016a. Comparing Notions on European Cultural Heritage in EU Policy Discourse and Scholarly Discussion. The International Journal of Interdisciplinary Social Sciences: Annual Review 11 (1): 1-14.

- 2016b. Politics of Tangibility, Intangibility, and Place in the Making of European Cultural Heritage in EU Heritage Policy. International Journal of Heritage Studies 22 (10): 766-780.

Lentin, A., and G. Titley. 2012. The Crisis of 'Multiculturalism' in Europe: Mediated Minarets, Intolerable Subjects. European Journal of Cultural Studies 15 (2): 123-138.

Mutz, D.C. 2002. Cross-Cutting Social Networks: Testing Democratic Theory in Practice. American Political Science Review 96 (1): 111-126.

Näss, H.E. 2009. A New Agenda? The European Union and Cultural Policy. London: Alliance Publishing Trust.

- 2010. The Ambiguities of Intercultural Dialogue: Critical Perspectives on the European Union's New Agenda for Culture. Journal of Intercultural Communication 23: 1404-1634. https://www.immi.se/intercultural/ nr23/nass.htm. 
O'Callaghan, C. 2011. Urban Anxieties and Creative Tensions in the European Capital of Culture 2005: 'It Couldn't Just Be about Cork, Like. International Journal of Cultural Policy 18 (2): 185-204.

Rosamond, B. 2000. Theories of European Integration. Basingstoke: Palgrave.

Sassatelli, M. 2006. The Logic of Europeanizing Cultural Policy. In Transcultural Europe: Cultural Policy in a Changing Europe, ed. by U. H. Meinhof and A. Triandafyllidou, 24-42. Basingstoke: Palgrave MacMillan.

- 2009. Becoming Europeans. Cultural Identity and Cultural Policies. New York: Palgrave Macmillan.

Shore, C. 2006. 'In uno plures' (?) EU Cultural Policy and the Governance of Europe. Cultural Analysis 5: 7-26.

Sniderman, P.M., P.E. Tetlock, J.M. Glaser, D.P. Green, and M. Hout. 1989. Principled Tolerance and the American Mass Public. British Journal of Political Science 19 (1): 25-45.

Sullivan, J.L., J. Piereson, and G.E. Marcus. 1979. An Alternative Conceptualization of Political Tolerance: Illusory Increases, 1950s-1970s. American Political Science Review 73 (3): 781-794.

Troitino, D.R. 2013. European Integration: Building Europe. Hauppauge: Nova Science Publishers.

UNESCO. 1995. Declaration of Principles on Tolerance. Proclaimed and Signed by the Member States of the UNESCO on 16 November 1995. Paris: UNESCO.

Open Access This chapter is licensed under the terms of the Creative Commons Attribution 4.0 International License (http://creativecommons.org/licenses/ by $/ 4.0 /$ ), which permits use, sharing, adaptation, distribution and reproduction in any medium or format, as long as you give appropriate credit to the original author(s) and the source, provide a link to the Creative Commons licence and indicate if changes were made.

The images or other third party material in this chapter are included in the chapter's Creative Commons licence, unless indicated otherwise in a credit line to the material. If material is not included in the chapter's Creative Commons licence and your intended use is not permitted by statutory regulation or exceeds the permitted use, you will need to obtain permission directly from the copyright holder.

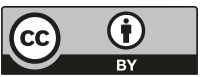




\title{
Analysing Intercultural Dialogue Through Conceptual Densities
}

\begin{abstract}
In this chapter, we exemplify our methodological approach to analysing 'densities' of interrelated concepts in European education policy documents. We scrutinize instances where many of the core concepts of intercultural dialogue appear in the documents at the same time. Four core educational themes and four longer excerpts from the selected policy documents are examined in more detail. The chosen documents deal especially with multilingualism, migration, history teaching, and lifelong learning. The analysis of the conceptual densities in the chosen excerpts indicates how the meanings of intercultural dialogue are constructed through the conceptual frameworks and co-occurrences of their core concepts in the documents, rather than through explicit definitions of the concept of intercultural dialogue itself.
\end{abstract}

Keywords Conceptual density $\bullet$ Multilingualism $\bullet$ Migration $\bullet$ History teaching • Lifelong learning

As the data excerpts in the previous chapter indicate, intercultural dialogue is discussed in European education policy documents through several conceptual variations, such as intercultural communication (CofEC 2005, 9; EP \& CofEU 2006, 15, 17; CofE 2011b, 11), intercultural or cross-cultural understanding (CofEC 2005, 8, 2013, 49, 52; EP \& CofEU 
2006, 14, 2013, 50n6), intercultural competences and skills (CofE 2008a, 2; CofEU \& EC 2015), intercultural and entrepreneurial capacities (CofEC 2008a, 3), and intercultural awareness (EP \& CofEU 2013, 58). The previous chapter also showed how intercultural dialogue is discussed in both academic literature and policy discourses through various conceptual frameworks and expressions. It is also implicitly referred to by emphasizing respect for cultural diversity, mutual understanding between individuals, and the importance of familiarizing oneself with Europe's culturally diverse features.

The most common contexts in which intercultural dialogue appears in our data include multilingualism, history teaching, and immigration. All the concepts, conceptual frameworks, and expressions used in discussing intercultural dialogue broaden its range of meanings, as these concepts, frameworks, and expressions include different semantic webs. When it is approached in our data through the contexts of linguistic diversity and multilingualism (e.g. CofEC 2008b), the idea of intercultural dialogue is framed through the themes of language learning and linguistic diversity and dialogue between cultures. However, when intercultural dialogue is connected to the semantics of religion (CofE $201 \mathrm{lb}, 2$ ), it transforms into "interfaith dialogue" and includes religious diversity and interaction. Moreover, references to intercultural skills and competences (EP \& CofEU 2006, 16; CofEC 2008b, 11) and intercultural education (CofE $2011 \mathrm{a}, 5, \mathrm{~b}, \mathrm{l}, 2)$ flesh out the educational and pedagogical contexts, as well as the importance of intercultural dialogue for the broader society.

In European education policies, therefore, intercultural dialogue is either explicitly or implicitly connected to diverse contextual frameworks, which occur with varying frequency. In order to narrow down and deepen our analysis of the overlaps and interrelatedness of the different concepts, terms, and expressions used for referring to intercultural dialogue, we have chosen to focus on four core educational themes. These themes are multilingualism, migration, and history teaching-contexts where intercultural dialogue is most often discussed in our data-but also lifelong learning. The themes are linked in various ways.

A few longer excerpts taken from some of the documents show a high co-occurrence rate of concepts examined in our research. The conceptual densities in these excerpts illustrate how the meanings of intercultural dialogue are constructed in our data. In other words, in the passages where different concepts related to intercultural dialogue occur together, the 
semantic web becomes especially rich. We now illustrate this richness by looking at excerpts related to each of the four themes in turn.

\section{Intercultural Dialogue in the Context of Multilingualism}

Our first longer excerpt is from the European Commission's 2005 communication, the New Framework Strategy for Multilingualism. This document aims to complement the Commission's "current initiative to improve communication between European citizens and the institutions that serve them" (CofEC 2005, 2). Moreover it "reaffirms the Commission's commitment to multilingualism in the European Union; sets out the Commission's strategy for promoting multilingualism in European society, in the economy and in the Commission itself; and proposes a number of specific actions stemming from this strategic framework" (ibid.). The document does not explicitly use the concept of intercultural dialogue but refers to "interculturalism" and "intercultural communication skills" (CofEC 2005, 6, 8-9, 20). It can, however, be interpreted as implicitly addressing intercultural dialogue through utilizing concepts, terms, and expressions typically used for discussing ideas, policy goals, and practices of intercultural dialogue.

The introductory section of the document introduces its core conceptual framework by starting from "European values" and how they are related to diversity. In this section, diversity is explicitly described as covering core anthropological differences (except ethnicity) between people: cultures, customs, beliefs, and languages. As the title indicates, the first subsection of the introduction sets out certain values as European. All these values are based on the idea of respect for different kinds of diversities. This respect is simultaneously understood as the foundation and source of mutual understanding and "unity in diversity" in the European Union (ibid., 2-3). The next excerpt illustrates the manner in which various concepts, terms, and expressions intertwine in the discourse that addresses multilingualism in the context of European values:

\section{I.1 Multilingualism and European Values}

The European Union is founded on 'unity in diversity': diversity of cultures, customs and beliefs-and of languages. Besides the 201 official languages of the Union, there are 60 or so other indigenous languages and scores of non-indigenous languages spoken by migrant communities. 
It is this diversity that makes the European Union what it is: not a 'melting pot' in which differences are rendered down, but a common home in which diversity is celebrated, and where our many mother tongues are a source of wealth and a bridge to greater solidarity and mutual understanding.

Language is the most direct expression of culture; it is what makes us human and what gives each of us a sense of identity. Article 22 of the Charter of Fundamental Rights of the European Union states that the Union shall respect cultural, religious and linguistic diversity. Article 21 prohibits discrimination based on a number of grounds, including language. Together with respect for the individual, openness towards other cultures, tolerance and acceptance of others, respect for linguistic diversity is a core value of the European Union. Action by the Union and the Member States to uphold multilingualism therefore has a direct impact on the life of every citizen. (CofEC 2005, 2, footnotes removed, emphasis added)

As becomes clear from this quote (and our emphases added to it), the discourse in the document includes a thick web of conceptual overlaps and interrelations. Semantic overlaps include diversity, culture, and languages (both indigenous and non-indigenous); wealth, solidarity, and mutual understanding; identity and cultural, religious, and linguistic diversity; and respect, openness, tolerance, multilingualism, and citizen(ship). Here, language is acknowledged as a building block of both European and individual identity and as an expression of culture. Linguistic diversity is equated with cultural and religious diversity as a celebrated and respected feature and core value of the European Union. Moreover, openness towards other cultures and respect for linguistic diversity imply that intercultural dialogue is inherent in the concept of multilingualism. This reflects the Council of Europe's White Paper (CofE 2008b, 10-11) in which intercultural dialogue is defined as resting upon an "open and respectful exchange of views between individuals, groups with different ethnic, cultural, religious and linguistic backgrounds and heritage on the basis of mutual understanding and respect".

This document emphasizes how language is an important issue to consider when aiming at facilitating intercultural dialogue or, in the words of the Commission, "solidarity and mutual understanding" within the European Union. In order to establish this understanding, skills or competences are needed to help people interact. There is a broad body of literature on intercultural competence, what it means, and how it could be 
obtained (Spitzberg and Changnon 2009; Barrett 2013a). Typically, the different takes on this emphasize adaptability in culturally diverse situations and sensitivity in interaction with people (or in dealing with representations of people) who are different from ourselves (see Barrett 2013a, 148-149). Barrett (2013a, 152) defines intercultural competence as "the set of values, attitudes, knowledge, understanding, skills and behaviours which are needed for: understanding and respecting people who are perceived to be cultural different from oneself; interacting and communicating effectively and appropriately with such people; and establishing positive and constructive relationships with such people". Language skills are essential in establishing intercultural competence.

The Council of Europe's White Paper on Intercultural Dialogue, the seminal paper of European intercultural dialogue policies, allegedly does not address the issue of language in detail. In fact, language is a somewhat neglected theme in the document. As Méndez García and Byram (2013, 133 ff) note, the White Paper avoids discussing how and in which language(s) the dialogues it envisions are going to take place. The White Paper does note that language is often "a barrier to conducting intercultural conversations" (CofE 2008b, 29), but it does not develop this concern in depth. As a general term, language may refer to official languages, minority languages, mother tongue, foreign and additional languages, and migrant languages - or, as the earlier-cited excerpt illustrates, indigenous and non-indigenous languages. The language barrier is also addressed by Barrett $(2013 \mathrm{~b}, 27)$, who notes that, besides individuals, groups, and political organizations "preaching hatred and intolerance towards people with different cultural affiliations", the difficulty of communicating without a lingua franca is one of the potential barriers to successful intercultural dialogue.

Ability to communicate in different languages has been explained and theorized with several concepts, such as multilingualism and plurilingualism. These concepts have been discussed in academia in the context of cultural diversity. According to Méndez García and Byram, the duality between multilingualism and plurilingualism is different from the dichotomy of interculturalism and multiculturalism. While multilingualism (understood as coexistence of several languages) is commonly related to multiculturalism (understood as coexistence of several cultural communities), such an obvious link does not exist between plurilingualism and interculturalism. The difference between the latter two lies in the process of identification. Someone who is plurilingual identifies with more than 
one language and more than one culture. In turn, interculturalism, or "interculturality" in Méndez García and Byram's discussion, encompasses "the capacity to experience and analyze cultural otherness, and to use this experience to reflect on matters that are usually taken for granted within one's own culture and environment" (Byram et al. 2009, 6; Méndez García and Byram 2013, 141, emphasis added). Interculturalism or intercultural dialogue does not expect identification with several cultures.

In the New Framework Strategy for Multilingualism, multilingualism is defined both as a person's ability and as a feature of diversity within a locality:

Multilingualism refers to both a person's ability to use several languages and the co-existence of different language communities in one geographical area. In this document, the term is used to describe the new field of Commission policy that promotes a climate that is conducive to the full expression of all languages, in which the teaching and learning of a variety of languages can flourish. (CofEC 2005, 3)

In general, language issues are commonly addressed in our data, also in the documents by the Council of Europe. One of its early documents, the European Cultural Convention (CofE 1954) speaks of the cultural exchange needed in order for the peoples of the member states to study each other's languages, histories, and civilizations. Within the Council of Europe documents, language issues are present above all in relation to schooling equality and migration. Regarding schooling equality, they focus on the national languages of the member states and the official languages of the Council of Europe (defined as English and French in CofE $2015,140,181,183$ ), as well as non-discrimination based on language, alongside race, ethnic or social origin, disability, religion, gender, political opinion, and so forth (CofE 1997, 5). Language issues feature prominently in the context of immigration, seen as early as the European Cultural Convention (CofE 1954). These issues include validating migrants' skills (CofE 2011a), improving migrants' employment (CofE 2008c), or advancing migrants' legal status in general (CofE 1977). The Council of Europe's document on children and adolescents from a migrant background (CofE 2018) points towards "language policy guidelines" and the Language Policy Programme (Language Policy Portal: www.coe. int/lang), and it notes that in order for people of migrant origin to integrate in the country in which they live and access schooling, they should 
"understand, speak and read that country's language" (CofE 2018, $2,6,29)$.

Besides this, member states should also "promote and facilitate, as far as practicable, the teaching of the migrant worker's mother tongue to the children of the migrant worker" (CofE 2018, 5) because mother tongues are seen "both as educational and cultural instruments" which "maintain and improve" the immigrants (and their children's) "links with their culture of origin" (CofE 2018,7). The same document quotes the Council of Europe's recommendation concerning modern languages, on the necessity to ensure that "there is parity of esteem between all the languages and cultures" in bilingual or multicultural areas so that "children in each community may have the opportunity to develop oracy and literacy in the language of their own community as well as to learn to understand and appreciate the language and culture of the other" (CofE 2018, 8-9). Similarly, the Council of the European Union's conclusions on the education of children with a migrant background stress that these children need to maintain a link to their "heritage culture and language" (CofEU 2009, 3, 7). The policies dealing with language and migration are mainly concerned with migrants' language skills-whether this means learning their host countries' languages or to maintaining their mother tongues.

Intercultural dialogue and human interaction rest on the ability to understand one's interlocutor(s). Though language is often approached in our data from this practical point of view, it also given deeper cultural meanings related to identities, heritages, and empathic encounter of other people. This meaning is also highlighted in the Commission's 2008 communication on multilingualism: "Languages define personal identities, but are also part of a shared inheritance. They can serve as a bridge to other people and open access to other countries and cultures, promoting mutual understanding" (CofEC 2008b, 3). Furthermore, multilingualism - and intercultural dialogue as belonging to it - is considered advantageous in a globalized world, as it is argued that "a successful multilingual policy can strengthen life chances of citizens: it may increase their employability, facilitate access to services and rights and contribute to solidarity through enhanced intercultural dialogue and social cohesion" (CofEC 2008b, 3). 


\section{Intercultural Dialogue in the Context of Migration}

As is evident from the previous chapter, the Council of Europe's 2018 recommendation on integrating and educating young people from a migrant background constructs intercultural dialogue through dense clusters of concepts, terms, and expressions. The document, a compilation of extracts from various conventions, recommendations, resolutions, and reports, was created by the Language Policy Programme of the Education Policy Division at the Council of Europe. It seeks to "set out the principles governing actions in the migration field" and-as noted earlier-offers "language policy guidelines and reference tools developed to support their effective implementation in member states" so as to achieve "an inclusive approach based on shared values and principles" (CofE 2018, 2). The guiding prescript of the document points out that further issues related to the document are discussed on the "[p]latform of resources and references for plurilingual and intercultural education" (ibid.), which explicitly links the document to the concept of plurilingualism and interculturalism in education.

Some of the densest conceptual references to intercultural dialogue can be found in this document's recommendation on teacher training in education for intercultural understanding, notably in the context of migration. This recommendation originally dates back to 1984, and to better suit the thematic focus of the compilation document, its authors shortened it as follows:

The Committee of Ministers, $[\ldots]$

[...]

6. Considering that flourishing relations in all fields require a fuller understanding of the cultures and ways of life of other peoples as well as, in the event of their common cultural heritage;

7. Considering that the presence in schools in Europe of millions of children from foreign cultural communities constitutes a source of enrichment and a major medium- and long-term asset, provided that education policies are geared to fostering open-mindedness and an understanding of cultural differences;

8. Considering the essential role of teachers in helping such pupils to integrate into school and society, as well as in developing mutual understanding;

$[\ldots]$ 
10. Considering that, in order to fulfil this task, the training given to teachers should equip them to adopt an intercultural approach and be based on an awareness of the enrichment constituted by intercultural understanding and of the value and originality of each culture;

$[\ldots]$

12. Considering, too, that teachers issuing from migrant populations are particularly suited to creating with their pupils an educational process which takes account of the interaction of the features of their cultures of origin and of their host milieu;

I. Recommends:

A. that the governments of member states $[\ldots]$

1. make the intercultural dimension and the understanding between different communities a feature of initial and in-service teacher training, and in particular:

1.l train teachers in such a way that they:

- become aware of the various forms of cultural expression present in their own national cultures, and in migrant communities;

- recognise that ethnocentric attitudes and stereotyping can damage individuals, and therefore, make an attempt to counteract their influence

- realise that they too should become agents of a process of cultural exchange and develop and use strategies for approaching, understanding and giving due consideration to other cultures as well as educating their pupils to give due consideration to them;

$[\ldots]$

2. encourage the development and use of appropriate materials to support the intercultural approach in the training of teachers and in school in order to give a "truer" image of the different cultures of their pupils;

$[\ldots]$

4. where appropriate, encourage the holding of national and international seminars and courses on the intercultural approach to education for teachers, teacher trainers, administrators and other persons involved in teacher-training, including welfare and labour officers who have close professional relations with migrant families. (CofE 2018, 7-8, emphasis added, omitted passages in the original)

In this excerpt, the five underlying considerations-which present migration as a source of enrichment, an asset, and a valued source of cultural diversity within the European community - are followed by a recommendation to make intercultural considerations an initial and in-service 
feature of teacher training. The recommendation also states that education policies in general be "geared to fostering open-mindedness and an understanding of cultural differences" in a manner that promotes integration and mutual understanding. The 'intercultural' is, thus, presented as a valuable feature of Europe to be promoted on the policy level in educational models that encompass teacher education, using appropriate materials for an "intercultural approach". The document also recommends arranging national and international seminars to combat ethnocentrism and false images of cultural others. "Awareness" of cultural differences and their value is an expression that comes up repeatedly in our data and can be linked to the idea of intercultural competence or skill alongside "open-mindedness" and "understanding of cultural differences". Here, "recognition", "due consideration", and "encouragement" of appropriate attitudes, materials, and educational means, as well as cultural differences in general, are depicted as tools of intercultural training.

As the policy context of this excerpt focuses on migration and teacher education, it presents migration in a cultural, rather than economic, light. The concepts related to intercultural dialogue that overlap in this case are cultures, cultural heritage, and cultural expression-all bound up with positive value statements. Explicit references to the 'intercultural' appear in the text as attached to the words "understanding", "dimension", "feature of teacher training", and "approach". Positive value statements are signalled by the use of wording such as "flourishing relations", "source of enrichment", and "a major medium- and long-term asset", as well as plain "value". Negative value is attached to ethnocentrism and stereotyping, which are described as possibly damaging to individuals. The positive and negative value statements are further discussed in the next chapter dealing with affectively sticky concepts. Besides teachers, welfare and labour officers dealing with migrants are mentioned among the professionals that need to engage in or profit from intercultural education. It is also worth noting that teachers of migrant background are mentioned as especially suited to creating intercultural education processes with their pupils. Above all, intercultural education is presented here as a form of awareness raising in the context of migration.

Though migration is a common context of intercultural education in the European education policy documents, immigrants are also referred to in other contexts in our data. Policy discourses seeking to advance immigrants' inclusion and integration in European societies also emphasize issues of employment and the economy. In general, the promotion of 
intercultural dialogue in our data stems from and combines economic, societal, educational, social, cultural, and historical contexts. The social and historical contexts are apparent in the discussion of intercultural dialogue in history teaching that follows.

\section{Intercultural Dialogue in the Context of History Teaching}

Calls for dialogical approaches to history teaching are made in statements such as the Council of Europe's 2001 recommendation on the future of history teaching in Europe, which states that:

History teaching in a democratic Europe should [-] make it possible to develop in pupils the intellectual ability to analyse and interpret information critically and responsibly, through dialogue, through the search for historical evidence and through open debate based on multiperspectivity, especially on controversial and sensitive issues. (CofE 2001, 4)

In the context of history teaching, the densities of significant concepts related to ideas and practices of intercultural dialogue follow the same value-laden rhetoric as in the cases of multilingualism and migration. These densities tend to cluster around value statements that celebrate cultural diversity, or, as in the aforementioned quote, multiperspectivity. The Council of Europe's 2011 recommendation on intercultural dialogue in history teaching describes cultural diversity as "great" and a "shared asset" and calls for "increasing sensibility to the diverse cultural legacies" of present-day European societies. According to this document, this sensibility may be fostered via knowledge of the "cultural history of the world's other regions and civilisations" (CofE 2011b, 4), as well as through placing one's own local, regional, and national history in a wider, global context. The recommendations begin by describing the aims of history teaching:

Goals of history teaching in the context of intercultural dialogue

With a view to strengthening intercultural dialogue, and having regard to the general aims of history teaching as embodied in Recommendation $\operatorname{Rec}(2001) 15$, history teaching should contribute in particular to: 
- raising awareness regarding the great cultural diversity of presentday European societies, and to increasing sensibility to the diverse cultural legacies of those societies;

- better knowledge, in the general context of globalisation, of the cultural history of the world's other regions and civilisations while maintaining an appropriate focus on local, national and regional history;

- positioning national culture and history in the European context and to positioning European culture and history in the world perspective;

- knowledge about the history of the relationships between cultures, civilisations and peoples, and about the contribution of each to the development, growth and creativity of the others;

- the development of the knowledge and skills needed to establish open, productive intercultural dialogue by enabling all future citizens to gain a perception and understanding of the history of others, and thereby better to perceive and understand their own;

- the development of a multiple-perspective approach in the analysis of history, especially the history of the relationships between cultures;

- the pinpointing and critical analysis of stereotypes, cut-and-dried images, bias, old-fashioned views and interpretations that are improper or liable to breed real misunderstandings or, more generally, inappropriate images of others;

- the prevention of tension and conflict in sensitive situations and to the furtherance of reconciliation processes in conflict and postconflict situations, above all where cultural diversity in the broad sense is or has been exploited in conflicts of a political kind;

- in association with other disciplines, fostering the preconditions for productive intercultural dialogue, namely promotion of the common values and references such as the fundamental rights needed for dialogue to be established on a sound basis, as specified in the White Paper;

- enabling future citizens to give their fully informed consent to "live together" in complex, changing contexts whose developments are often unpredictable or unexpected. (CofE 2011b, 4-5, emphasis added)

In this excerpt, intercultural dialogue is framed through various concepts, terms, and expressions already discussed in relation to previous examples. The excerpt emphasizes cultural diversity and relationships between different cultures and seeks to raise "awareness" and "sensibility" towards the difference. Though the text addresses knowledge about the 
relationship of cultures and "the contribution of each to the development, growth and creativity of the others", it still draws a clear distinction between one's own culture and history and those of others. The text deals with culture and history only in territorial terms and as concentrated circles-local, regional, national, and European-as distinct from culture and history elsewhere, that is, the "cultural history of the world's other regions and civilisations". The excerpt includes value rhetoric referring to "common values and references, such as fundamental rights" as the basis for intercultural dialogue.

The document provides a specified list of skills, abilities, and attitudes through which it recommends advancing "the learning of the history of others" (CofE $201 \mathrm{lb}, 8$, title). The listed attitudes include interest, curiosity, awareness, and receptiveness. The list includes the abilities "to perceive cultural diversity as a shared asset"; "to position one's own culture in a broader context"; "to identify stereotypes and prejudices"; "to hear and respect other viewpoints and be amenable to dialogue"; "to control one's emotions and accept when other people express theirs"; "to distinguish what pertains to the facts of history from judgments"; "to construct reasoned critical judgments"; and "to comprehend, compare and analyse sources of different kinds and origins" (CofE 2011b, 8-9). Awareness raising is, again, mentioned as one of the most valuable goals of teaching intercultural dialogue, while knowledge is connected to critical analysis as the means to the desired multi-perspective end.

In the discourse of the recommendation, the ultimate aim of history teaching in the context of intercultural dialogue is to battle old-fashioned views and improper interpretations or stereotypes that breed misunderstandings and inappropriate images of others in ways that may lead to tension and conflicts. Although it is not mentioned explicitly, the goal of this kind of history teaching is to prevent the recurrence of the conflicts that continue to define the key themes in European history writing.

\section{Intercultural Dialogue in the Context OF LIFELONG LEARNING}

The process of acquiring and maintaining one's competence in intercultural dialogue may be regarded as lifelong learning. The origins of the idea of lifelong learning can be traced back to the 1960s and 1970s, but interest in the subject really peaked in the 1990s. By the beginning of the twenty-first century, the concept had been adopted "with an astonishing political consensus in the postindustrial societies of the western 
hemisphere", as Siivonen $(2010,38)$ notes. The reasons behind this embrace of lifelong learning as a political concept can be sought in the 'new economy' with its move from manufacturing to services and innovative business design, and its increasing demand for an ever-flexible workforce (Siivonen 2010, 38-39). The firm belief in education as the promoter of societal progress - the core idea included in lifelong learning (Siivonen 2010,39)-is prevalent in European education policies.

In its White Paper on Intercultural Dialogue, the Council of Europe argues that intercultural competence needs to be "learned, practised and maintained throughout life" (CofE 2008b, 29). Formal education (primary, secondary, and higher education) systems are the core promoters of intercultural competence, but civil society organizations, religious communities, and the media make an important contribution to developing intercultural competence (CofE 2008b, 29; Barrett 2013b, 26-27). The idea of acquiring and maintaining intercultural competence throughout one's life also is emphasized by the European Parliament and the Council of the European Union in their 2006 recommendation on the key competences for lifelong learning. This document recommends that member states "develop the provision of key competences for all as part of their lifelong learning strategies, including their strategies for achieving universal literacy, and use the 'Key Competences for Lifelong Learning-A European Reference Framework' [-] as a reference tool" (EP \& CofEU 2006, 11). This framework introduces eight key competences: communication in the mother tongue; communication in foreign languages; mathematical competence and basic competences in science and technology; digital competence; learning to learn; social and civic competences; sense of initiative and entrepreneurship; and cultural awareness and expression. Though intercultural dialogue is not mentioned in the document as such, the descriptions of "communication in foreign languages" and "social and civic competences" implicitly evoke it by referring to "intercultural understanding" (ibid., 14), "intercultural communication" (ibid., 15, 17), and "intercultural competences" (ibid., 16). Here, the 'intercultural' is again related to "appreciation of cultural diversity" (ibid., 15) and respecting others. The document's definition of social competence includes a density of concepts, terms, and expressions that are commonly used in discussing intercultural competence:

Social competence is linked to personal and social well-being which requires an understanding of how individuals can ensure optimum physical and mental health, including as a resource for oneself and one's family and one's 
immediate social environment, and knowledge of how a healthy lifestyle can contribute to this. For successful interpersonal and social participation it is essential to understand the codes of conduct and manners generally accepted in different societies and environments (e.g. at work). It is equally important to be aware of basic concepts relating to individuals, groups, work organisations, gender equality and non-discrimination, society and culture. Understanding the multi-cultural and socio-economic dimensions of European societies and how national cultural identity interacts with the European identity is essential.

The core skills of this competence include the ability to communicate constructively in different environments, to show tolerance, express and understand different viewpoints, to negotiate with the ability to create confidence, and to feel empathy. Individuals should be capable of coping with stress and frustration and expressing them in a constructive way and should also distinguish between the personal and professional spheres.

The competence is based on an attitude of collaboration, assertiveness and integrity. Individuals should have an interest in socio-economic developments and intercultural communication and should value diversity and respect others, and be prepared both to overcome prejudices and to compromise. (EP \& CofEU 2006, 17, emphasis added)

As the excerpt illustrates, intercultural competence is approached and embedded in a broader framework of social competence. The description of this competence ties together concepts such as social participation, culture, gender equality, non-discrimination, identity, tolerance, empathy, diversity, and respect.

Skills relevant for intercultural dialogue are also inherent in the definition of cultural awareness and expression:

A solid understanding of one's own culture and a sense of identity can be the basis for an open attitude towards and respect for diversity of cultural expression. A positive attitude also covers creativity, and the willingness to cultivate aesthetic capacity through artistic self-expression and participation in cultural life. (Ibid., 18, emphasis added)

Here, intercultural dialogue is evoked through openness and respect for diversity, and connected to "[a] solid understanding of one's own culture a sense of identity" and "participation in cultural life" (ibid.). Intercultural dialogue, thus, comes across as an important skill on both the social and societal levels. 


\section{Intercultural Dialogue as a Key Skill In Europe Today}

The dense occurrences of concepts analysed in this chapter illustrate how intercultural dialogue is discussed in the European education policy documents through the use of varied related concepts that bring with them a multitude of meanings. Our research on these dense occurrences indicates how the ability to practise intercultural dialogue can be seen as one of the most important transversal skills for Europeans today, in a globalized world that increasingly requires communication between cultures. Yet, as recently as 2017, the European Commission still remarked that there is a "mismatch" between the skills that Europe needs and the skills that it has.

The European Commission's recent Renewed EU Agenda for Higher Education calls for improvement in both basic literacy, numeracy, and digital skills acquired during compulsory schooling and transversal skills such as problem-solving and communication (EC 2017a, 3). The Commission's communication on School Development and Excellent Teaching for a Great Start in Life from the same year likewise calls for transversal skills such as creativity and critical thinking (EC 2017b, 3, 5). From our point of view, competence for intercultural dialogue represents exactly this kind of transversal and ever-timely competence, which all age groups need in a range of situations. Thus, intercultural dialogue should be explicitly promoted in education policies.

\section{REFERENCES}

Barrett, M. 2013a. Intercultural Competence: A Distinctive Hallmark of Interculturalism? In Interculturalism and Multiculturalism: Similarities and Differences, ed. M. Barrett, 147-168. Strasbourg: Council of Europe.

- 2013b. Introduction-Interculturalism and Multiculturalism: Concepts and Controversies. In Interculturalism and Multiculturalism: Similarities and Differences, ed. M. Barrett, 15-42. Strasbourg: Council of Europe.

Byram, M., M. Barrett, J. Ipgrave, R. Jackson, and M.C. Méndez García. 2009. Autobiography of Intercultural Encounters: Context, Concepts and Theories. Strasbourg: Council of European Publishing.

CofE (Council of Europe). 1977. European Convention on the Legal Status of Migrant Workers. Strasbourg, 24 November 1977. Strasbourg: Council of Europe. 
1997. The Lisbon Convention (Convention on the Recognition of Qualifications concerning Higher Education in the European Region). Lisbon, 11 April 1997. Strasbourg: Council of Europe.

- 1954. European Cultural Convention. Paris, December 19. Strasbourg: Council of Europe.

- 2001. Recommendation Rec(2001)15 on History Teaching in Twenty-FirstCentury Europe. Adopted by the Committee of Ministers on 31 October 2001 at the 771st Meeting of the Ministers' Deputies. Strasbourg: Council of Europe.

- 2008a. Recommendation Rec(2008)4 on Strengthening the Integration of Children of Migrants and of Immigrant Background. Adopted by the Committee of Ministers on 20 February 2008 at the 7018th Meeting of the Ministers' Deputies. Strasbourg: Council of Europe.

- 2008b. White Paper on Intercultural Dialogue. In Living Together as Equals in Dignity. Strasbourg: Council of Europe.

- 2008c. Recommendation Rec(2008)10 on Improving Access of Migrants and Persons of Immigrant Background to Employment. Adopted by the Committee of Ministers on 10 July 2008 at the 7032nd Meeting of the Ministers' Deputies. Strasbourg: Council of Europe.

- 2011a. Recommendation Rec(2011)2 on Validating Migrants' Skills. Adopted by the Committee of Ministers on 19 January 2011 at the 1103rd Meeting of the Ministers' Deputies. Strasbourg: Council of Europe.

- 2011b. Recommendation Rec(2011)6 on Intercultural Dialogue and the Image of the Other in History Teaching. Adopted by the Committee of Ministers on 6 July 2011 at the 1118th Meeting of the Ministers' Deputies. Strasbourg: Council of Europe.

- 2015. European Social Charter (Collected Texts, 7th Edition). I January 2015. Strasbourg: Council of Europe.

- 2018. Children and Adolescents from a Migrant Background: Integration and Education. Extracts from Conventions, Recommendations, Resolutions and Reports. Revised and Enriched Version-April 2018. Strasbourg: Council of Europe.

CofEC (Commission of the European Communities). 2005. Communication from the Commission to the Council, the European Parliament, the European Economic and Social Committee and the Committee of the Regions. $\operatorname{COM}(2005)$ 596 Final. A New Framework Strategy for Multilingualism. Brussels: Commission of the European Communities.

- 2008a. Communication from the Commission to the European Parliament, the Council, the European Economic and Social Committee and the Committee of the Regions. Improving Competences for the 21st Century: An Agenda for European Cooperation on Schools. COM(2008) 425 Final. Brussels: Commission of the European Communities. 
2008b. Communication from the Commission to the European Parliament, the Council, the European Economic and Social Committee and the Committee of the Regions-Multilingualism: An Asset for Europe and a Shared Commitment. $\operatorname{COM}(2008) 566$ Final. Brussels: Commission of the European Communities. CofEU (Council of the European Union). 2009. Council Conclusions of 26 November 2009 on the Education of Children with a Migrant Background, 2009/C 301/07. Official Journal of the European Union C301: 5-8.

- 2013. 2013/776/EU: Commission Implementing Decision of 18 December 2013 Establishing the 'Education, Audiovisual and Culture Executive Agency' and Repealing Decision 2009/336/EC. Official Journal of the European Union L343: 46-53.

CofEU \& EC (Council of the European Union \& the European Commission). 2015. Joint Report of the Council and the Commission on the implementation of the Strategic Framework for European Cooperation in Education and Training (ET 2020): New Priorities for European Cooperation in Education and Training. (2015/C 417/04). Official Journal of the European Union C417: 25-35.

EC (European Commission). 2017a. Communication from the Commission to the European Parliament, the Council, the European Economic and Social Committee and the Committee of the Regions on a Renewed EU Agenda for Higher Education. $\operatorname{COM}(2017) 247$ Final. Brussels: European Commission.

- 2017b. Communication from the Commission to the European Parliament, the Council, the European Economic and Social Committee and the Committee of the Regions: School Development and Excellent Teaching for a Great Start in Life. $\operatorname{COM}(2017) 248$ Final. Brussels: European Commission.

EP \& CofEU (European Parliament and the Council of European Union). 2013. Regulation (EU) no 1288/2013 of the European Parliament and of the Council of 11 December 2013 Establishing 'Erasmust': The Union Programme for Education, Training, Youth and Sport and Repealing Decisions No 1719/2006/EC, No 1720/2006/EC and No 1298/2008/EC (Text with EEA Relevance). Official Journal of the European Union L347: 50-73.

EP \& CofEU (European Parliament and the Council of the European Union). 2006. Recommendation of the European Parliament and of the Council of 18 December 2006 on Key Competences for Lifelong Learning. (2006/962/ EC). Official Journal of the European Union L394: 10-18.

Méndez García, M.C., and M. Byram. 2013. Interculturalism, Multiculturalism and Language Issues and Policies. In Interculturalism and Multiculturalism: Similarities and Differences, ed. M. Barrett, 133-146. Strasbourg: Council of Europe.

Siivonen, P. 2010. From a "Student" to a Lifelong "Consumer" of Education? Constructions of Educability in Adult Student's Narrative Life Histories. Jyväskylä: Finnish Educational Research Association. 
Spitzberg, B.H., and G. Changnon. 2009. Conceptualizing Intercultural Competence. In The SAGE Handbook of Intercultural Competence, ed. D.K. Deardorff, 2-52. Thousand Oaks: Sage.

Open Access This chapter is licensed under the terms of the Creative Commons Attribution 4.0 International License (http://creativecommons.org/licenses/ by $/ 4.0 /)$, which permits use, sharing, adaptation, distribution and reproduction in any medium or format, as long as you give appropriate credit to the original author(s) and the source, provide a link to the Creative Commons licence and indicate if changes were made.

The images or other third party material in this chapter are included in the chapter's Creative Commons licence, unless indicated otherwise in a credit line to the material. If material is not included in the chapter's Creative Commons licence and your intended use is not permitted by statutory regulation or exceeds the permitted use, you will need to obtain permission directly from the copyright holder.

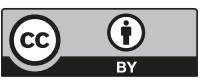




\title{
Affective Rhetoric and 'Sticky Concepts' in European Education Policy Documents
}

\begin{abstract}
Concepts carry not only meanings but also affective associations and cultural connotations. In this chapter, we elaborate on the affective dimensions of European education policy documents. Many of the conceptual densities discussed in this book form affective peaks or rhetorical pinnacles that transmit the idea of intercultural dialogue-and the values attached to it-more effectively than the definitions of the concept alone are able to do. Drawing on theories of affect, we trace the affective transmission of ideals and values in the education policy documents and examine what kind of affects and affective connotations 'stick' to the concept of intercultural dialogue. We suggest affective rhetoric is used in European education policy documents to legitimize the commissioning bodies' attempts to advance intercultural dialogue.
\end{abstract}

Keywords Affect $\bullet$ Sticky concepts $\bullet$ Affective rhetoric $\bullet$ Values

Policies function as 'actants' that are able to create webs of meanings, social and semantic spaces, and action. Policy rhetoric names, gives meanings to, and categorizes issues and explicitly states how these issues and related practices should be approached. Moreover, it is able to 'move' its recipients at a more intimate level. In this chapter, we discuss the affective associations, or 'stickiness' (e.g. Ahmed 2004a, b, c) evoked by the rhetorical use of the concepts related to intercultural dialogue in European

(C) The Author(s) 2020

T. Lähdesmäki et al., Intercultural Dialogue in the European

Education Policies, https://doi.org/10.1007/978-3-030-41517-4_5 
education policy documents. Before going further, it is necessary to briefly define affect, a very elusive concept in itself, for the purposes of the book at hand.

In the last few decades, cultural studies and the social sciences have seen a "surge of interest" (Wetherell 2012,2) in affects; so much so, that scholars have sometimes dubbed this an "affective turn" (e.g. Clough 2010; Koivunen 2010; Thompson and Hoggett 2012b). The growing interest in affect has produced several competing strands of research, and this has not led to any single affect theory — or, for that matter, any single understanding of what constitutes 'affect' (Seigworth and Gregg 2010; Wetherell 2012). Wetherell notes that affect is often juxtaposed with emotion: affect is defined as physical and sensory experiences, whereas emotion is understood as the social and recognizable expressions of affective states (Wetherell 2012, 2, 51-76). Wetherell distinguishes two strands of affect in social sciences. In her words: "Sometimes 'affect' includes every aspect of emotion and sometimes it refers just to physical disturbance and bodily activity [-] as opposed to 'feelings' or more elaborated subjective experiences" (Wetherell 2012, 2). For our purposes, it is relevant that Wetherell $(2012,2-4,12)$ sees these two strands as complemented by a broader understanding of the processes of what she calls embodied meaning-making, which is a social practice. Ahmed (2004a, b, c, 2010a, b) also emphasizes the social and discursive dimension of affects, which can be linked to objects and mediated through cultural practices. As Wetherell (2012, 1-4), Ahmed (2004c, 2010b), Brennan (2004), and others have noted, affect also refers to 'being affected' by something or someone, thus emphasizing its mediated and transferable aspects.

In this chapter, we follow these views that configurations of affect are social and culturally mediated (see also Connolly 2002; Blackman and Venn 2010; Lähdesmäki 2017) and therefore expressed through discourses found in the European education policy documents. To put it simply, we see affect as deeply interconnected to cultural practices of signification, representation, and mediation. Thus, we do not consider affect as 'merely' physical, biological, or separate from cognitive processes (see also Lähdesmäki 2017). Our approach is therefore contrary to theories that consider affect as prior to cognition, representation, culture, or discourse (on criticism of the non-representational approach to affect, see e.g. Wetherell 2012; Smith and Campbell 2015; Lähdesmäki 2017). 
In our analysis, we build especially on Ahmed's theories about the stickiness of affects. For Ahmed (2010b, 29), "Affect is what sticks, or what sustains or preserves the connection between ideas, values, and objects". In other words, the way that affects are attached to objects or subjects-or words, concepts, and ideas-influences the way in which they are valued. This attachment is a social, cultural, and discursive process. Ahmed introduces her idea of stickiness especially in relation to racialized, gendered, and queer bodies, bodies that become othered and cast as different via evocations of 'impurity' and danger (e.g. Ahmed 2004a, b, c, 2010b). Impurity and danger are good examples of the transmission of affect, because they evoke negative emotional responses without being emotions themselves. Similarly, positive affects may be produced by the evocation of purity and safety (or, as in the case of the education policy language analysed here, e.g. the ideas of 'unity', 'social cohesion', and 'mutual understanding'), although the positivity/negativity of any state of being affected depends on the cultural and situational alignment of the perceiver (see Ahmed 2010b). Through their liaison with values, affects also have the power to align people with certain others that share or promote the same values, while casting them as being in opposition to "other others" (Ahmed 2004a, b, c, 2). Although (the prevention of) impurity or danger are not as explicitly discussed in the European education policy documents as they are in Ahmed's examples, our analysis establishes that concerns over social and societal disorder and instability are implicitly expressed through concepts that evoke ideals of unity and peace, creating a specific affective space in these documents.

We therefore argue that-like objects, spaces, events, and bodies-concepts too can become saturated with affect. We approach certain concepts, such as 'freedom', 'tolerance', and 'human rights', as more affective and 'sticky' than others, thereby adhering to views that understand affects as representational and transmittable 'moods' or 'emotional effects' that can be willingly produced and performatively used to further certain discursive agendas. Ahmed (2004a, 122) analyses how words evoking fear and threat-such as 'flood' and 'swamped'-became stuck to 'asylum seeker' in speeches given by William Hague, the leader of the British Conservative Party in the year 2000. These speeches served as an attempt to generate certain negative affective dispositions against asylum seekers (Ahmed 2004a, 121-124). The European education policy documents also invoke affective dispositions through their implicit or explicit use of the concepts related to intercultural dialogue. 
We assert that affects can be linked to both values and valuing as well as, importantly, to political rhetoric and action. In national (and European) politics or political rhetoric, the affective force of language and especially sticky phrases and expressions have long been used to promote certain ideologies while discouraging others. Propaganda is a case in point. Yet even the less flashy, less obvious cases of rhetorical manoeuvring merit consideration. It is important to become aware that even everyday words and practices carry affective meanings and that we are influenced by the most minute changes in tonalities. Policy discourse is an excellent example, as it is carefully crafted so as to enable wide affective alignment with the politics it conveys. The political dimension of affect has been discussed in several studies that take an empirical approach to political campaigning and public policy (e.g. Redlawsk 2005; Thompson and Hoggett 2012b; Halperin 2013) and in more theoretical studies of the politics of affect (e.g. Thrift 2008; Barnett 2008; Blackman and Venn 2010). Scholars have, however, rarely explored how concepts become invested with affect in political rhetoric-particularly in European-level policies.

\section{Affectively and Effectively Transmitting European IDEALS AND VALUES}

The concept 'intercultural dialogue' and its interrelated concepts 'culture', 'multiculturalism', 'values', 'tolerance', 'empathy', 'identity', 'inclusion', and 'heritage' can all be said to have acquired affective value in today's cultural discourses - some more than others. For example, multiculturalism has evoked and still often stirs up heated discussions in today's media landscape; concepts such as 'identity', 'heritage', and 'inclusion' are frequently utilized in populist attempts to discredit specific 'identity politics' or to deny people with a certain heritage entry to the national body (see e.g. Mudde 2017; also Wodak 2015). In the European education policy documents, these concepts are conveyed through policy jargon, which has a distancing effect. This emotionally distancing tone can be interpreted as striving for objective, neutral, and matter-of-fact language in contrast to populist emotionally laden rhetoric. Moreover, this language can be interpreted as a tactic for convincing the readers of the meanings and values promoted in the policies. That said, the policy documents cannot escape the affective load carried by the concepts utilized in them, and 
this language thus only makes certain concepts 'stick out', making dense concept occurrences even more affectively and effectively sticky.

Countering emotionally appealing populist rhetoric has become a growing concern, even for actors who have traditionally operated in less easily approachable spheres and rhetoric. However, these actors may themselves utilize emotive utterances and affective language in their arguments against populist discourses. As established below, affect is transmitted in the European education policy documents especially through value statements. While analysing European Union policy tropes, Lähdesmäki $(2017,718)$ posits that in the European policy documents, a "poetic dimension" is employed through the emphasis of "values, ideals, and political principles that are seen as the basis of the union and as the key elements the union seeks to promote through its politics and policies". This poetic dimension utilizes rhetoric and diverse concepts invested with affect and, therefore, brings lofty and idealistic tones that seek to lift the ethos of this policy discourse above everyday and bureaucratic political decision-making. It seeks to impact on its recipients not only at the rational but also emotional level. Similarly, in a discussion on landscape renewal, Van Stokkom $(2012,41)$ argues that "policymaking processes can be enriched by drawing upon affective and narrative types of communication".

In general, risk talk and the evocation of fears speak to feelings and intuition more effectively than critical evaluation aiming at neutrality. Tension and controversy may thus be considered more sticky (see Ahmed $2004 a$, b) than reportage of minor successes, as we know well from news reporting that tends to neglect positive stories in favour of negative content that has more viral potential. Idealistic, uplifting, and edifying rhetoric may also be used similarly to 'stir up' emotions. Following Newman (2011), Thompson and Hoggett suggest that communication can never be free of an "affective register" that either supports or counters the narrative presented. When policymakers promote a development using a hopeful rhetoric, they are deploying an affective register to support their aims (Thompson and Hoggett 2012a, 5).

The concepts used in the European policy documents are sticky with affective connotations and associations acquired through their circulation in political debates, media, and cultural and social discourses. But the concepts are, and do, more. Within their circulation, and their dense occurrences, concepts are interconnected, forming new affective associations. 
Many of the conceptual conglomerations discussed in the previous chapter form affective peaks or rhetorical pinnacles that transmit the idea of intercultural dialogue - and the values attached to it - more forcefully than the mere definitions of the concept are able to do. Our analysis therefore focuses on the affective impact of these dense co-occurrences of the core concepts of intercultural dialogue. We argue that when concepts sticky with affective force or value (see e.g. Ahmed 2004a, b, c; Lähdesmäki 2017 ) or are brought (or stick) together in dense co-occurrences, the text becomes heavy with affect.

The European education policy documents use uplifting affective language especially in relation to 'honourable' values that are either implicitly or explicitly defined as European (see the previous chapter). These values explicitly include 'freedom', 'tolerance', 'non-discrimination', and 'human rights' (e.g. CofEU 2015a, 2n6, b, 36, 2016, 5, 5nl; CofEU \& EC 2015, 25n2; CofEU \& RofGofMS 2016, 1, ln4) in the European Union's documents, and 'tolerance', 'mutual understanding', 'human rights', and 'democratic values' in the Council of Europe's documentation (see CofE $2001,2,4,5,8,15)$. When we think of concepts such as freedom and human rights, these words immediately invoke associations of sublimity and honourable principles, as well as the process of fighting for a greater cause or breaking free from oppression. These values can therefore be called sticky concepts, as they evoke associations to common, humanist values, ideals, and cultural-historical phenomena behind struggles for human rights, peace, and equality all over the globe. As such, the affective rhetoric of the policy documents is also morally hard to resist and critique, as it draws on values that are 'universal'. As we have seen in the previous chapters, many of the aforementioned values are used in the European education policy documents to define intercultural dialogue, so it becomes sticky with the affective content associated with these values. Sometimes in our data, intercultural dialogue is explicitly connected to values. For instance, in the recommendation on integrating and educating children with a migrant background, teaching "intercultural competence" is considered as important as teaching human rights and democratic citizenship (CofE 2008, 4).

An example of dense concept occurrences, where concepts sticky with affective value become stuck together to create meanings and affective associations, appears in the Council of Europe Charter on Education for Democratic Citizenship and Human Rights Education (CofE 2010). 
Here, affective rhetoric is used to define the desirable European democratic values, including intercultural dialogue:

An essential element of all education for democratic citizenship and human rights education is the promotion of social cohesion and intercultural dialogue and the valuing of diversity and equality, including gender equality; to this end, it is essential to develop knowledge, personal and social skills and understanding that reduce conflict, increase appreciation and understanding of the differences between faith and ethnic groups, build mutual respect for human dignity and shared values, encourage dialogue and promote non-violence in the resolution of problems and disputes. (CofE 2010, 9, emphasis added)

Intercultural dialogue thus becomes sticky with affective value invested in concepts such as unity, mutual respect, dialogue, diversity, human dignity, and social cohesion.

Even though the affective rhetoric of the education policy documents mostly relies on positive connotations, sometimes values and ideals are also conveyed by less optimistic means. This becomes evident in the documents that utilize concepts referring to threats. In the previous excerpt (CofE 2010,9), valuing diversity, equality, and mutual understanding are also seen as reducing conflict. This excerpt thus draws upon the threats of violent upheavals to establish its uplifting affective tone and to promote 'universally positive' values. To offer another example, in the resolution on promoting socio-economic development and inclusiveness in the European Union through education, 'European' ideals and values are contrasted with terrorism and violent radicalization that are seen as threats to (democratic/active) citizenship in "our societies" (CofEU \& RofGofMS 2016, 1-4). The same resolution presents education as an important factor in tackling this radicalization and in promoting "the common values of freedom, tolerance and non-discrimination" (CofEU \& RofGofMS 2016, 1, $\ln 4$ ). Violence and terrorism can be argued to be, in essence, affective phenomena. Thus, by contrasting violence to these 'affectively sticky' values, the document is employing specific affective rhetoric and seeking affective responses. 


\section{Affective Alignment: Constructing a 'We' in the European Education Policy Documents}

Affects are also mobilized in the European education policy documents by the construction of a common European 'us' into which immigrants and other minorities are 'welcome' to integrate (by accepting specific 'European' values). Above, we discussed how specific desirable values are defined as 'European' in the data; shared Europeanness is also emphasized by the use of expressions such as "our common heritage" (CofE 2011b), "common historical heritage" (CofE 2001, 5), "our common European principles" (CofEU \& RofGofMS 2006, 2), or "our common cultural background" (CofEC 2008, 5-6). For example, the European Union document promoting multilingualism states that:

Each of the many national, regional, minority and migrant languages spoken in Europe adds a facet to our common cultural background. It should be shared to foster dialogue and mutual respect. There are areas in the EU where citizens successfully combine speaking a regional or minority language with the national language and score well in foreign languages too. Multilingual people are a precious asset because they act as the glue between different cultures. (CofEC 2008, 5-6, emphasis added)

This repetition of phrases such as 'our common' works to create an affective sense of belonging, especially when they appear in connection to the uplifting, affective value rhetoric discussed above. The idea of 'our common Europe' thus becomes sticky with the values invested in the affect-laden concepts utilized in this rhetoric. For example, the Council of Europe's Recommendation on Intercultural Dialogue and the Image of the Other in History Teaching deploys the idea of a common European identity based on shared values:

Recalling that the Heads of State and Government of the Council of Europe, at the Warsaw Summit (2005), expressed their wish to encourage a European identity and unity based on shared fundamental values, respect for our common heritage and cultural diversity, and their conviction that "dialogue between cultures is also fostered by accurate understanding of history", and endorsed the Council of Europe's work regarding history and the related projects [-]. (CofE 2011b, 1, emphasis added) 
This quotation also offers a thick cluster of concept occurrences, 'sticking' the concept of 'identity' to 'unity', 'values', 'cultural heritage', 'cultural diversity', and 'intercultural dialogue'. Here, references to history also suggest a common heritage that invites affective connotations: the emphasis on unity stems from and thus carries with it implicit (and in some documents explicit) references to times when lack of dialogue and shared values led to wars in Europe. Dialogue in general, and intercultural dialogue in particular, thus becomes sticky with affects representative of 'better times'. Following Ahmed (e.g. 2004a, 123-124), we therefore posit that the European education policy documents construct an imagined 'we' (i.e. Europeans) that shares specific values and ideals and is potentially threatened by 'others' who do not share these values.

Europeanness is also constructed by deploying the idea of "unity within diversity'. This becomes evident, again, in the European Union's document on multilingualism from 2008:

The harmonious co-existence of many languages in Europe is a powerful symbol of the European Union's aspiration to be united in diversity, one of the cornerstones of the European project. Languages define personal identities, but are also part of a shared inheritance. They can serve as a bridge to other people and open access to other countries and cultures, promoting mutual understanding. A successful multilingualism policy can strengthen life chances of citizens: it may increase their employability, facilitate access to services and rights and contribute to solidarity through enhanced intercultural dialogue and social cohesion. Approached in this spirit, linguistic diversity can become a precious asset, increasingly so in today's globalised world. (CofEC 2008, 3, emphasis added)

In the European Commission's New Framework Strategy for Multilingualism from 2005, one sentence specifically deploys a range of metaphors to illustrate the European Union's 'united in diversity' slogan in terms of home, prosperity, and aspirations of development towards an ever-better future. The idea of the European Union as a 'common home' is, in this case, fleshed out by a reference to "many mother tongues" that are "a source of wealth" and "a bridge to greater solidarity and mutual understanding" (CofEC 2005, 2). Here, diversity-and thus implicitly intercultural dialogue - sticks to concepts such as 'wealth' as a signifier of positive growth, well-being, and development, as well as to 'universal' and 
positive values such as 'solidarity'. Although affective responses are elusive, it is hard not to see that the concepts utilized here are meant to evoke positive affects. Indeed, they make the European Union (itself represented as positive and necessary for European well-being in these documents) what it is. This affective evocation is contrasted with the idea of a melting pot, which is cast as undesirable, thus underlining the autonomy of each culture within the Union. Performatively, this rhetoric casts the European Union as familiar (home), rich (wealth), and dynamic (bridge to greater solidarity), as the New Framework Strategy states:

It is this diversity that makes the European Union what it is: not a 'melting pot' in which differences are rendered down, but a common home in which diversity is celebrated, and where our many mother tongues are a source of wealth and a bridge to greater solidarity and mutual understanding. (CofEC 2005, 2, emphasis added)

Diversity is, thus, portrayed as extremely positive, something that Europeans can identify with and take pride in, creating a stark contrast to the rhetoric discussed by Ahmed (2004a), where immigrants were associated with natural disasters such as floods. In distancing itself from 'the melting pot', the document also creates a contrast between the European Union and the country most closely associated with this phrase, the USA. For many Europeans familiar with human rights violations (e.g. of refugees and women's reproductive health) in the USA, this contradiction may stir affective responses that align the recipients of the rhetoric more closely with Europe and the European Union-although it too undoubtedly has its own problems with the human rights of specific groups. In this sense, the USA serves as the other, perhaps even a threat, in contrast with the 'us' constructed by the policy documents.

For Thompson and Hoggett (2012a, 6), "emotions are [-] intimately involved in the processes of governance and policymaking. In the late modernity, the state becomes the focus of social anxieties which manifest themselves in recurrent moral and risk panic". They argue that the state may embody social anxieties, which becomes evident through the rules and regulations posited to safeguard its citizens from these risk factors (Thompson and Hoggett 2012a, 6-7). In this sense, Europe here becomes the 'state' shoring up against the risk of a 'melting pot' society. The fundamental utility of representing the European Union as a "humanistic enterprise" based on various social virtues and common cultural roots and 
identity, as Shore $(1993,785-786)$ has described it, is in its affective nature. The emphasis on common history and culture and shared memory in the European Union's policy discourse “aims to appeal to people's feelings of belonging, sense of communality, and cultural and social attachments, thereby striving to justify the promotion of cultural integration in the EU", as Lähdesmäki $(2014,17)$ notes. The Council of the European Union's document on educating children with a migrant background, for example, also states that "cultural diversity in our societies should be welcomed" (CofEU 2009, 7). Here, again, Europe and the Europeans nevertheless become associated with the 'our' (or 'us'). The Europeans 'are' the society and can, thus, 'welcome' or 'not welcome' diversity (i.e. 'the others', such as the immigrants).

The same document continues with uplifting rhetoric, now directly used to affectively promote the importance of multilingualism and linguistic diversity:

Language is the most direct expression of culture; it is what makes us human and what gives each of us a sense of identity. Article 22 of the Charter of Fundamental Rights of the European Union states that the Union shall respect cultural, religious and linguistic diversity. Article 21 prohibits discrimination based on a number of grounds, including language. Together with respect for the individual, openness towards other cultures, tolerance and acceptance of others, respect for linguistic diversity is a core value of the European Union. Action by the Union and the Member States to uphold multilingualism therefore has a direct impact on the life of every citizen. (CofEC 2005, 2, footnotes removed, emphasis added)

In this document, positive, uplifting rhetoric is evident in the definition of Europe as "a common home in which diversity is celebrated, and where our many mother tongues are a source of wealth and a bridge to greater solidarity and mutual understanding". Skills related to intercultural dialogue, such as 'respect', 'openness', 'tolerance', and 'acceptance of others', are also mentioned, creating a clear link between linguistic diversity and intercultural dialogue. Furthermore, diversity and intercultural dialogue become aligned with positive values such as "respect for the individual, openness towards other cultures, tolerance and acceptance of others, respect for linguistic diversity". Acceptance of diversity and the multilingualism that this requires are seen as fundamental values for the European Union and its citizens. To top it all, acceptance of linguistic 
diversity (and intercultural dialogue) comes across as a precondition for humanity itself, as language is "what makes us human and what gives each of us a sense of identity". Interestingly, diversity mostly comes across through discussions of cultural differences, equality, and access regarding ethnicity, gender, (dis)ability, and socio-economic status, but ethnicity, for example, is mostly framed in the context of migration and cultural exchange. Indigenous peoples, for example, are left outside the focus (cf. CofE 2018, 18; CofEC 2005, 2). Moreover, discussions of sexual orientation appear only in a few documents (CofE 2015; EP \& CofEU 2004, 2013).

The idea of a 'unified, European we' is also implicitly expressed through the value of non-discrimination and the concept of (social) inclusion:

Education and training plays a major role in promoting equity, social inclusion and active citizenship. Social exclusion of the low-skilled, learners from a migrant background, the unemployed and those with special educational needs is often the result of cumulating elements such as low formal qualification and the lack of basic skills and transversal competences. Education and training can be important forces to counter social exclusion [-]. (EC 2010, 8, emphasis added)

Unemployment and social exclusion are here contrasted with the positive values of inclusion and equity achieved through education. The principle of non-discrimination is also foregrounded in the Council of Europe's Lisbon Convention:

No discrimination shall be made in this respect on any ground such as the applicant's gender, race, colour, disability, language, religion, political or other opinion, national, ethnic or social origin, association with a national minority, property, birth or other status, or on the grounds of any other circumstance not related to the merits of the qualification for which recognition is sought. In order to assure this right, each Party undertakes to make appropriate arrangements for the assessment of an application for recognition of qualifications solely on the basis of the knowledge and skills achieved. (CofE 1997, 5)

The same principle of recognition also applies to refugees, displaced persons, and persons in a refugee-like situation (CofE 1997, 9). The concept of 'integration' is also used in the documents with reference to including (im)migrants, often expressed in a positive light. The Council of 
Europe's recommendation on the subject states that "the integration of migrants and persons of immigrant background is a pillar of social cohesion of European societies" (CofE 2008, 1). Interestingly, in this document, integration is defined as "an interactive process based upon mutual willingness to adapt by both migrants and the receiving society" (CofE $2008,1)$. The document therefore maintains a clear division between the accepting 'us' (Europe/Europeans) and the accepted 'others' ([im]migrants). Contrary to the populist rhetoric that considers immigrants as a threat to 'our' societies, the European education policy documents clearly construct the exclusion of immigrants as threat to societal unity and cohesion. For example, in the Council of Europe's recommendation on validating migrants' skills (CofE $201 \mathrm{la}, 1$ ), it is argued that its members can achieve greater unity "through common action in the fields of migration, integration and community relations". The word '(im)migrant' thus is invested - or sticky - with positive instead of negative affect, which counters the affective rhetoric of the aforementioned populist discourse.

\section{Affectivity of Intercultural Dialogue}

Sticky concepts are extremely effective rhetorical tools, so they are often used in political discourses (Lähdesmäki 2017). Our analysis of European education policy documents shows how the concept of intercultural dialogue and its related concepts are invested with affective meanings and cultural connotations. In our analysis, we applied Ahmed's (2004a, b, c, $2010 \mathrm{a}, \mathrm{b})$ theory on the stickiness of affects by approaching some core and repeated expressions in our data as sticky concepts. We argued that affects are brought into play in implicit and explicit co-occurrences of concepts and in the use of value rhetoric, especially where this rhetoric is positive and uplifting and deploys 'universal' values. Concepts such as 'freedom', 'human rights', 'equality', and 'democracy' include a special sticky layer of meanings due to their long history in European policy discourse and their emotional connotations created in the political context of post-war and cold war Europe. Similarly, 'diversity', 'mutual understanding', 'unity', 'tolerance', and 'solidarity' are expressed as positive values. Moreover, the affective stickiness of these concepts impacts on other concepts in conceptual densities. Stickiness makes all these concepts appealing, compelling, and difficult to argue against rationally. Using such sticky concepts makes it easy to argue for policy goals. 
Although affect is mostly expressed through positive rhetoric in the European education policy documents, the concepts analysed in this chapter are also affective through their implicit associations to Europe's violent history. Values elicited in the documents are represented as a key to avoid the repetition of such violent upheaval. Sometimes threats such as terrorism are explicitly mentioned in the European education policy documents. Furthermore, by constructing a common, European 'we', these policy documents evoke a sense of belonging, inviting their readers to be a part of this 'we' and, thus, to gain access to these uplifting values. Through this affective rhetoric, intercultural dialogue thus becomes the means for greater belonging in a culturally diverse Europe. Affects are a powerful tool for mediating cultural values and ideas. Policymakers should thus give affective rhetoric their close attention.

\section{REFERENCES}

Ahmed, S. 2004a. Affective Economies. Social Text 79 (22): 117-139.

- 2004b. Collective Feelings, or the Impressions Left by Others. Theory, Culture \& Society 21 (2): 25-42.

- 2004c. The Cultural Politics of Emotion. Edinburgh: Edinburgh University Press.

—. 2010a. Creating Disturbance: Feminism, Happiness and Affective Differences. In Working with Affect in Feminist Readings: Disturbing Differences, ed. M. Liljeström and S. Paasonen, 31-44. London: Routledge.

. 2010b. Happy Objects. In The Affect Theory Reader, ed. G.J. Seigworth and M. Gregg, 29-51. Durham: Duke University Press.

Barnett, C. 2008. Political Affects in Public Space: Normative Blind-Spots in NonRepresentational Ontologies. Transactions of the Institute of British Geographers 33 (2): 186-200.

Blackman, L., and C. Venn. 2010. Affect. Body \& Society 16 (1): 7-28.

Brennan, T. 2004. The Transmission of Affect. London: Cornell University Press. Clough, Patricia T. 2010. The Affective Turn: Political Economy, Biomedia, and Bodies. In The Affect Theory Reader, ed. M. Gregg and G.J. Seigworth, 206-225. Durham \& London: Duke University Press.

CofE (Council of Europe). 1997. The Lisbon Convention. Convention on the Recognition of Qualifications Concerning Higher Education in the European Region. Lisbon, April 11. Strasbourg: Council of Europe.

- 2001. Recommendation Rec(2001)15 on History Teaching in Twenty-FirstCentury Europe. Adopted by the Committee of Ministers on 31 October 2001 at the 771st Meeting of the Ministers' Deputies. Strasbourg: Council of Europe. 
2008. Recommendation Rec(2008)4 on Strengthening the Integration of Children of Migrants and of Immigrant Background. Adopted by the Committee of Ministers on 20 February 2008 at the 7018th Meeting of the Ministers' Deputies. Strasbourg: Council of Europe.

- 2010. Council of Europe Charter on Education for Democratic Citizenship and Human Rights Education. Strasbourg: Council of Europe.

- 201la. Recommendation Rec(2011)2 on Validating Migrants' Skills. Adopted by the Committee of Ministers on 19 January 2011 at the 1103rd Meeting of the Ministers' Deputies. Strasbourg: Council of Europe.

- 2011b. Recommendation Rec(2011)6 on Intercultural Dialogue and the Image of the Other in History Teaching. Adopted by the Committee of Ministers on 6 July 2011 at the 1118 th Meeting of the Ministers' Deputies. Strasbourg: Council of Europe.

- 2015. European Social Charter (Collected Texts, 7th Edition). January 1. Strasbourg: Council of Europe.

- 2018. Children and Adolescents from a Migrant Background: Integration and Education. Extracts From Conventions, Recommendations, Resolutions and Reports. Revised and Enriched Version-April 2018. Strasbourg: Council of Europe.

CofEC (Commission of the European Communities). 2005. Communication from the Commission to the Council, the European Parliament, the European Economic and Social Committee and the Committee of the Regions. COM(2005) 596 Final. A New Framework Strategy for Multilingualism. Brussels: Commission of the European Communities.

- 2008. Communication from the Commission to the European Parliament, the Council, the European Economic and Social Committee and the Committee of the Regions-Multilingualism: An Asset for Europe and a Shared Commitment. $\operatorname{COM}(2008) 566$ Final. Brussels: Commission of the European Communities. CofEU \& EC (the Council of the European Union and the European Commission). 2015. Joint Report of the Council and the Commission on the Implementation of the Strategic Framework for European Cooperation in Education and Training (ET 2020). New Priorities for European Cooperation in Education and Training. (2015/C 417/04). Official Journal of the European Union C417: 25-35.

CofEU \& RofGofMS (the Council of the European Union and the Representatives of the Governments of the Member States). 2006. Resolution of the Council and of the Representatives of the Governments of the Member States, Meeting Within the Council, on the Recognition of the Value of Non-formal and Informal Learning within the European Youth Field. (2006/C 168/01). Official Journal of the European Union C168: 1-3.

- 2016. Resolution of the Council and of the Representatives of the Governments of the Member States, Meeting Within the Council, of 24 
February 2016 on Promoting Socioeconomic Development and Inclusiveness in the EU Through Education: The Contribution of Education and Training to the European Semester 2016. (2016/C 105/01). Official Journal of the European Union C105: 1-4.

CofEU (the Council of the European Union). 2009. Council Conclusions of 26 November 2009 on the Education of Children with a Migrant Background. (2009/C 301/07). Official Journal of the European Union C301: 5-8.

- 2015a. Council Conclusions on Reinforcing Youth Work to Ensure Cohesive Societies. (2015/C 170/02). Official Journal of the European Union C170/2-C170/3, May 23.

- 2015b. Council Conclusions on Reducing Early School Leaving and Promoting Success in School. (2015/C 417/05). Official Journal of the European Union C417: 36-40.

- 2016. Council Conclusions of 30 May 2016 on Developing Media Literacy and Critical Thinking Through Education and Training. (2016/C 212/05). Official Journal of the European Union C212: 5-8.

Connolly, W.E. 2002. Neuropolitics: Thinking, Culture, Speed. Minneapolis: University of Minnesota Press.

EP \& CofEU (the European Parliament and the Council of European Union). 2013. Regulation (EU) No 1288/2013 of the European Parliament and of the Council of 11 December 2013 establishing 'Erasmust': The Union Programme for Education, Training, Youth and Sport and Repealing Decisions No 1719/2006/EC, No 1720/2006/EC and No 1298/2008/EC (Text with EEA relevance). Official Journal of the European Union L347: 50-73.

EP \& CofEU (the European Parliament and the Council of the European Union). 2004. Directive 2004/38/EC of the European Parliament and of the Council of 29 April 2004 on the Right of Citizens of the Union and their Family Members to Move and Reside Freely Within the Territory of the Member States Amending Regulation (EEC) No 1612/68 and Repealing Directives 64/221/EEC, 68/360/EEC, 72/194/EEC, 73/148/EEC, 75/34/EEC, 75/35/EEC, 90/364/EEC, 90/365/EEC and 93/96/EEC (Text with EEA Relevance). Official Journal of the European Union L158: 77-123.

EC (European Commission). 2010. Communication from the Commission to the European Parliament, the Council, the European Economic and Social Committee and the Committee of the Regions. A New Impetus for European Cooperation in Vocational Education and Training to Support the Europe 2020 Strategy. COM(2010) 296 Final. Brussels: European Commission.

Halperin, E. 2013. Emotion, Emotion Regulation, and Conflict Resolution. Emotion Review 6 (1): 68-76.

Koivunen, A. 2010. An Affective Turn? Reimagining the Subject of Feminist Theory. In Working with Affect in Feminist Readings, ed. M. Liljeström and S. Paasonen, 8-28. New York: Routledge. 
Lähdesmäki, T. 2014. Identity Politics in the European Capital of Culture Initiative. Joensuu: University of Eastern Finland.

- 2017. Politics of Affect in the EU Heritage Policy Discourse: An Analysis of Promotional Videos of Sites Awarded with the European Heritage Label. International Journal of Heritage Studies 23 (8): 709-722.

Mudde, C. 2017. Introduction to the Populist Radical Right. In The Populist Radical Right: A Reader, ed. C. Mudde, 1-10. London: Routledge.

Newman, J. 2011. Activism, Emotion, Affect and Performance: Problems of Theory and Method. Paper Presented at the Fourth Interpretive Policy Analysis Conference, University of Cardiff.

Redlawsk, D., ed. 2005. Feeling Politics: Emotion in Political Information Processing. Basingstoke: Palgrave Macmillan.

Seigworth, G.J., and M. Gregg. 2010. An Inventory of Shimmers. In The Affect Theory Reader, ed. G.J. Seigworth and M. Gregg, 1-25. Durham: Duke University Press.

Shore, C. 1993. Inventing the 'People's Europe': Critical Approaches to European Community 'Cultural Policy'. Man 28 (4): 779-800.

Smith, L., and G. Campbell. 2015. The Elephant in the Room: Heritage, Affect and Emotion. In A Companion to Heritage Studies, ed. W. Logan, M. Nic Craith, and U. Kockel, 443-460. London: Wiley-Blackwell.

Thompson, S., and P. Hoggett. 2012a. Introduction. In Politics and the Emotions: The Affective Turn in Contemporary Political Studies, 2-19. New York: Continuum.

—, eds. 2012b. Politics and the Emotions: The Affective Turn in Contemporary Political Studies. New York: Continuum.

Thrift, N. 2008. Non-Representational Theory: Space, Politics and Affect. London: Routledge.

Van Stokkom, B. 2012. Deliberate Rituals. Emotional Energy and Enthusiasm in Debating Landscape Renewal. In Politics and the Emotions: The Affective Turn in Contemporary Political Studies, ed. S. Thompson and P. Hoggett, 41-58. New York: Continuum.

Wetherell, M. 2012. Affect and Emotion. A New Social Science Understanding. London: Sage.

Wodak, R. 2015. The Politics of Fear: What Right-Wing Populist Discourses Mean. London: Sage. 
Open Access This chapter is licensed under the terms of the Creative Commons Attribution 4.0 International License (http://creativecommons.org/licenses/ by $/ 4.0 /$ ), which permits use, sharing, adaptation, distribution and reproduction in any medium or format, as long as you give appropriate credit to the original author(s) and the source, provide a link to the Creative Commons licence and indicate if changes were made.

The images or other third party material in this chapter are included in the chapter's Creative Commons licence, unless indicated otherwise in a credit line to the material. If material is not included in the chapter's Creative Commons licence and your intended use is not permitted by statutory regulation or exceeds the permitted use, you will need to obtain permission directly from the copyright holder. 


\title{
Conclusions and Suggestions for Improving European Education Policies
}

\begin{abstract}
In the concluding chapter, we draw together the main arguments and results of the research, highlighting the differences and similarities between the education policy documents produced by the European Union and the Council of Europe. We also provide suggestions for improving future education policies to better encompass the concerns about the lack of dialogue in a diversified but also polarized Europe. Education policy documents dealing with intercultural dialogue act as important guidelines for tackling racism, chauvinism, xenophobia, homophobia, and other forms of prejudice in Europe. As policies function as 'actants' that create webs of meanings and action, it is crucial that policy documents are conceptually well formulated and clear and reflect today's societies. Lastly, we suggest new a conceptual means-cultural literacyto enhance and implement intercultural dialogue in education.
\end{abstract}

Keywords Policy recommendation • European education policy • Cultural literacy $\bullet$ Dialogue $\bullet$ Empathy

Our analysis of their education policy documents indicates how the Council of Europe and the European Union have continually engaged with enhancing intercultural dialogue in the field of education. The ethos of promoting cultural interaction and mutual respect between people with different national, religious, ethnic, cultural, and linguistic backgrounds 
was embedded in these actors' efforts even before the concept of intercultural dialogue was introduced and established in their policies. The implicit presence of the idea of intercultural dialogue became an explicit goal in their policy discourses during the 2000s, particularly after 2008, when the Council of Europe published its White Paper on Intercultural Dialogue. As our contextual exploration of intercultural dialogue in the introductory chapter highlights, the White Paper contributed to a broader political and scholarly debate on diversity policies in pluricultural and super-diverse Europe. This debate led to the transformation of diversity policies-at least at the discursive and rhetorical levels. Instead of multiculturalism, policy language started to emphasize interculturalism and intercultural dialogue as a practice or process of implementing policy aims. As we noted in the introductory chapter, it is difficult to draw strict distinctions between multiculturalism and interculturalism, as the policy goals and conceptual language are discursively fluid.

In the second chapter, we discussed the emergence and adaption of the concept of intercultural dialogue in the policy discourses deployed by the European Union and the Council of Europe in their education documents. These discourses have developed in close interaction-though the European Union's policy language has often followed the conceptual and thematic formulations of the Council of Europe with a short delay. Our analysis indicated that the Council of Europe and the European Union share a similar understanding of intercultural dialogue-but the frameworks in which they promote it differ. Both actors seek to advance intercultural dialogue as a means of inclusion, cooperation, and mutual (cultural) understanding. In addition to these social emphases, the European Union's stance on intercultural dialogue reflects its interests in promoting political integration in the Union, as well as in economic development and employment in its member states.

Our methodological and theoretical approach to the European education policy documents stemmed from the constructivist perspective on concepts and their capacity to bring about action. The conceptual analysis of the documents indicated how the idea of intercultural dialogue gets its meaning through and in relation to other concepts and terms, such as culture, cultural heritage, identity, diversity, values, inclusion, integration, tolerance, multiculturalism, and multilingualism. These concepts and terms form a discursive ethos that illustrates what areas of life and sectors of societies intercultural dialogue is expected to engage in and impact on. Our analysis demonstrated how these concepts and terms often emerge in 
the policy documents as closely interrelated both semantically (commonly used in descriptions or definitions of each other) and textually (commonly used in the same sentences or paragraphs). We argue that these conceptual densities tell us much more about the discursive meanings of intercultural dialogue than its explicit (and often superficial or lacking) definitions in the policy documents. The concepts and terms often included in these densities - such as multilingualism, migration, cultural exchange, living together, and lifelong learning-underline the more general interest behind the diversity policies of these two actors: to increase the inclusiveness of a multicultural European society.

In the European education policy documents, ideas and practices of intercultural dialogue were addressed to promote specific policy goals. These goals included improving cooperation and communication between (particularly young) people, increasing the cross-border mobility of people in Europe, and strengthening employment prospects through learning foreign languages and being familiar with different cultures in European countries. Moreover, intercultural dialogue was often related to the skills of interacting with people from migrant backgrounds in multicultural environments. Cultural knowledge of national, regional, and local heritages, as well as familiarity with cultural differences and similarities in Europe, were also commonly introduced in the policy documents as key to intercultural dialogue, enabling an open attitude towards others, respect for diversity, and a better understanding of Europe as a whole (DIALLS 2018, 2019).

Our analysis of the European education policy documents brought out how in them concepts are invested with affective meanings and cultural connotations. The conceptual densities in the documents are particularly charged with affects when several powerful concepts, terms, and expressions are brought together and used to argue for political aims. We developed Ahmed's (2004) theory on the stickiness of affects and applied it to our data by approaching some of its core and often-repeated expressions as sticky concepts. Concepts such as peace, freedom, human rights, equality, and democracy have a special layer of meanings due to their long history in European policy discourse and the emotional connotations with them arising from the political contests in post-war and cold war Europe. Moreover, their affective stickiness impacts on other concepts, terms, and expressions found in conceptual densities in the documents. The stickiness makes the concepts appealing, compelling, and difficult to object to. Using these sticky concepts, it is easy to argue for policy goals such as 
promoting intercultural dialogue. Sticky concepts are extremely effective rhetorical tools and, therefore, commonly used in political discourses (Lähdesmäki 2017).

\section{Policy Recommendations}

Education policy documents dealing with intercultural dialogue have the potential to influence how children, young people, and adults are taught about culture, cultural differences, and cultural similarities. They thus serve as important guidelines for tackling prejudice across Europe, including racism, chauvinism, xenophobia, and homophobia. As policies function as 'actants' that create social and semantic spaces, webs of meanings, and action, it is crucial that policy documents are conceptually well formulated and clear and reflect today's pluricultural societies. Concepts have a performative dimension in policy documents: they participate in shaping and giving meanings to the matter at hand, outlining the community at which the policy is aimed, and transforming political goals into action.

We end our book by providing suggestions for improving future European education policies to better encompass the concerns connected to the lack of dialogue in an increasingly diversified but also polarized Europe. These suggestions stem from our data, but we have also taken into account previous scholarly studies on diversity policies and their recommendations for policy-makers. We utilize the UNESCO Survey on Intercultural Dialogue (2018), and its views on advancing intercultural dialogue and supporting respect for cultural diversity and difference, as a general frame of reference for our policy recommendations.

The survey report recommends that policy-makers "[a]dopt education policies that incorporate intercultural dialogue principles" (UNESCO 2018,39 ) and emphasizes the importance of education at all levels, from primary schools to universities, as a mechanism for supporting intercultural dialogue (UNESCO 2018, 8). Moreover, the report notes the need for "the development of closer ties between education and culture, especially through joint projects" (UNESCO 2018, 36). These views resonate with the recommendations provided by the evaluation report of the European Year of Intercultural Dialogue, celebrated by the European Union in 2008. This report suggests the European Union support crosssectoral cooperation between education, culture, youth services, public services, and active citizenship (ECOTEC 2009, 105). We fully agree with the educational priority of advancing intercultural dialogue and the 
importance of bringing educational and cultural practices together as a joint arena for creativity, learning, inclusion, and exchange of views, experiences, and ideas.

The UNESCO survey identifies several challenges and enabling factors for implementing intercultural dialogue in practice. As our research did not focus on the implementation of education policies, we find it important to summarize these here. The report identifies several core challenges for intercultural dialogue: past and present conflicts and violence within and between communities that hinders bringing different people together and having a respectful and mutual dialogue; the absence of national policy on intercultural dialogue and the limited political will and funding for it; increased migration and the practical pressure it may put on education systems; today's media and particularly social media that can generate and propagate negative stereotypes, prejudices, and hate speech; and deeprooted prejudices and rigid social norms that may prevent people, communities, and societies from opening up to cultural differences (UNESCO $2018,8)$. As the enabling factors of intercultural dialogue, the survey report mentions the following: respecting, tolerant, and accepting environments; citizens' comprehensive understanding of cultural diversity that is supported by quality education, media, and other knowledge dissemination practices; policy frameworks that include clear and specific priorities for advancing intercultural dialogue; and an inclusive approach to processes and policy-making regarding intercultural dialogue to enable deeper engagement and ownership of citizens (UNESCO 2018, 8).

Stemming from these results of the UNESCO Survey on Intercultural Dialogue and relying on recommendations provided by the DIALLS project's first policy brief (DIALLS 2019), we suggest the following improvements to European education policies. These suggestions focus on the definitions and uses of concepts and on rethinking the semantics included in them.

As our book has indicated, intercultural dialogue is a fluid concept that is rarely explicitly defined in European education policy documents. The concept gets a variety of meanings through the discursive and affective contexts in which it is used and in relation to other concepts and terms used in describing policy goals. To avoid conceptual ambiguity and vagueness of policies dealing with intercultural dialogue and to enable their efficient implementation, the meaning of the concept of intercultural dialogue should be clearly defined in the policy documents. Conceptual clarity was a core recommendation emphasized over a decade ago, in the ERICart 
report that surveyed diversity policies in 34 European countries in 2008 . It notes how a clear definition of intercultural dialogue helps avoid potential misinterpretations of policy objectives and makes it easier to evaluate their success (Wiesand et al. 2008, xv).

European education policy documents would benefit from a clearer conceptual and contextual specificity overall. Therefore, the key concepts and terms linked to intercultural dialogue and their social, cultural, and political contexts should be explained. This would make the documents more accessible to audiences who are not familiar with the policy rhetoric of the Council of Europe and the European Union. In turn, this would open up the policies for a broader range of potential end-users and facilitate their implementation. We want to emphasize the need to clearly define three concepts - culture, identity, and diversity - that are commonly used in the policy discourses on intercultural dialogue but which may include a variety of different meanings, even within the same document.

The European education policy documents should clearly indicate whose culture is addressed in them, what features in people's behaviour and habits are viewed as 'cultural', what is the relationship between values and culture, and which values can be perceived as cultural (see Lähdesmäki and Wagener 2015,27). The concept of culture should be grounded in a social constructionist approach. Instead of understanding it as a static and normative entity that can be taught and transmitted to future generations, we recommend approaching culture as a social construction-as a constantly transforming and fluid collective interaction between diverse people (see Otten 2003; Abdallah-Pretceille 2006). Related to this point of view, we recommend that practising intercultural dialogue would not centre around teaching and learning factual knowledge of others' cultures. Teaching and learning 'facts' about different cultures may lead to perceptions of people as stable representatives of their cultural group, whether it be nation, religion, or ethnic origin. This may lead to cultural stereotyping and categorizing that makes it more difficult to perceive people as individuals, and may even engender prejudices (Abdallah-Pretceille 2006; Portera 2008). The ERICart report suggested taking a critical view of cultural canons - established or even listed nationally or internationally important cultural 'facts' and artefacts-and questioning their normative role in education (Wiesand et al. 2008, 146). The creation and transmission of cultural canons construct static cultural understandings of homogeneous communities and maintain the idea of cultural differences between 'us' and 'them' (Maine et al. 2019). The ERICart report 
recommended that education and art institutes shift their focus from traditional and national cultural canons to open processes of creative interaction between people (Wiesand et al. 2008, 146). Openness, cultural hybridity, and learning processes in creative interaction lay a fruitful foundation for intercultural dialogue in today's super-diversified Europe.

Another challenging concept in the European education policy documents is that of identity. The authors of the documents should clearly explain whose and what kind of identity they are addressing. The examined Council of Europe and the European Union documents refer to both individual and collective identities. We recommend approaching both individual and collective identities as plural, multi-layered, processual, and transforming. Moreover, different kinds and formations of identities should be addressed in a non-exclusive manner. Identity and culture are closely connected to diversity and how it is dealt with and given meanings in education policy documents. We recommend that education policies do not limit their approach to diversity to differences in national culture, ethnicity, religion, or language but include (cultural) differences evoked by history, social class, gender, sexual orientation, (dis)ability, indigenousness, and worldviews. The documents we analysed contained very few explicit mentions of these latter differences. Moreover, in the documents, the view of gender was based on static male/female binary. We recommend that the notion of intercultural dialogue should address a broad variety of differences and approach them from an intersectional point of view (Lähdesmäki et al. 2015, 345).

Lähdesmäki and Wagener's (2015) analysis of the White Paper on Intercultural Dialogue showed how the Council of Europe's policy discourse includes hierarchical power positions between those who are expected to lead and facilitate intercultural dialogue and those expected (only) to participate in it. Therefore, we consider it crucial to ask from whose point of view policies and practices on intercultural dialogue are planned. Our analysis indicated that migrants and refugees from nonEuropean countries form a major target group for intercultural dialogue in European education policies. It is important that these policies recognize the power structures between the underprivileged and privileged, such as migrants, refugees, or minorities and majority cultures or inhabitants in receiving countries. Intercultural dialogue may, moreover, create hierarchical structures between different minority communities. As some communities are more commonly explicitly included in the policy discourses on intercultural dialogue, they may be more 'naturally' targeted in the 
implementation of those policies and, thus, have better access to intercultural dialogue than those communities ignored or rarely mentioned in these policies.

European education policy documents commonly use universalizing rhetoric, in terms such as 'equal access' and 'non-discrimination'. Instead of vague idealistic expressions, we recommend identifying the problems of access and discrimination for specific groups and explaining whose access and what kind of discrimination the documents are addressing. This advances the recognition of specific problems and discrimination, making it possible to tackle them more efficiently. We also recommend explicitly acknowledging the problem-based roots of European education policy documents, as they are commonly created as a response to some specific concern or debate.

We recommend paying more attention to the affective connotations and symbolic value of European education policy rhetoric. For example, European education policies commonly include idealistic rhetoric that affectively and effectively appeals to inclusion and integration in Europe, referring to 'us' as a community with shared cultural features, heritage, and/or values. Particularly in the policies of the European Union, the emphasis on the unity of an imagined 'us' may create a symbolic border between those who conform to it and those who do not. The emphasis on 'us' calls for definitions of 'them'. The idea of unity may thus turn into affectively charged antagonism against other continents, economic powers, non-European opponents, migrants, and so on. Similarly, the concept of tolerance is inherent with tensions between otherness and inclusion: the one who tolerates manifests the 'norm' and has the power to decide what kinds of differences are acceptable, while those being tolerated manifest the other (Moore et al. 2011; Brown and Forst 2014). Instead of using implicitly hierarchical expressions and concepts, we recommend emphasizing dialogue in the education policy documents.

\section{Enhancing Intercultural Dialogue Through Cultural Literacy Education}

The DIALLS project has elaborated on the concept of cultural literacy and created a Cultural Literacy Learning Programme as a new means of advancing intercultural dialogue in schools. DIALLS' notion of cultural literacy stems from criticism of teaching knowledge and 'facts' of different 
cultures as a point of departure for understanding cultural differences and being able to encounter people with different cultural backgrounds. The concept of cultural literacy is not a new one but has been discussed in academia since the 1980s. In this early scholarly literature (e.g. Hirsch 1989; Hirsch et al. 1993, 2002), cultural literacy is often narrowly perceived as knowledge of culture gained through the exploration of cultural products, such as literature and art, and learning canonical cultural and historical facts and narratives. This notion conveys cultural literacy as a monologic one-way transmission of cultural knowledge and as something removed everyday life and the constantly transforming reality of pluricultural societies (Maine et al. 2019).

In DIALLS, cultural literacy is reconceptualized as a social practice (see Street 1984) that is inherently dialogic and based on learning and gaining knowledge through emphatic, tolerant, and inclusive interaction with others. It is defined as a process of engaging with cultures, based on an emphatic, tolerant, and inclusive mindset and a co-creation and expression of cultural identities and values. Being culturally literate is defined as an individual's competence and skill to encounter cultural differences and to elaborate on one's own identity in respectful interaction with other people. For DIALLS, being culturally literate means understanding that people may hold differing views but it also presupposes metacognitive awareness of how people's own cultural affiliations influence their responses and feelings towards others (DIALLS 2019; Maine et al. 2019).

Intercultural dialogue as policy needs to be implemented through more concrete tools. European education policy documents rarely explicitly seek to promote intercultural dialogue through learning and gaining knowledge from empathetic interaction with others or through training and strengthening competencies and skills to simultaneously encounter cultural differences and elaborate on one's own identity in respectful social interaction. Even though different forms of literacy, such as media literacy, are addressed in the European education policy documents, literacy as cultural communication, interaction, and empathetic understanding deserves more attention in future policies. Therefore, we recommend that European education policies more clearly emphasize intercultural dialogue instead of dialogue between monolithic cultures and use cultural literacy as a conceptual and practical means to advance this. 


\section{REFERENCES}

Abdallah-Pretceille, M. 2006. Interculturalism as a Paradigm to Think About Diversity. Journal of Intercultural Education 17 (5): 457-483.

Ahmed, S. 2004. The Cultural Politics of Emotion. Edinburgh: Edinburgh University Press.

Brown, W., and R. Forst. 2014. The Power of Tolerance: A Debate. New York: Columbia University Press.

DIALLS. 2018. Cultural Analysis Framework. https://dialls2020.eu/wp-content/uploads/2019/09/resubmitted-cultural-analysis-framework-with-coversheet-.pdf.

- 2019. Developing Education Policies in Europe to Enhance Cultural Literacy. https://dialls2020.eu/wp-content/uploads/2019/04/DIALLSPolicy-Brief-1-Developing-Educational-Policies.pdf.

ECOTEC. 2009. Evaluation of the European Year of Intercultural Dialogue 2008. Final Report. Birmingham: ECOTEC. https://ec.europa.eu/culture/sites/ culture/files/intercultural-dialogue-year-evaluation-2009_en.pdf.

Hirsch, E.D. 1989. A First Dictionary for Cultural Literacy: What Our Children Need to Know. New York: Houghton Mifflin Harcourt.

Hirsch, E.D., J.F. Kett, and J. Trefil. 1993. The Dictionary of Cultural Literacy. What Every American Needs to Know. 2nd ed. New York: Houghton Mifflin Company.

- 2002. The New Dictionary of Cultural Literacy: What Every American Needs to Know. 3rd ed. Boston, New York: Houghton Mifflin Company.

Lähdesmäki, T. 2017. Politics of Affect in the EU Heritage Policy Discourse: An Analysis of Promotional Videos of Sites Awarded with the European Heritage Label. International Journal of Heritage Studies 23 (8): 709-722.

Lähdesmäki, T., and A. Wagener. 2015. Discourses on Governing Diversity in Europe: Critical Analysis of the White Paper on Intercultural Dialogue. International Journal of Intercultural Relations 44: 13-28.

Lähdesmäki, T., P.C.C.A. Heynderickx, A. Wagener, and S.M.F. Dieltjens. 2015. Negations and Negativity as Linguistic Devices in Policy Discourse of Intercultural Cities. Journal of Multicultural Discourses 10 (3): 332-348.

Maine, F., V. Cook, and T. Lähdesmäki. 2019. Reconceptualizing Cultural Literacy as a Dialogic Practice. London Review of Education 17 (3): 382-391.

Moore, H., K. Walker, and C. Alan. 2011. Tolerance: A Concept Analysis. Journal of Theory Construction \& Testing 15 (2): 48-52.

Otten, H. 2003. Intercultural Learning and Diversity in Higher Education. Journal of Studies in International Education 7 (1): 12-26.

Portera, A. 2008. Intercultural Education in Europe: Epistemological and Semantic Aspects. Intercultural Education 19 (6): 481-491. 
Street, B. 1984. Literacy in Theory and Practice. Cambridge: Cambridge University Press.

UNESCO. 2018. UNESCO Survey on Intercultural Dialogue 2017. Analysis of Findings. Paris: UNESCO.

Wiesand, A., I. Heiskanen, R. Mitchell, D. Cliché, M. Fisher, and L. Marsio. 2008. Sharing Diversity. National Approaches to Intercultural Dialogue in Europe. Bonn: European Institute for Comparative Cultural Research.

Open Access This chapter is licensed under the terms of the Creative Commons Attribution 4.0 International License (http://creativecommons.org/licenses/ by $/ 4.0 /$ ), which permits use, sharing, adaptation, distribution and reproduction in any medium or format, as long as you give appropriate credit to the original author(s) and the source, provide a link to the Creative Commons licence and indicate if changes were made.

The images or other third party material in this chapter are included in the chapter's Creative Commons licence, unless indicated otherwise in a credit line to the material. If material is not included in the chapter's Creative Commons licence and your intended use is not permitted by statutory regulation or exceeds the permitted use, you will need to obtain permission directly from the copyright holder.

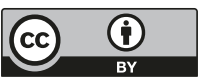




\section{INDEX}

A

Actant, 3, 23, 81, 102

Affect

affective rhetoric, 4, 25, 34, 35, 81-94

affective turn, 82

affect theory, 34, 82, 83, 93, 101

politics of affect, 4,84

Anti-Semitic, 2, 6

Art, v, 3, 105, 107

Assimilation, 8

Asylum seeker, 27, 83

Awareness, 12, 26, 54, 62, 69, 70, $72-75,107$

B

Belonging, 6, 14, 30, 42, 46, 47, 67, $88,91,94$

Bodies, 24-26, 32, 43, 64, 83, 84

C

Citizenship, 14, 26, 28, 32, 33, 44, $47,50,52,54,86,87,92,102$ citizenship education, 28,87
Cohesion, 2, 10, 11, 13, 25, $28,32,43,49,53,54,67$, $87,89,93$

Complex diversity, 7, 8, 29

Concept analysis, 3, 4, 15, 23, 33-35, $52,62,93$

Conceptual density, 34 , 61-76, 93, 101

Constructivist perspective to concepts, $22,33,100$

Contextualism, 23, 33

Cooperation, vi, 14, 24, 27, 28, 41, $45,54,100-102$

Council of Europe, the, vi, $2,23-25,39,64$, 86,99

Creative, 11, 12, 105

Crisis, 5-7

Cultural canon, 104, 105, 107

Cultural heritage, 33,43 , $44,49,51,52,54,68$, $70,89,100$

Cultural literacy, v, vi, 4, 106-107

Culturally literate, 107

Cultural pluralization, 2

(C) The Author(s) 2020 
D

Democratic, 5, 11, 27, 30, 32, 47, $54,86,87$

democracy, $7,11,27,28,30,32$, $46,47,93,101$

Dialogic, 12, 49, 107

Dialogue, v, vi, 1-15, 21-35, 39-54,

$$
\begin{aligned}
& \text { 61-76, 81, 83, 86-89, } \\
& 91-94,99-107
\end{aligned}
$$

Discourse, 2-5, 8, 10, 12, 14, 15,

$$
\begin{aligned}
& 21-30,33-35,40,44-46,52, \\
& 62-64,70,73,82,84,85,91, \\
& 93,100-102,104,105
\end{aligned}
$$

Discrimination, $10,30,50,53,54$, $64,91,92,106$

Distancing rhetoric, 84

Diversity, v, 2, 8-14, 22, 42, $62,87,100$

diversity policy, 8-14, 22, 25-28, $45,100-102,104$

$\mathrm{E}$

Education policy documents, v, vi, 3 , $4,23,31,34,35,39,43,50,52$, $53,61,70,76,81-94,99-107$

Emotion, 23, 73, 82, 83, 85, 90

Empathy, v, 11, 12, 33, 44, 47-50, 53, $54,75,84$ intellectual empathy, 12

Employment, 31, 41, 43, 50, 66, 70, 100,101

Equality, 10, 11, 28, 30, 31, 42, 46, $47,53,54,66,75,86,87$, $92,93,101$

Ethnicity, 10, 44, 46, 63, 92, 105

Eurocentric, 14

European Education Area, 7

European education policy, v, vi, 3, 4, $23,34,35,47,49,52,53,61$, $62,70,74,76,81-94,99-107$
European Union, the, vi, 2, 22, $24-25,39,63,86,99$

Exclusion, 23, 50, 54, 92, 93

F

Freedom, 11, 28-30, 46-48, 83, 86, $87,93,101$

G

Gender, 31, 44, 46, 66, 75, 87, 92, 105 gender equality, $31,46,75,87$

Genre, 33

$\mathrm{H}$

Hate speech, 103

History teaching, 32, 41, 42, 49, 52, $62,71-73$

Home, 7, 64, 89-91

Homophobia, 6, 102

Human rights, 11, 30, 32, 46-49, 53, $83,86,87,90,93,101$

I

Identity

cultural identity, 29, 50, 52, $54,75,107$

European identity, 5, 33, 49, 50, $54,75,88$

Immigrant, 5, 10, 33, 42, 46, 51, 52, $67,70,88,90,91,93$

Inclusion, v, 2, 11, 23, 25, 33, 34, 41, $42,44,50-54,70,84,92,100$, 103,106

Indigenous, 63-65, 92

Integration, $5,6,8-10,24,28,32$, $34,41,42,45,46,50-54,70$, $91-93,100,106$ 
Intercultural

intercultural communication, 3,41 , $54,61,74,75$

intercultural competence, 30, 34,

$40,41,43,47,48,54,62,64$, $65,70,74,75,86$

intercultural dialogue, $\mathrm{v}, \mathrm{vi}, \mathrm{l}-15$, 21-35, 39-54, 61-76, 81, 83, $84,86,87,89,91-94,99-107$ intercultural education, 3 , 13, 30, $54,62,68,70$

interculturalism, 3, 4, 9-11, 13, 44, $45,47,48,54,63,65$, $66,68,100$

interculturality, 30, 31, 66

intercultural skill, 26, 34, 40, 41, $43,44,54,62$

Intersectional, 9, 14, 105

Intolerance, 2, 48, 53, 54, 65

Islamophobic, 2, 6

L

Learning, v, 13, 14, 27, 29, 31, 43, $44,49,50,54,62,66,67$, $73-75,101,103-105,107$

Liberal, 30, 47, 52

Lifelong learning, 31, 43, 49, 50, 62, $73-75,101$

Literacy, v, vi, 4, 31, 67, 74,

$76,106-107$

M

Majority, 8, 9, 51, 105

Melting pot, 64, 90

Migration, 15, 31, 51, 62, 66-71, 92, $93,101,103$ migrant, $15,27,31,32,41,42$, 49-51, 63, 65-70, 86, 88, $91-93,101,105,106$
Minority, 8, 9, 13, 30-32, 46, 47, 65, $88,92,105$

Misogyny, 6

Monologic, 107

Multicultural, v, 9-11, 14, 26, 45, 53, $54,67,101$

multiculturalism, 3, 4, 8-11, 13, 25, $28,29,33,44-47,49,53,54$, $65,84,100$

Multilingualism, 26, 31, 40, 41, 43, $49,54,62-67,71,88,89,91$, 100,101

Multiperspectivity, 12,71

Muslim, 10, 46, 51, 52

Mutual understanding, 1, 10, 28, 29, $40,47,49,53,54,62-64,67$, $68,70,83,86,87,89-91,93$

$\mathrm{N}$

Narrative, 5-7, 33, 85, 107

Nation

nationalism, 6

nationality, 44, 46, 50

Nativism, 6

O

Openness, 7, 47, 48, 54, 64, $75,91,105$

P

Participation, 11, 28, 33, 44, 51, $52,54,75$

Performativity of language, $\mathrm{v}, 22,33$

Pluricultural, 1, 4, 7, 54, 100, 102,107

Plurilingualism, 32, 53, 54, 65, 68

Poetic dimension, $34,45,85$

Policy recommendation, 2, 102-106 
Political language, 22

Populism, 6

Populist, 2, 5-7, 84, 85, 93

Power, 10, 14, 15, 21, 23, 24, 46, 83, 105,106

Prejudice, 10, 48, 54, 73, $75,102-104$

$\mathbf{R}$

Race

racism, 102

racist, 2,6

Radical right, 5, 6

Refugee, 27, 31, 92, 105

Religion, 10, 44, 62, 66, 92, 104, 105 religious, $8,24,28,42,47,52,62$, $64,74,91,99$

$S$

Secular, 46, 47, 52

Sensitivity, 8, 30, 65

Sexual minority, 46

Sexual orientation, 44, 92, 105

Shared space, 12

Social class, 44, 105

Social competence, $49,50,74,75$

Social responsibility, 33, 44, 53, 54

Solidarity, 14, 27, 30, 43, 49, 53, 54, $64,67,89-91,93$

Speaker position, 33

Speech act, 22

Stereotype, 10, 12, 72, 73, 103

Sticky concepts, 70, 81-94, 101, $102 \quad \mathrm{X}$

Super-diversity, 8
$\mathrm{T}$

Teaching, 14, 32, 41, 42, 49, $52,62,66,67,71-73,86$, 104,106

Terrorism, 32, 87, 94

Tolerance, v, 2, 5, 10, $28,30,33,34,42$, $44,46-50,52-54$, $64,75,83,84,86$, $87,91,93,100,106$

$\mathrm{U}$

UNESCO, 12, 24, 25, 30, 31, 48, 102,103

Unity, 5, 9, 45, 46, 51-54, 83, $87-89,93,106$

USA, 90

V

Values

European values, 7, 32, 46, 63-64, 88

universal values, $11,86,89,93$

Violence, 87, 103

W

White Paper on Intercultural

Dialogue, 25, 26, 40, 65, 74, 100,105

$\mathrm{X}$

Xenophobia, 6, 102 